\title{
AN ASSESSMENT OF SUBSEA PRODUCTION SYSTEMS
}

\author{
A Thesis \\ by \\ DEEPAK DEVEGOWDA
}

\author{
Submitted to the Office of Graduate Studies of \\ Texas A\&M University \\ in partial fulfillment of the requirements for the degree of \\ MASTER OF SCIENCE
}

December 2003

Major Subject: Petroleum Engineering 


\title{
AN ASSESSMENT OF SUBSEA PRODUCTION SYSTEMS
}

\author{
A Thesis \\ by \\ DEEPAK DEVEGOWDA \\ Submitted to the Office of Graduate Studies of \\ Texas A\&M University \\ in partial fulfillment of the requirements for the degree of \\ MASTER OF SCIENCE
}

Approved as to style and content by:

Stuart L. Scott

(Chair of Committee)
Hans C. Juvkam-Wold (Member)

\section{Richard Mercier \\ (Member)}

Hans C. Juvkam-Wold

(Head of Department)

December 2003

Major Subject: Petroleum Engineering 


\author{
ABSTRACT \\ An Assessment of Subsea Production Systems. \\ December 2003 \\ Deepak Devegowda, B.S., Indian Institute of Technology, Madras \\ Chair of Advisory Committee: Dr. Stuart L. Scott
}

The decreasing gap between technology and it's applicability in the oil industry has led to a rapid development of deepwater resources. Beginning with larger fields where the chances of economic success are high, to marginal fields where project economics becomes a more critical parameter, the petroleum industry has come a long way.

However, the ever growing water depths and harsher environments being encountered are presently posing challenges to subsea production. Being able to develop a field and then proceeding to ensure flow for the life of the field comprises many situations where the production equipment can fail and falter or through external factors, be deemed unavailable. Some of the areas where most of the current developments in subsea production are being seen are in subsea processing, flow assurance, long term well monitoring and intervention technologies - areas that pose some of the biggest challenges to smooth operation in the deepwater environment.

This research highlights the challenges to overcome in subsea production and well systems and details the advances in technology to mitigate those problems. The emphasis for this part of the research is on multiphase pumping, subsea processing, flow assurance, sustained casing pressure problems and well intervention.

Furthermore, most operators realize a reduced ultimate recovery from subsea reservoirs owing to the higher backpressure imposed by longer flowlines and taller risers. This study investigates the reasons for this by developing a global energy balance and detailing measures to improve production rates and ultimate recoveries. The 
conclusions from this energy balance are validated by simulating a deepwater field under various subsea production scenarios. 


\section{DEDICATION}

This work is dedicated to G, Mod, Ramprasad, my brother and my parents. Someday we'll all sit and have a cup of coffee without wondering how long will it last, because we'll all be together. My parents deserve the hugest mention for standing by me. I loved the mountain bike trails at Lake Bryan where I could get away from it all. 


\section{ACKNOWLEDGMENTS}

I would like to express my sincerest gratitude and appreciation to Dr. Stuart L. Scott, chair of my advisory committee, for his valuable guidance, his support and his patience in helping me bring this research to completion.

A word of appreciation goes out to all the people in the Multiphase Research Group for being there to help and for being there when I wanted a break.

I would also like to thank some of my friends at the department and outside Emeline Chong, Ketaki Desai, Hui Gao, Sandeep Kaul, Candace Massengill, Aditya Singh and Eric Snyder.

Thanks to the Minerals Management Service for participating and providing the funding for this research project. 


\section{TABLE OF CONTENTS}

Page

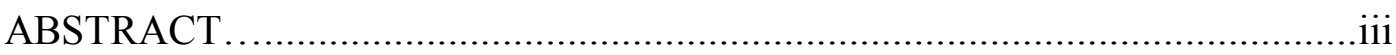

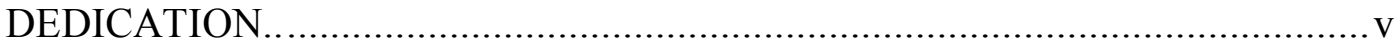

ACKNOWLEDGMENTS ......................................................................... vi

TABLE OF CONTENTS ..................................................................... vii

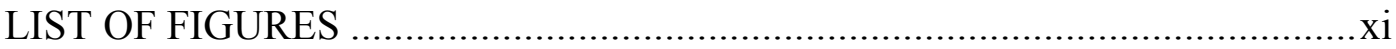

LIST OF TABLES .......................................................................

CHAPTER

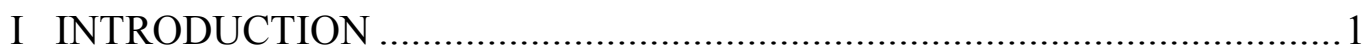

II SUBSEA PROCESSING SYSTEMS ..................................................

2.1 Downhole Separation Technology .............................................6

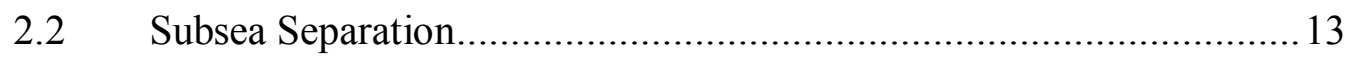

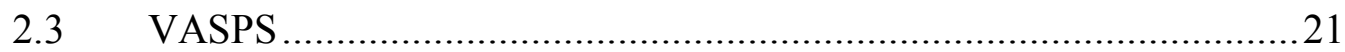

2.4 Subsea Pumping Equipment and Boosting ..................................23

2.5 Challenges in Subsea Processing .................................................22

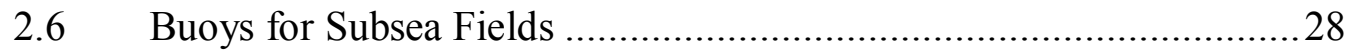

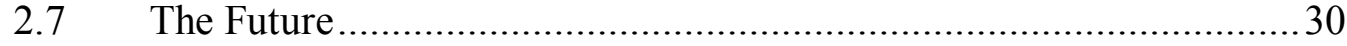

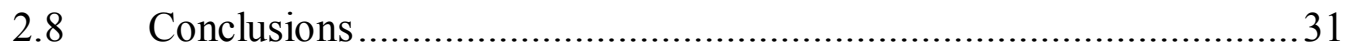

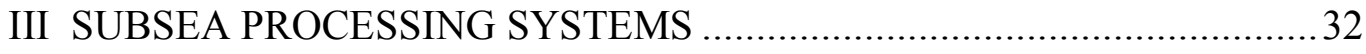

3.1 Monitoring Sand Production and Erosion ...................................... 33

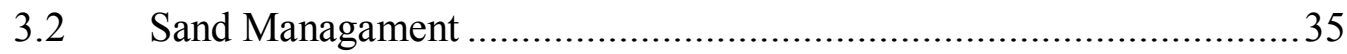

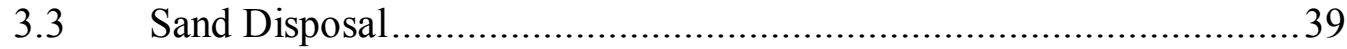

3.4 Technology Needs in the Sand Disposal Area..............................40 
CHAPTER Page

IV FLOW ASSURANCE .................................................................. 41

4.1 Introduction................................................................. 41

4.2 Blockage Detection ............................................................ 44

$4.3 \quad$ Hydrate Control............................................................................ 48

$4.4 \quad$ Remedying Hydrate Blockages .............................................50

4.5 Waxes/Paraffin Prediction and Control ........................................56

4.6 Erosion Due to Sand Production .....................................................5 57

4.7 Other Methods of Ensuring Flow ...............................................59

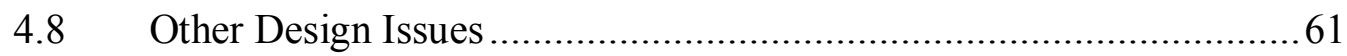

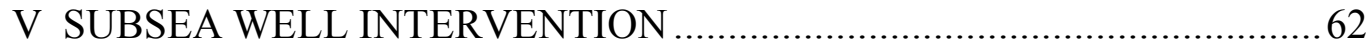

$5.1 \quad$ "Intelligent" Completions ....................................................6 62

5.2 Intelligent Well Systems-Reliability Issues .................................63

5.3 Downhole Monitoring from an Onshore Facility.............................66

5.4 The Significance of Safety Valves ...............................................69

$5.5 \quad$ IWS and Intervention Avoidance ............................................ 70

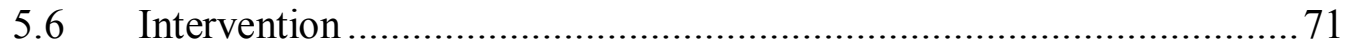

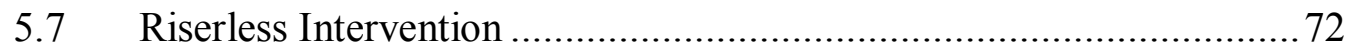

5.8 Dynamically Positioned Vehicles and Riser Based

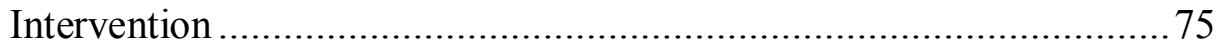

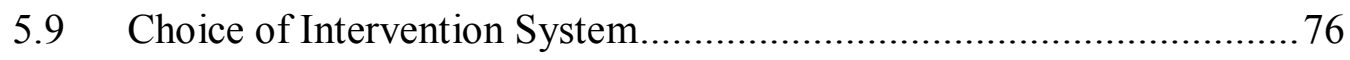

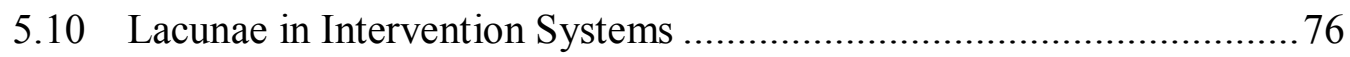

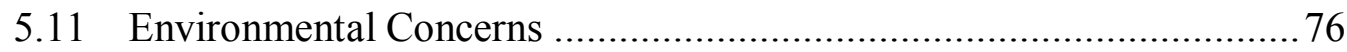

VI SUSTAINED CASING PRESSURE .................................................. 79

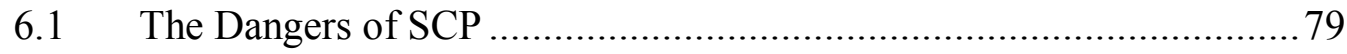

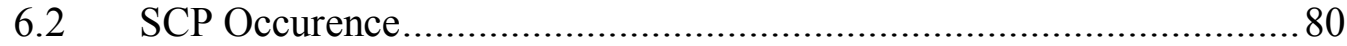

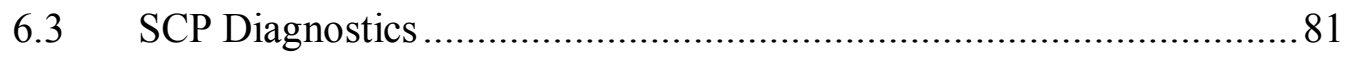


CHAPTER Page

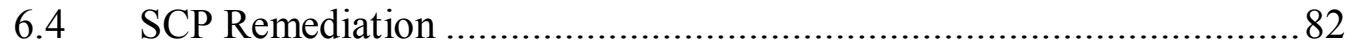

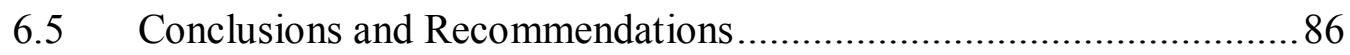

6.6 The Difficulties in Sustained Casing Pressure Remediation ...............8 87

VII THE GLOBAL ENERGY BALANCE ........................................... 89

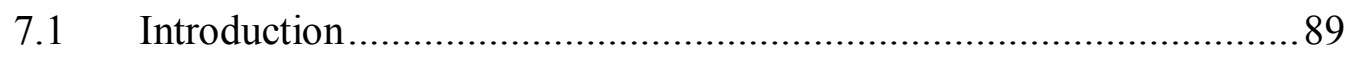

7.2 Energy Losses in a Production Facility ........................................ 91

7.3 The Global Energy Balance .................................................. 95

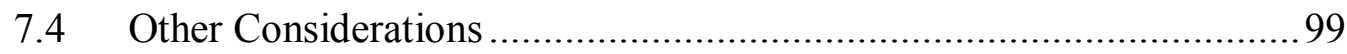

7.5 Comparison of Pressure Energy and Heat Energy ........................... 101

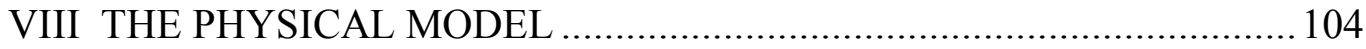

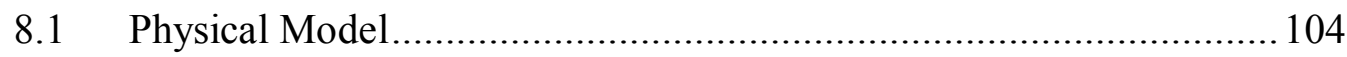

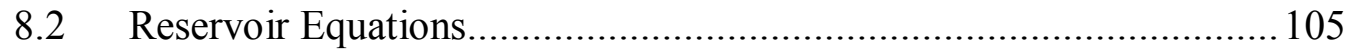

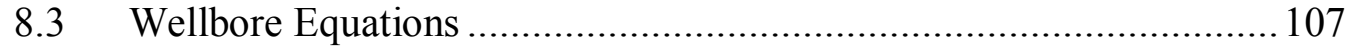

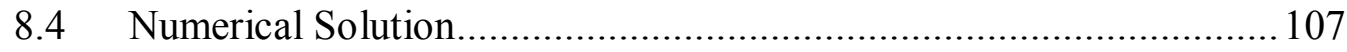

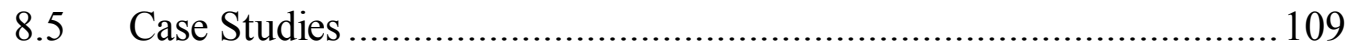

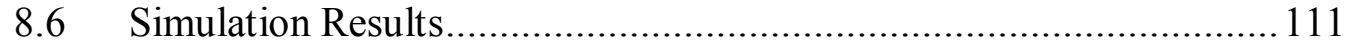

IX RESERVOIR AND PRODUCTION FACILITY INTERACTION ........... 113

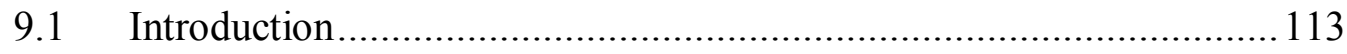

9.2 Simulation Model.................................................................... 114

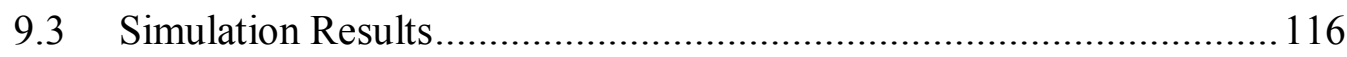

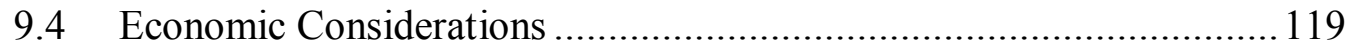

X CONCLUSIONS AND RECOMMENDATIONS................................. 122

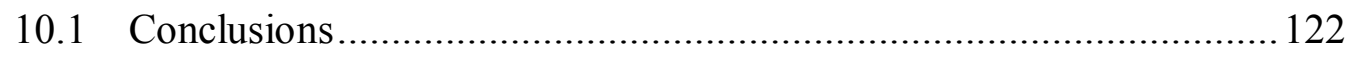

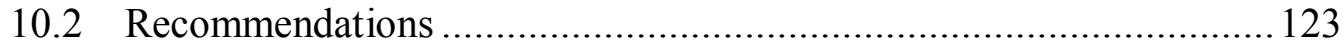


NOMENCLATURE..................................................... 124

REFERENCES ........................................................ 126

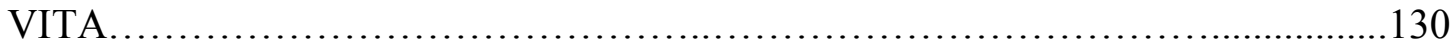




\section{LIST OF FIGURES}

FIGURE

Page

1.1 An artist's rendition of subsea architecture showing the complexity of subsea systems 2

2.1 Graph showing maturity of various subsea processing technologies............... 6

2.2 A downhole oil-water cyclonic separator ............................................... 8

2.3 A downhole oil-water separation system for horizontal wells ..................... 12

2.4 Another illustration of a downhole oil-water separation and boosting

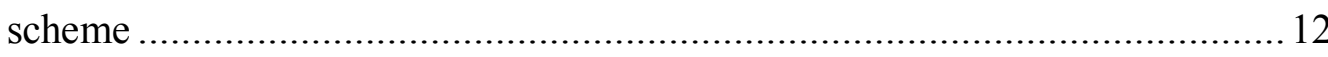

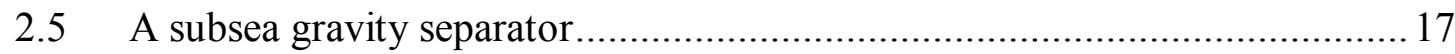

2.6 Illustration of a subsea compact separation facility ............................... 18

$2.7 \quad$ I-Sep compact separation illustration ..................................................... 19

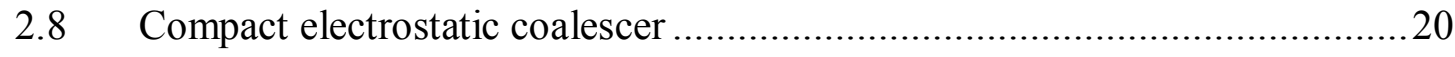

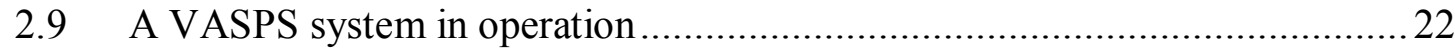

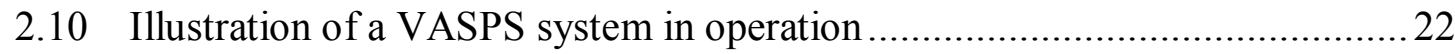

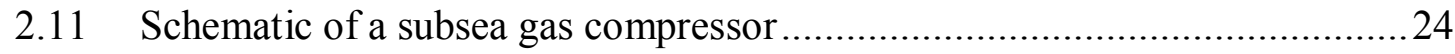

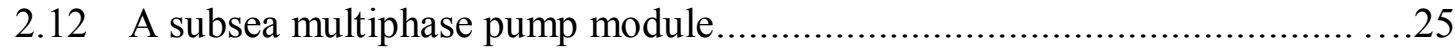

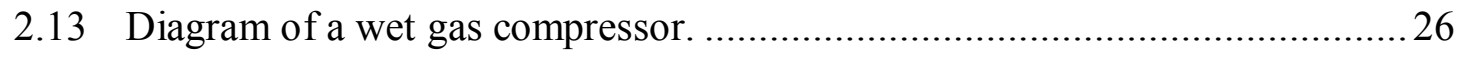

2.14 A schematic of a subsea liquid booster. .................................................27

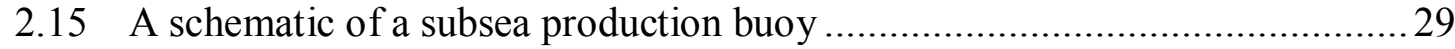

3.1 An example of how desanding may be carried out in a subsea

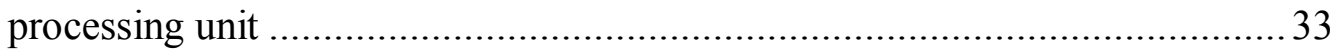

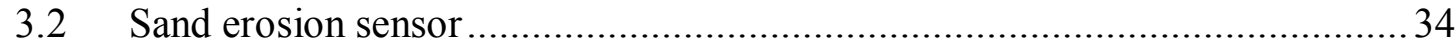

3.3 Subsea particle monitors are capable of measuring erosion on pipe walls ...... 35

3.4 Illustration of a desanding cyclone upstream of the primary separator ........... 36

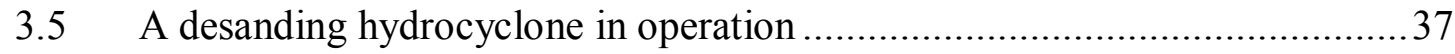

3.6 Cutout of a desanding multicyclone ....................................................... 38

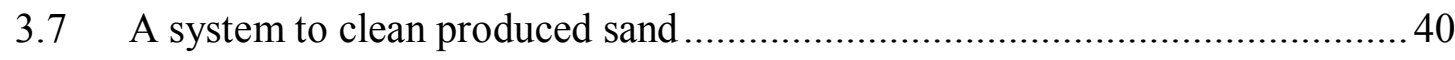


4.1 Illustration of the considerations for flow assurance monitoring and

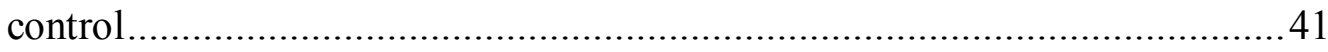

4.2 An asphaltene plug removed from a pipeline .......................................42

4.3 Chart showing maturity of various technologies for flow assurance. .............. 43

4.4 A gamma ray absorption pipe scanner........................................... 45

4.5 Illustration of optic fibre and conduit in a pipeline for monitoring

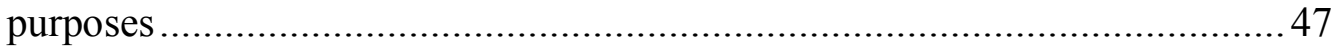

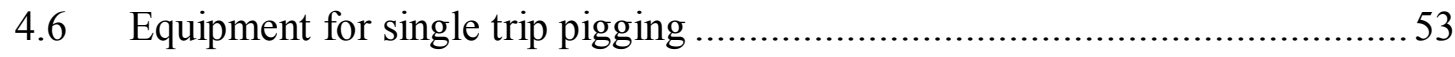

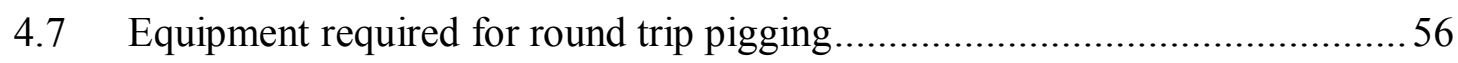

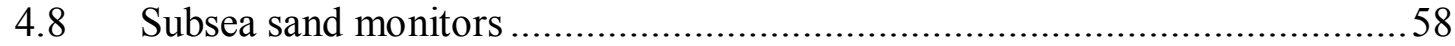

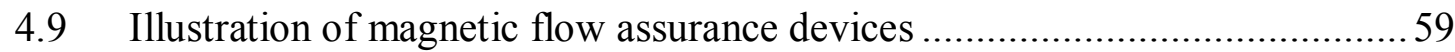

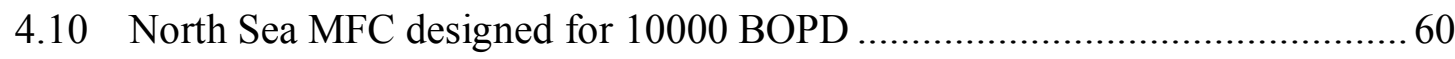

5.1 Maturity of IWS offered by various companies .....................................64

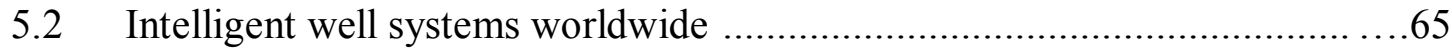

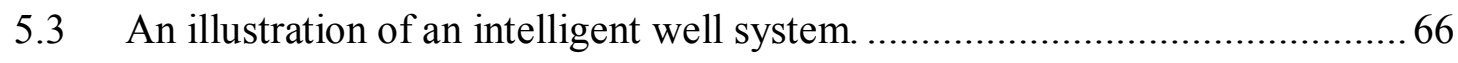

$5.4 \quad$ Schematic of the Incharge well system. 68

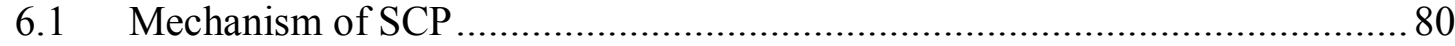

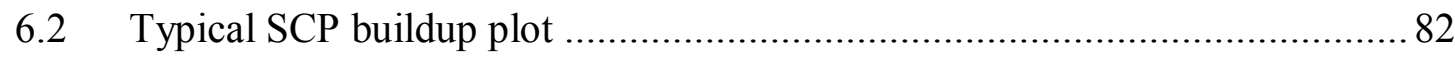

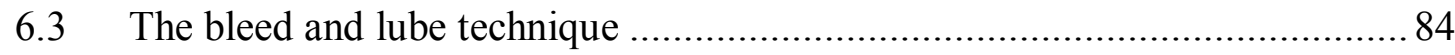

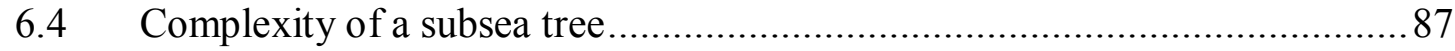

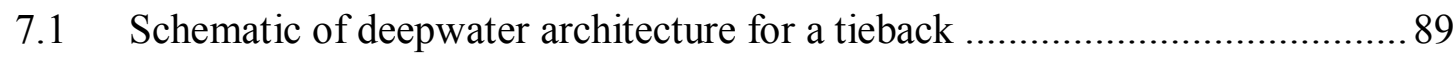

7.2 Depiction of the process involved during production under backpressure. The reservoir produces till it attains the value of

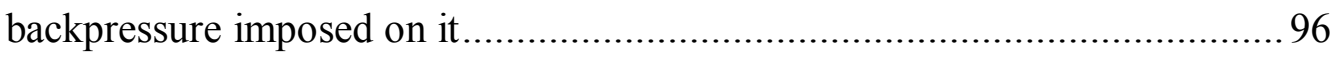

7.3 Illustration of the reservoir and the borehole and the pressures therein......... 100

7.4 Chart showing comparison of the pressure energy to be tapped from a gas reservoir versus the thermal energy available. 
FIGURE Page

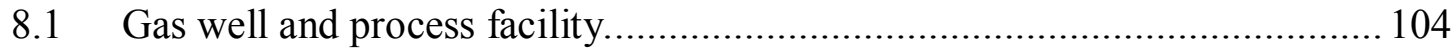

8.2 Chart showing differences in production rate owing to differences in backpressure caused by two different flowline lengths.......................... 111

8.3 Chart showing earlier recovery with a shorter flowline ........................... 112

9.1 Interaction between reservoir and facilities model .................................. 113

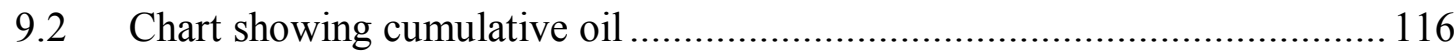

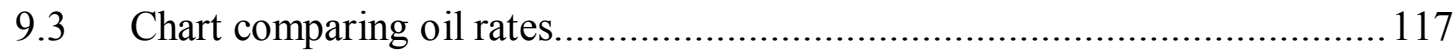

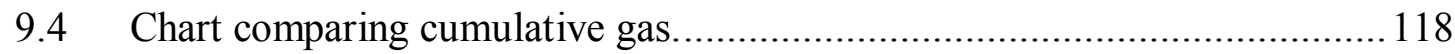

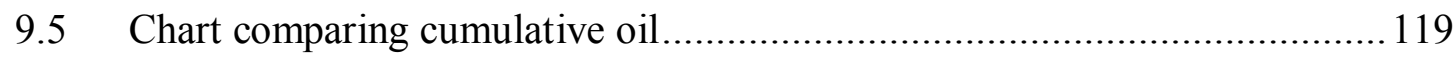

9.6 Costs of subsea mulitphase pumping compared with subsea separation and boosting. ...... 


\section{LIST OF TABLES}

TABLE Page

8.1 Table of reservoir and production facility characteristics. ........................ 109

8.2 Coefficients used to calculate enthalpy for air.................................... 110

9.1 Reservoir Properties.............................................. 115

9.2 Subsea Tieback Design......................................... 115

9.3 Comparison of the cost of subsea separation and boosting versus...........120 subsea multiphase pumping 


\section{CHAPTER I}

\section{INTRODUCTION}

The rapidly accelerating shift to subsea production systems represents a significant departure from conventional operations. Historically, subsea wells have had a good track record. However, complex subsea systems are now being deployed in ways rarely encountered in previous development schemes. These increasingly complex systems present a number of technical challenges. This research presents an assessment of subsea production systems, considering the technical, operations and safety issues associated with this development modality.

This assessment considers the following general areas: 1) subsea processing; 2) flow assurance; 3) long-term well monitoring and, 4) safety \& environmental concerns. A review of the state-of-the-art in each of these areas is presented and several technical and operational gaps are identified.

The subsea environment is perhaps the most remote and unexplored on earth. The remoteness of subsea wells, coupled with a number of complex interactions between subsea wells/flowlines and the ocean environment make monitoring, intervention and routine operation much more difficult. These systems are now being deployed in ways rarely encountered in previous development schemes. One of the forces driving increased use of subsea production systems is the dramatic reduction in development costs when compared with conventional methods. In many cases, the use of a subsea tieback is the only viable option to develop these resources. In recent years, we have seen a rapid maturing of the technology being developed for subsea use.

This thesis follows the style of the Journal of Petroleum Technology. 


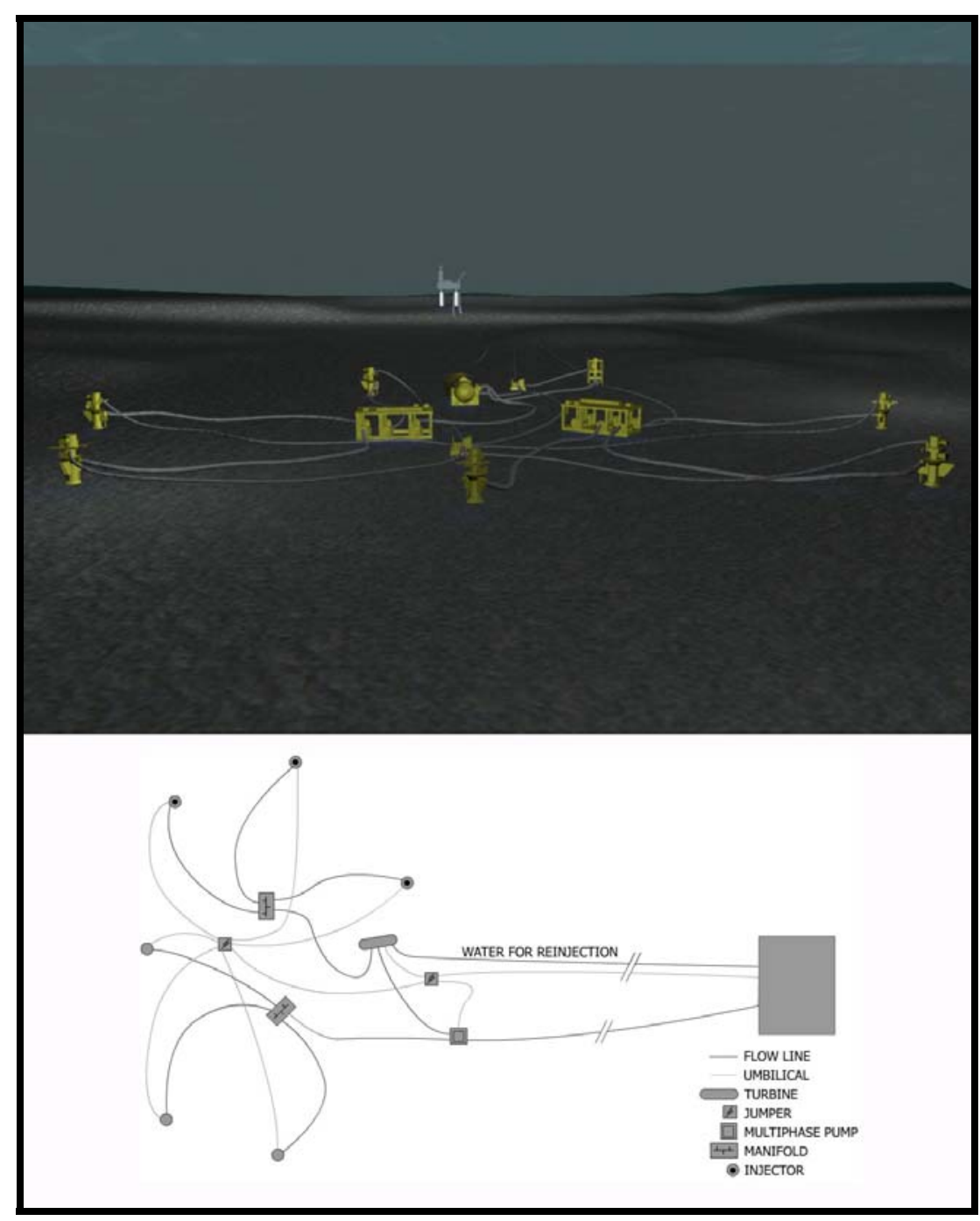

Figure 1.1: An artist's rendition of subsea architecture showing the complexity of subsea systems.

However, a number of technical issues are associated with subsea production. Industry and regulators are increasingly becoming aware that long, multiphase flowlines add additional backpressure, reducing flow rates and ultimate recoveries. For example, conventional production operations routinely drawdown wellhead pressures to $100-200$ psig. A subsea completed well, however, may have abandonment wellhead pressures of 1,000-2,000 psig due to the backpressure added by the long multiphase flowline. Consequently, there is a growing interest in processing the produced fluids subsea. 
Strategic technologies that are believed to be essential for the successful implementation

of subsea production include multiphase pumping, multiphase metering ${ }^{1}$ and compact separation. One of the challenges posed by subsea production is how to reduce wellhead pressure to allow effective recovery of hydrocarbon resources. Multiphase pumping is one technology being considered to help remedy this situation, as well as pressure boosting deployed in advanced subsea well systems ${ }^{2}$.

Other challenges in the subsea arena are in the areas of flow assurance and well monitoring and intervention. Sustained casing pressure has been identified as one of the key areas requiring inexpensive and effective intervention options ${ }^{3}$. Another key area is the area of blockage monitoring. For the past decade research has focused on developing design methodology, while relatively little attention has been paid to the long-term problem of monitoring subsea flowlines for the buildup of wax, scale, hydrates, etc. There is a need for analysis techniques to help identify and locate partial pipeline blockages and new development of sensors to monitor the flow.

This research discusses some of the fundamental issues associated with subsea processing. The various options are discussed and the advantages and disadvantages of each type of technology are highlighted. Most importantly, technology gaps are identified that, if not properly addressed, may limit the application of subsea technology.

This research proposes the new concept of a global energy balance to evaluate energy usage in the production system. The energy losses encountered are shown to be largely frictional losses in the flowline and acceleration losses across chokes in addition to the gravitational losses due to high water depths. The research proposes the concept that energy losses occurring across a choke or in the flow system are a waste of reservoir energy - energy that could be used to extract more fluids from the reservoir and improve ultimate recoveries. It is also shown that the backpressure imposed on the wellhead increases with pipeline length and longer flowlines are shown to decrease production rates from the reservoir. Finally, classical reservoir engineering methods combined with numerical multiphase flow simulators are used to model the interaction between the 
reservoir and the production facilities, thereby helping to compare and contrast various subsea processing strategies.

This thesis is divided in 9 chapters. Chapter II is a literature review on subsea processing systems with recommendations and conclusions. Chapter III deals with subsea sand disposal and other associated problems including operational and environmental issues. Chapter IV deals with flow assurance technologies currently in use and evaluates some of the options available for application in the subsea environment. Chapter $\mathrm{V}$ is a discussion of subsea well intervention options with an emphasis on the various well intervention options and a brief discussion of each. Chapter VI is a literature review on sustained casing pressure highlighting the state of the art in SCP detection and remediation. Chapter VII is the proposed global energy balance that incorporates a relationship between backpressure and reservoir performance. A Visual Basic code written to simulate the energy and mass balances in a gas reservoir, showing the effect of backpressure on reservoir performance and ultimate recoveries constitutes Chapter VIII. Chapter IX investigates the effects of backpressure due to various subsea production strategies by linking pipe flow simulators with the Eclipse reservoir simulator to model the complete subsea reservoir and production system. Chapter $\mathrm{X}$ concludes with the recommendations and conclusions from this study. 


\section{CHAPTER II}

\section{SUBSEA PROCESSING SYSTEMS}

With the rapid development of marginal subsea fields once thought to be unprofitable due to the severe conditions and expense involved of exploiting the available resources, more and more companies are looking towards subsea processing as one of the main methods of reducing both CAPEX and OPEX costs. Traditional offshore development has focused on the construction of fixed leg platforms in shallow water. In deeper waters, the emphasis has been on the use of FPSOs or long distance tiebacks to existing production platforms.

However with all these methods only being emerging technologies having to still face problems, the industry is looking forward to new concepts like subsea processing. As opposed to the traditional methods of processing reservoir fluids at a process station, subsea processing holds great promise in that all the processing to a final saleable crude is being done at the seafloor itself. This offers cost benefits and also improves recovery factors from the reservoir. Other advantages include a lesser susceptibility to hydrate formation and a lower operating expenditure.

Currently, with traditional long distance tie-backs to existing floating production facilities, abandonment wellhead pressures are as high as about 3000 psi and wells are being abandoned when they reach rates of around $5000 \mathrm{bbls} / \mathrm{D}$ ! All this due to the fact that subsea separation and subsea boosting haven't yet been accepted as viable technologies. Several companies are investigating concepts in subsea fluid separation. Separating fluids subsea will avoid lifting large volumes of water to the surface for

processing and disposal. This can reduce lifting costs and allow economies in topside water processing and handling capacities and could extend the economic life of the deepwater projects and reduce development risks ${ }^{4}$.

This is only an emerging technology and there is still some resistance from major operators to the use of subsea processing but once the drawbacks which stem from 
mostly increased power requirements to intervention problems, it looks to be a promising area of development in the subsea field.

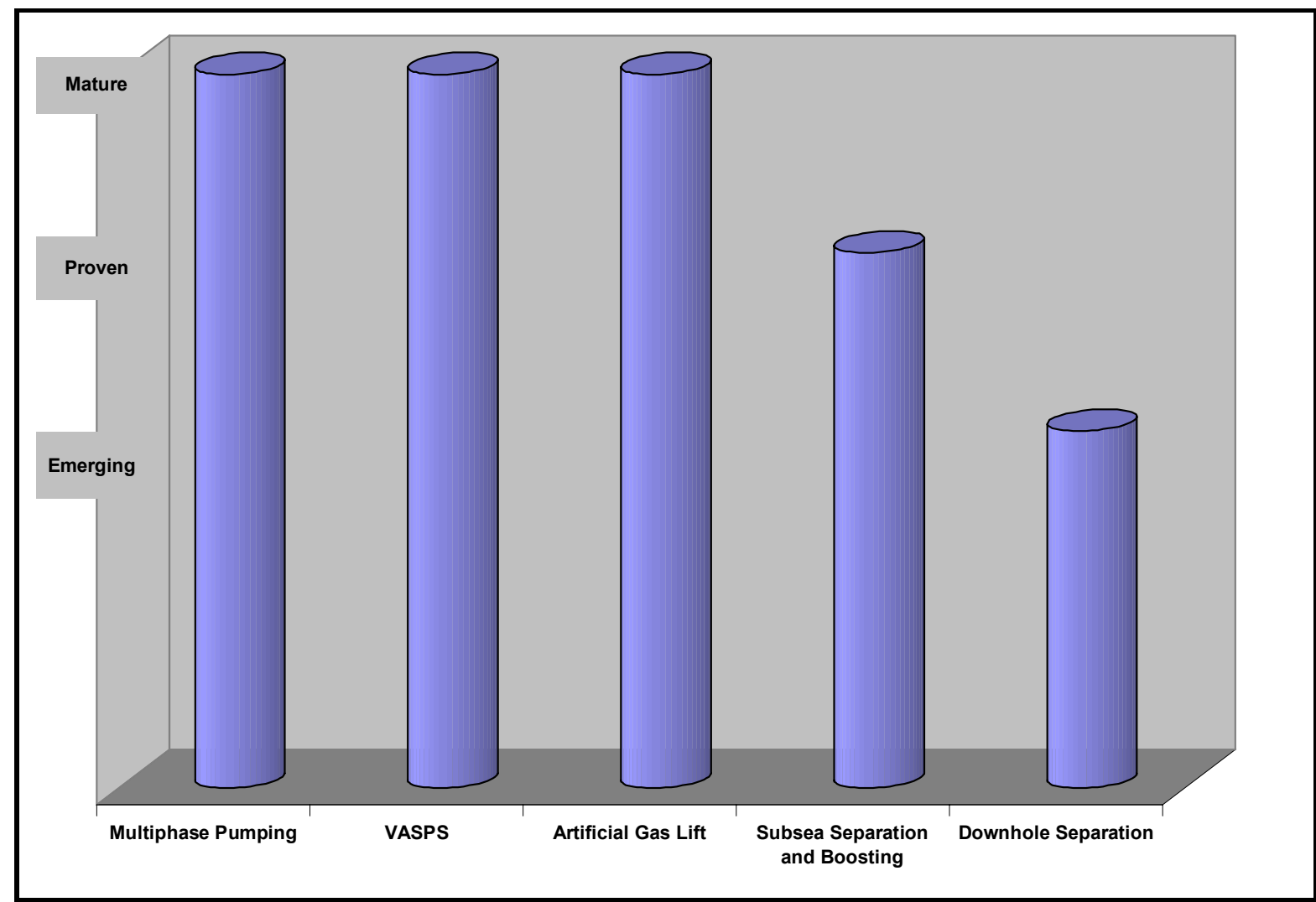

Figure 2.1: Graph showing maturity of various subsea processing technologies

\subsection{Downhole Separation Technology}

As water encroachment and reduced wellhead pressure increase lifting costs, profitable fields become marginal and also new discoveries may lie idle owing to the high costs of lifting, treating and disposing of the water. The new water management technology of downhole oil/water separation involves producing a concentrated oil stream to the surface while continuously injecting clean water into a disposal zone located accessible from the same wellbore. 
The alternatives for downhole separation are:

Gravity based separation

Cyclone based separation

\subsubsection{Control and Monitoring}

It is also possible to offer downhole control and monitoring services for the downhole separator system.

The instrumentation usually monitors

Processes: Startup and Upset conditions and changes in water cut and injectivity.

Reservoir: Characterize and diagnose through pressure monitoring.

Conditions: Validates equipment perfomance.

The process parameters that are monitored are surface flow rate, water cut, pump speed, surface choke pressure, injection pressure, injection flow rate and injection water quality.

The advantages to installing a monitoring system with a downhole oil-water separator are:

Understanding changes to the injection zone by monitoring producing injection pressure and injection rate.

Understanding changes in the producing zone by monitoring producing BHP and zone water cut.

Ensuring separation is optimized.

Monitoring injection water stream quality to chart changes in injectivity.

At the time of writing this report, there have not been any instances of the use of downhole separators in subsea wells. The main reasons for this are:

The production of sand creates problems for downhole processing equipment.

There is a drive towards simplicity in subsea systems. A downhole separator increases complicity with extra power and hydraulic line requirements.

Intervention costs are extremely high and do not justify the use of downhole separation technology. 


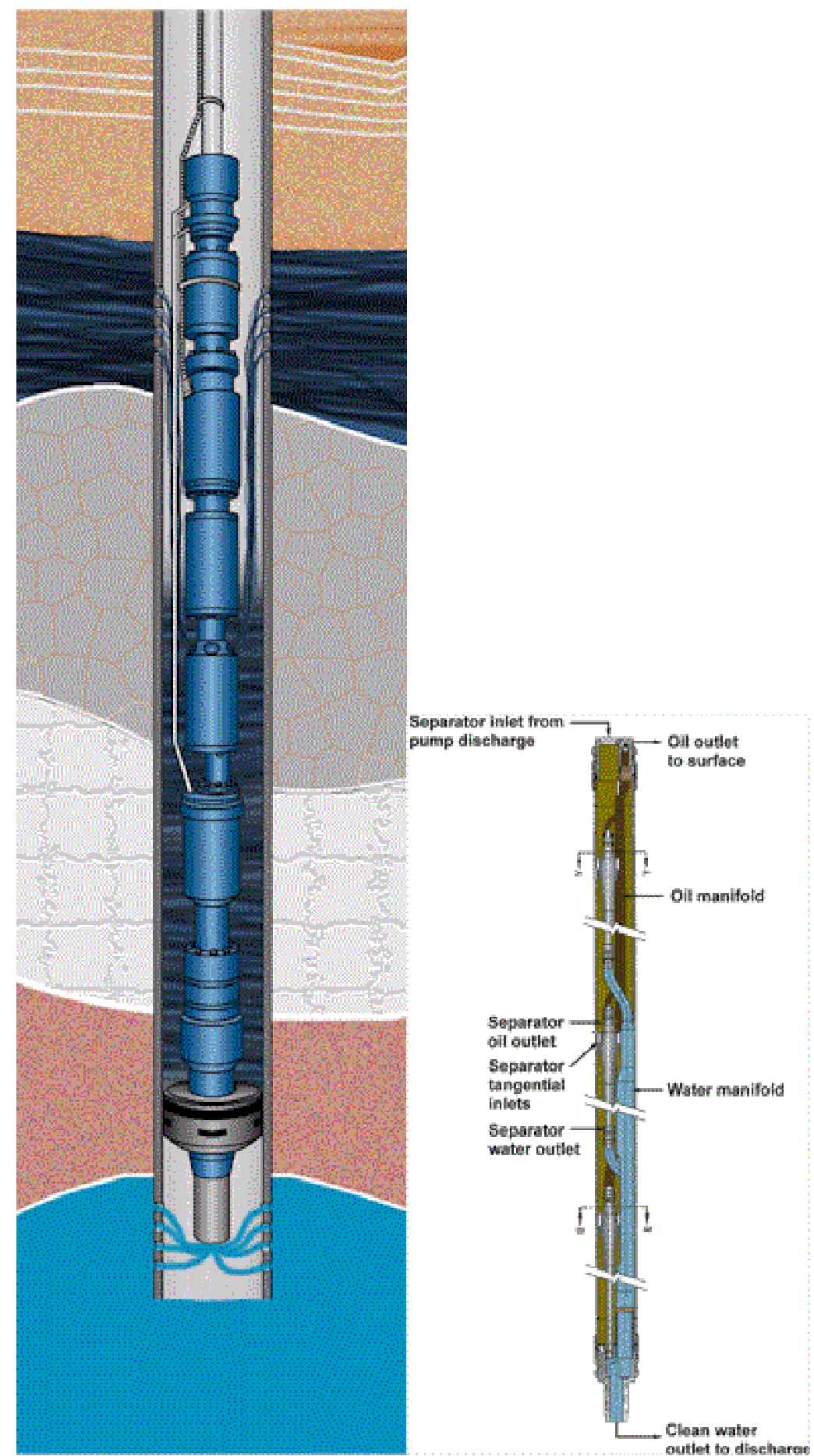

Figure 2.2: A downhole oil-water cyclonic separator ${ }^{5}$. 
There is a trend towards Downhole Oil/Water Separation and Reinjection systems (DOWS). Some of the advantages of these systems can be summarized as follows:

Increased Oil Production:

While water production rates have increased over the years and oil production rates have dropped off, increasing amounts of horsepower is being devoted to lifting produced water back to the surface. Installing a DOWS scheme, reduces the loading on existing water handling and injection systems ${ }^{5}$. For e.g. If a well were not operating at maximum recommended drawdown because the water handling facilites are fully loaded, installation of a DOWS scheme would allow increased drawdown and therefore increased production rates. It can also allow wells that were shut-in due to increased water production problems to come on line. The few fields that are not operating efficiently due to horsepower restrictions can be made economically more viable with the reduced horsepower requirement of a DOWS scheme.

Power Consumption:

Reservoirs with pressure support will undergo a decline in oil rates as the life of the reservoir increases. So in many cases, artificial lift is required that consumes a significant portion of the energy required for the field, just to move the produced fluids, a large part of which is water, to the surface. It will be more efficient to separate and dispose of the water downhole.

Also subsea completions require heating systems on the flowlines and risers and this would be more expensive if it entailed the transport of water also.

Chemical Consumption:

Increased water production means that the hydrate inhibitor chemicals used would also have to be increased and apart from environmental factors, it would be more expensive to use and dispose of these hydrate inhibitor chemicals.

Formation: 
Reinjection provides the following benefits: pressure maintenance of the producing formation, potential sweeping of the additional oil that was bypassed, and maintenance of injection pressures at constant differential to the producing pressure.

Environmental benefits: Downhole separation offers significant environmental benefits in that dirty produced water is reinjected in to the reservoir reducing risks to the subsea environment.

Disadvantages:

The cost of such a system depends on the system capacity, pressure requirements, well depth etc. However, even now, since these systems are relatively new, the economics of scale hasn't yet come into effect. So a detailed analysis of the costs involved over a certain time period has to be performed to evaluate any option.

Hydrocyclone systems can handle a maximum of $10-15 \%$ gas volume beyond which they fail.

\subsubsection{DOWS systems: Basic Types and Configurations of Cyclone Based Systems}

There are a variety of downhole separation systems in use today including systems for gas/liquid, liquid/solid and liquid/liquid separation. A range of separator types is used including in some cases, the wellbore itself. Hydrocyclones are widely used for oil/water separation at the surface and downhole. Due to their high efficiency, the oil content of the disposal water stream will be limited to $200 \mathrm{ppm}$.

\subsubsection{Static Hydrocyclones and Conventional ESP}

Based on current technology limitations, a single hydrocyclone tube can operate in the range of 500-2000 BPD inlet flow rate and a 50-200 psi pressure drop at the inlet to the water side. The maximum operable depth is around 12000 feet.

For $9.625 "$ wells, recommendation is a $7.625 "$ separator with up to 10 hydrocyclone tubes and a capacity of 7500-20000 BOPD.

\subsubsection{Static Hydrocyclones and PSPs}

These systems can also handle 500-2000 BPD. 
Either of these can be of the following two types:

Pull through Systems: Here the produced fluid enters the pump prior to entering the separator. The pump is sized to dispose of the water into the given injection zone while the residual oil may be pumped up to the surface if it does not have sufficient pressure to do so. So there may be a second pump to do this job.

The disadvantages are the risks of poor separation due to the formation of small oil droplets caused by the feed pump.

Pull though Systems: Here the produced fluid enters the separator first and the separator outlets are pumped. Again, if the oil has insufficient pressure to reach the surface, a second pump may be deployed.

\subsubsection{Potential Applications for DOWS and Re-injection}

Injection below the producing zone: All units installed so far of this type of application. This helps in maintaining pressure support resulting in reduced disposal costs and increased oil production.

Cross flooding: This is a new concept and involves flooding two zones without surfacing any of the produced water.

\subsubsection{DOWS-Gravity Based Separation}

The gravity separation process simplifies downhole oil-water separation, by employing the horizontal section of the wellbore as the separator. The conditions here (fluid properties, temperature and pressure) are ideal to help in separation. Under these conditions, fluid separation occurs in seconds as opposed to a few minutes if separation 


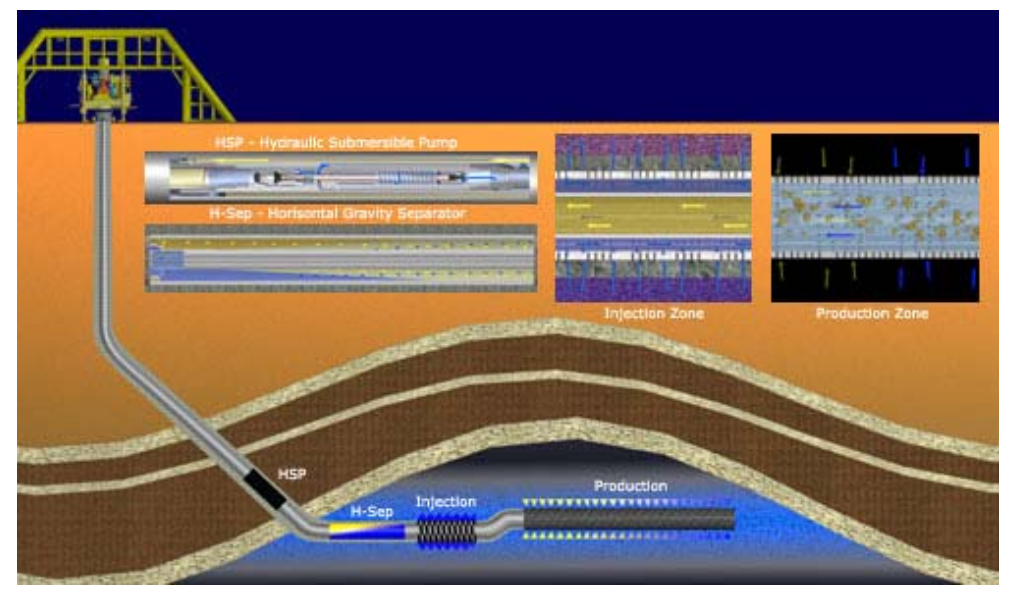

Figure 2.3: A downhole oil-water separation system for horizontal wells ${ }^{5}$.

was attempted topsides. The oil produced has less than $0.5 \% \mathrm{WC}$ and the separated water has less than 500 ppm of oil, which can be reinjected into the flanks of the reservoir for pressure support.

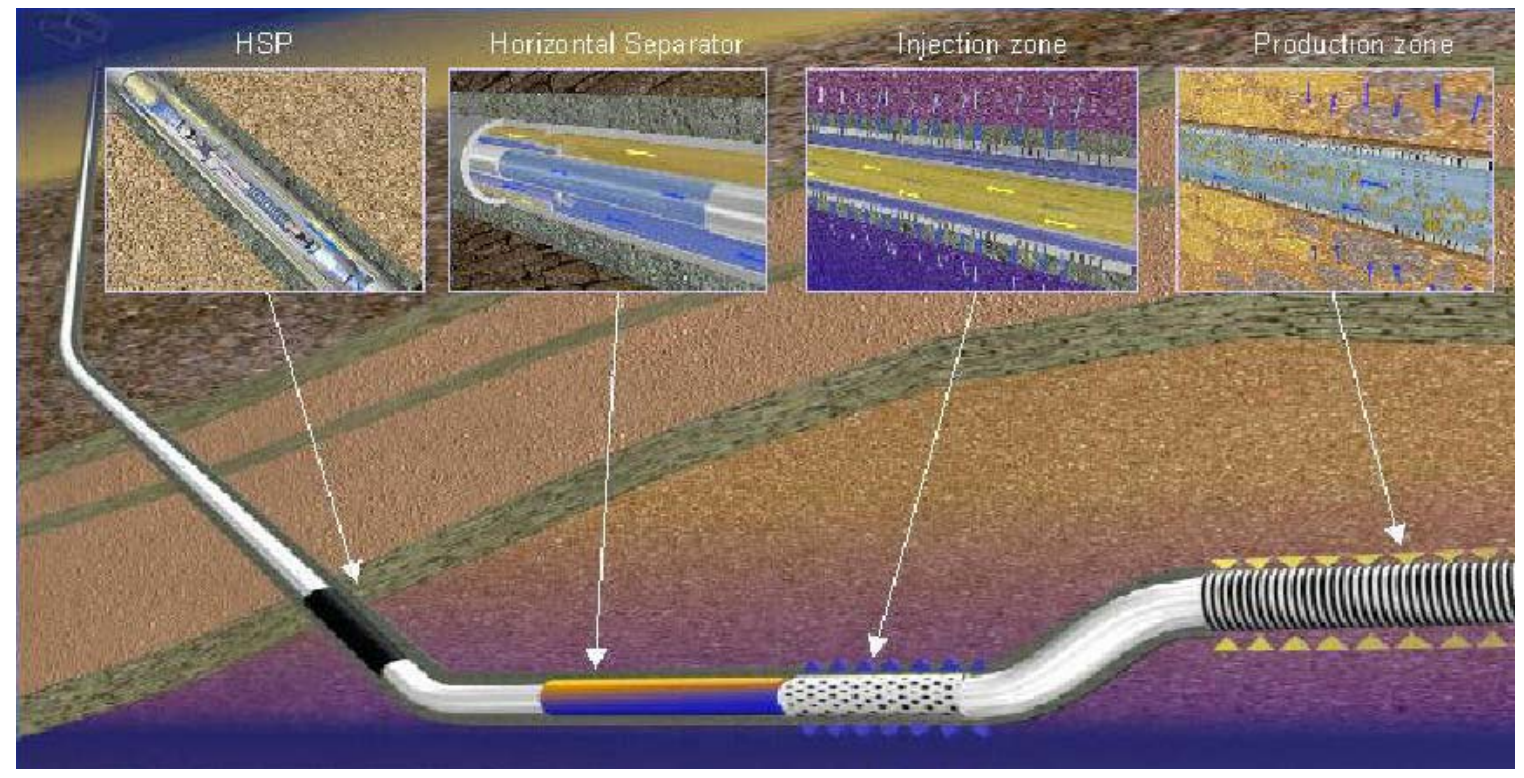

Figure 2.4: Another illustration of a downhole gravity separation and boosting scheme $^{5}$. 
The reservoir fluids are passed into a horizontal separator and this allows oil and gas to separate from the produced water. The separated water is reinjected for pressure maintenance. This reinjection is achieved by using a Hydraulic Submersible Pump driven by a power fluid delivered from the surface through an annulus in the wellbore the power fluid may be either oil or water and this power fluid is mixed with the produced water and both of these pass further down into the injection zone.

\section{Advantages}

Hydrocyclones and ESPs have limitations when it comes to the volume of gas they can handle and are also efficient only at water cuts of above $50 \%$.

The gravity separator is more compact and comes in a package that allows well intervention without requiring pulling out the separator or the pump.

\subsection{Subsea Separation}

Subsea gas/liquid separation is one of the alternatives to multiphase boosting to extend the distances of multiphase transportation. The development of offshore gas and oil reserves continues to move into deeper waters and marginal fields. The economics of many of these fields do not justify the use of fixed leg platforms or of floating production facilities. Some of these fields tieback to existing host platforms where available production capacity may be used.

The ability to tieback to an existing host platform can be limited by available processing capacity. And floating production systems have to cope with the motions of the vessel and severe weather conditions can lead to a shutdown of production equipment. Hence, it is necessary to look into the benefits of subsea processing.

Some other points to take into consideration are:

Subsea water separators will only do significant useful work after a high percentage of recoverable reserves have been extracted.

The separator has to be designed initially to handle the maximum hydrocarbon and water flowrate. 
A water injection pump will have to be designed accordingly.

Water separability

A first requirement to evaluate subsea water separation is the adequate separability of the water from the oil at conditions existing in the separator. If the crude/water separability is poor, subsea water separation is not an option.

Hydrodynamic conditions

In transient conditions, the operating procedures and the equipment must allow for appropriate handling of the separated phases in the upstream network. Flow instabilities are expected to be larger and last longer when the distance between the separator and the well increases. Separator levels also need some time to stabilize and this also needs to be modeled.

Sand production

In the case of sand production, the subsea separation system must be capable of removing the sand continuously.

Production, water cut and GLR profiles

The production profile of all relevant area prospects and their phasing-in timings must be considered to determine the optimum installation strategy for the separator as well as the capacity.

The inlet of the separator has a bearing on the separation efficiency and will be designed for water/HC separation.

Transport capacity

The production network is usually designed as a function of the needs for oil and gas transportation in the plateau production phase. Subsea water transportation would free up some of the capacity in the system as water cut increases. The utilization of this free capacity is essential to the economy of the separator installation.

Hydrate/wax prevention ${ }^{6}$

Hydrate and wax prevention begins with keeping the temperatures as high as possible. The use of a subsea separator will result in a flow downstream of the separator that has a lower volume rate and a lower heat capacity. Therefore the temperature drop 
will be more sever in comparison the flow without separation. In order to compensate for this, several flowlines could be routed to fewer risers; this has the additional benefit of preventing slugging.

The residual water may require some hydrate inhibitors.

Pipeline thermal insulation

Topside water handling capacity

The handling capacity topside can be reduced by the use of a subsea separation system resulting in a lesser cost and a smaller footprint. The water break through timing is often encountered with uncertainty. The capacity required also depends on the presence of an injection well.

Maintenance and operation

The maintenance of a subsea facility will have to be largely remote, with a few of them being managed by ROV intervention.

Some other questions that can arise are:

How will the use of a subsea separator alter the production profile?

How will the subsea separation process compete with other alternatives?

In May 2000, Norsk Hydro installed the Troll Pilot subsea separator system in the North Sea off the coast of Norway. The project was installed in 350 meters of water in the Troll field, approximately 60 kilometers west of Bergen, Norway. The Troll pilot separates the large amount of water produced from this field and transfers it to the reinjection system. While the water is being re-injected into the reservoir, the oil and gas are commingled and flowed back to the TROLL C semi-submersible. This happens to be the only operating subsea processing system today.

\subsubsection{Subsea Gas/Liquid Separation}

Subsea gas/liquid separation has a few benefits if it is combined with pumping of the liquid phase to one line and natural flow of gas in a separate riser. 
There is a low pressure drop in the gas line, this has the advantage of eliminating the compressor topsides.

Low erosion velocity for the top of the riser due to low gas velocity.

Reduced hydrate risk because of the possibility to decompress the separator and deep water flowline through the gas riser

Easier restart of wells by lowering separator pressure.

Possibility of using a standard centrifugal pump to lift the liquid.

\subsubsection{Transport Capacity}

The gas/liquid separation scheme also opens for a reduction in the diameters of the risers as compared to multiphase flow. The liquid flow will be pumped and the gas to a large extent has been removed from the oil, gas expansion due to riser pressure drop will be minimal or non-existing. If the pump creates a delta-P equivalent to the hydrostatic pressure loss, then all the gas remains dissolved in the oil. Gas will also flow to the surface with little pressure drop.

\subsubsection{Hydrate/Wax Prevention Strategy}

One benefit of the gas/liquid separation scheme is that it allows for depressuring of the horizontal pipeline by a combination of gas venting through the gas riser system and pumping of the liquid from the separator.

\subsubsection{Equipment Required for Subsea Separation}

The Subsea processing building blocks for the gas/liquid separation and boosting scheme are one or a combination of the following:

Subsea Gravity Separator 


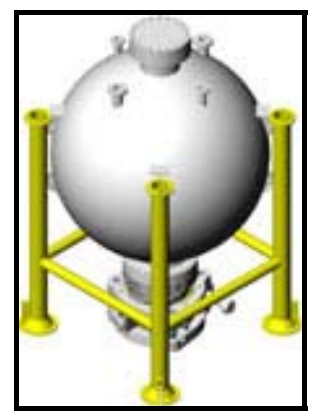

\section{Figure 2.5: A subsea gravity separator ${ }^{7}$.}

Some of the features of subsea gravity separators are:

Typical maximum liquid flowrates for these systems are around 8000 BOPD.

They are inexpensive, tried and mature designs that are very robust and capable of handling most non-severe situations.

However, there are many disadvantages to the gravity separator design.

They are massive and occupy greater seafloor space.

For higher pressure systems and deployment in higher water depths, the pressure ratings of such gravity separators would require them to be very thick walled and hence bulky and expensive.

Sand production would decrease the capacity of such gravity separators and increase the residence time, thereby decreasing efficiency.

With the above features, subsea gravity separation does not seem to be as attractive an option as subsea compact separation.

Subsea Compact Separator

Some of the other cyclonic based separators currently on the market are capable of handling:

Solid/gas separation

Liquid/Liquid separation

Solid/Liquid separation

Gas/Liquid separation 


\section{Subsea Compact Separation}

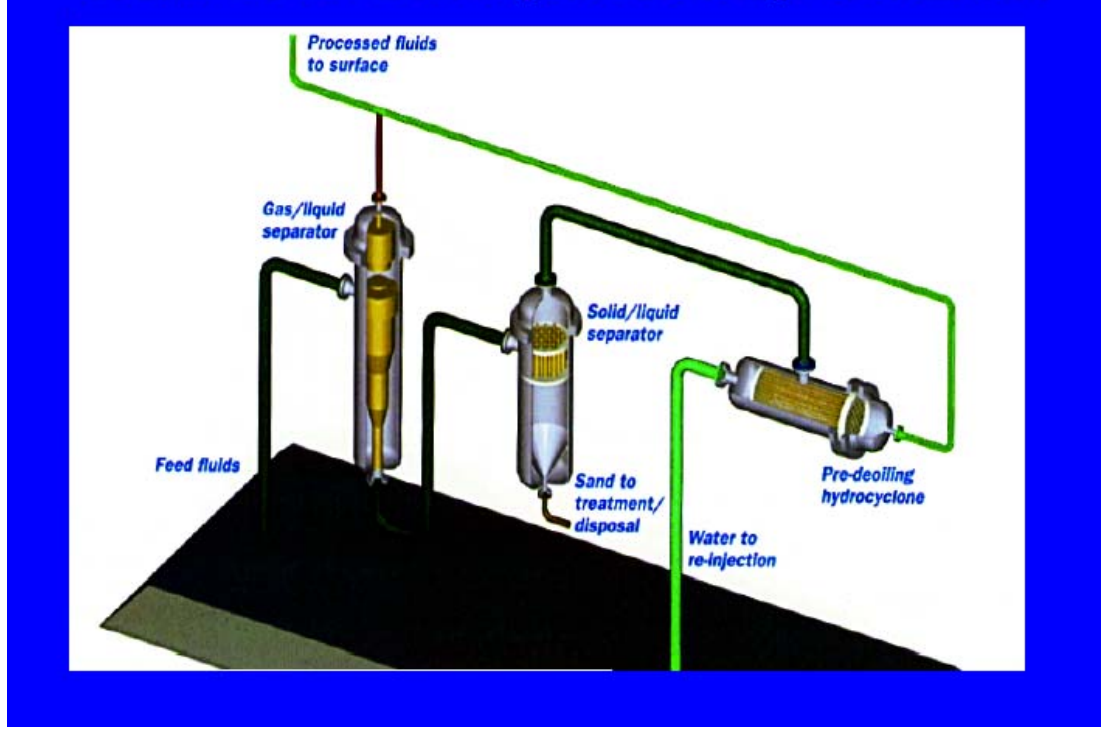

Figure 2.6: Illustration of a subsea compact separation facility ${ }^{7}$.

So a cyclonic separation scheme can have a series of cyclonic separators to separate reservoir fluids/sand and then to separate the reservoir fluids themselves into separate oil and water or oil and gas or liquid and gas streams as shown in Figure 2.6.

Some of the advantages of an in-line cyclonic separator design are ${ }^{7}$ :

Small size

Compact and in-line

Multiple stages possible

High pressure rating

Low pressure drop

No moving parts

Simple to manufacture

Not motion sensitive 


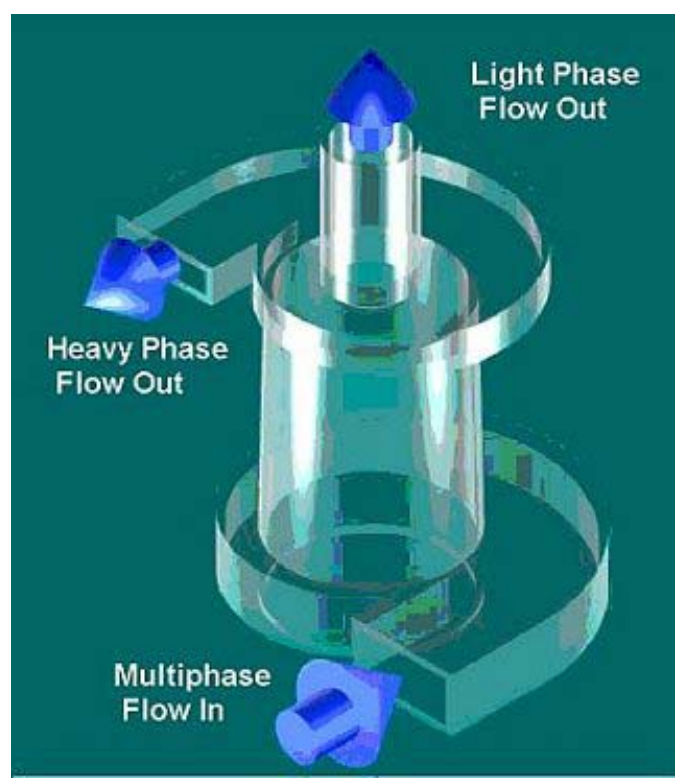

Figure 2.7: I-Sep compact separation illustration ${ }^{8}$.

One of the advantages of the cyclonic separator is that it can be used in multiple stages to effect higher separation efficiencies. These are installed in line on the flowline and require little or no maintenance due to the absence of moving parts.

\section{Electrostatic Coalescers}

Electrostatic coalescers are used to aid in improving oil-water separation by coalescence of droplets of water entrained in the oil stream into larger droplets that are easier to separate out in a downstream separator. The larger and more massive droplets of water tend to be able to settle down faster in gravity separators and can be separated with greater efficiency in compact cyclonic separators. There have been some field installations of compact electric coalescers made by Kvaerner Oilfield Products notably in the FPSO vessel 'Petrojarl1' and has been in operation since July 2002.

Not only is the water in the oil stream separated to a greater degree, but also other impurities like salt dissolved in the water phase are removed largely, helping to produce export quality crude right at the ocean floor. 


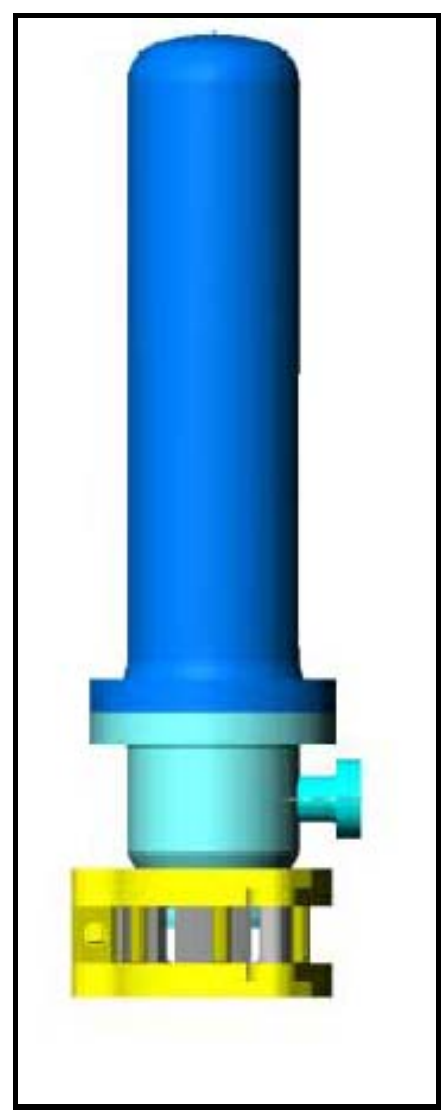

Figure 2.8: Compact electrostatic coalescer ${ }^{7}$.

The advantages of electrostatic coalescers are:

They do not incorporate any moving parts and are fairly robust and reliable.

They have a small footprint and can be retrofitted to existing installations.

The means to produce refinery grade crude right at the seafloor is possible with electrostatic coalescers followed by a cyclonic separator, whereby almost all the water and salt content in the oil stream is removed.

The removal of the water phase aids in flow assurance since there is little or no water remaining in the oil stream following coalescence and separation. 
Corrosion in flowlines becomes less of an issue and lower capital outlays would be required for flowline installation owing to the reduced water content in the oil stream, which does not demand higher quality, corrosion resistant alloys.

Some of the disadvantages of using this technology are:

The requirement of electrical power for operation entails the use of a dedicated power source and a subsea umbilical to supply power to the coalescer. This increases the complexity of the system.

In case of failure of one of these units, the operating parameters would have to be redesigned to accommodate for higher water content. This would entail some emergency backup plan for hydrate mitigation and corrosion resistance.

Electrostatic coalescence is an emerging technology and there are very few installations subsea. However these units have been performing satisfactorily on surface installations.

\subsection{VASPS (Vertical Annular Separation and Pumping System)}

VASPS is a subsea separation system where the produced fluid (oil and gas) from subsea well enters tangentially into a dummy well with a 26 " diameter and $60 \mathrm{~m}$ depth and located as near as possible to the subsea production well. This multiphase stream is forced into a helical downward flow where the centrifugal forces cause effective gas-liquid separation.

The separated gas flows via differential pressure to a host platform and the oil is accumulated at the bottom of the dummy well and is pumped by conventional ESP. Some of the advantages of a VASPS system are to reduce the wellhead backpressure by separating the gas and liquid streams as close to the production well as possible and doing all of this subsea. 


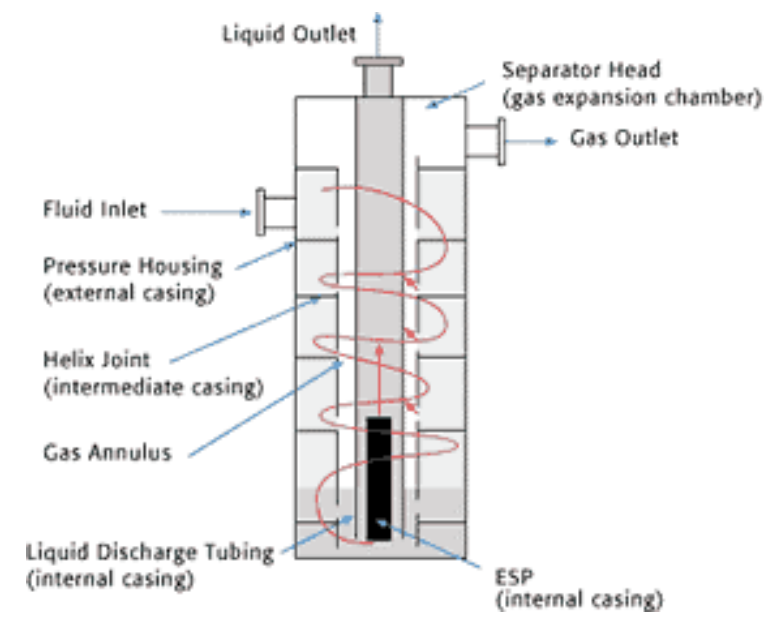

Figure 2.9: A VASPS system in operation?.

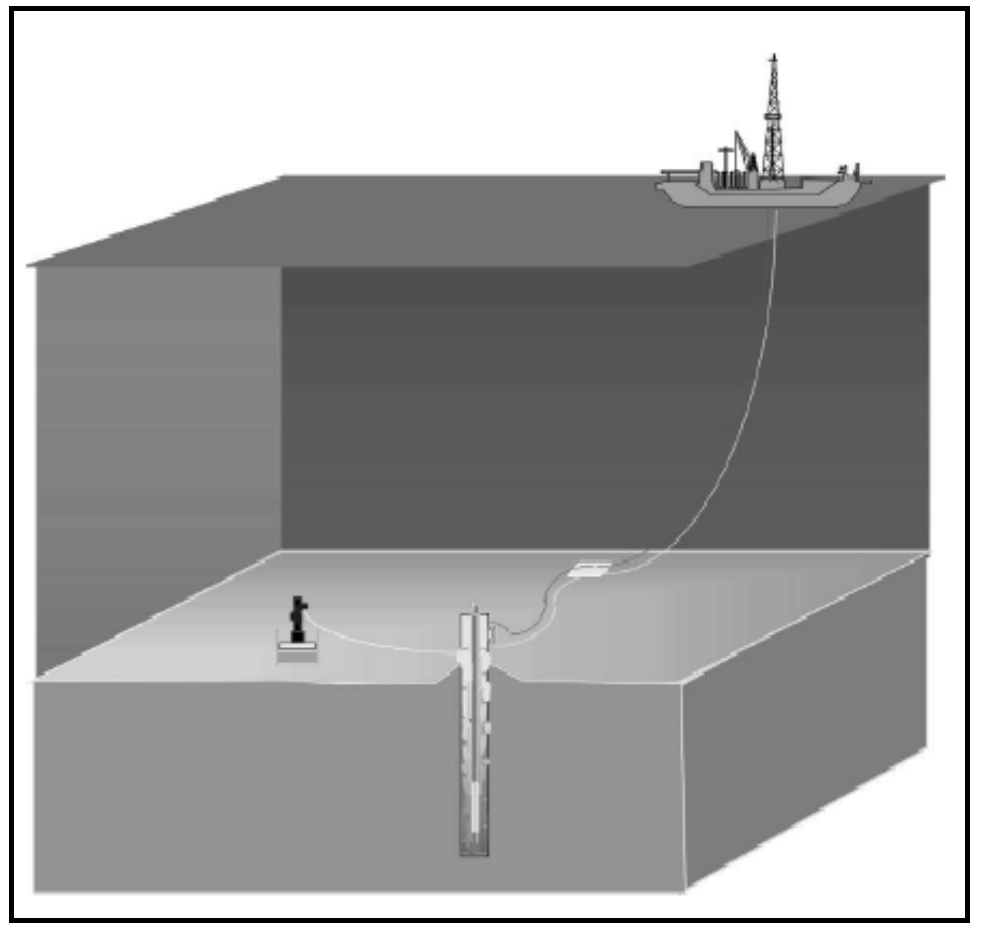

Figure 2.10: Illustration of a VASPS system in operation 
The size of the dummy well and the ESP performance would be dictated by the flow from the production well. PETROBRAS, ENI-Agip and Mobil North Sea have one operational in the Campos Basin, Brazil and designed for $1200 \mathrm{cu} . \mathrm{M} / \mathrm{D}$ of oil and $120,000 \mathrm{cu} . \mathrm{M} / \mathrm{D}$ of gas.

The advantages of a VASPS system are:

The system allows for easy and timely intervention since the main components of the separation and boosting system are directly beneath the surface facility. Power requirements are reduced since there is no need for longer umbilicals. The capital outlay is also reduced owing to the requirement for only one flowline from the subsea well to the riser base where the VASPS system is located. These systems have been in operation since 2000 and have proven to be reliable and robust.

\subsection{Subsea Pumping Equipment and Boosting}

Subsea pumping and boosting equipment are of three kinds:

Single phase boosters (for liquids)

Multiphase boosters

Gas compressors

The advantages of subsea boosting can be listed as follows

Enhanced and faster production

- Wellhead pressure drawdown

- Compressor discharge pressure overcomes backpressure and frictional losses.

Reduced OPEX due to boosted production earlier in the life of the reservoir, which help to reach ultimate recovery scenarios earlier.

Delayed CAPEX due to a greater plateau production

Development and production of low pressure reservoirs.

Disadvantages 
While subsea boosting offers reduced capital expenditure in terms of production facilities on existing or new FPSO's or TLPs, there is an increased electric power requirement that does really add to the CAPEX and in actuality, the reduced footprint offered by subsea boosting equipment is offset by the increased area required for power generation.

Reliability in the subsea regime is still an issue.

Sand production can cause expensive equipment failures.

\subsubsection{Components of a Boosting Station}

Subsea Gas Compressor

A gas booster can be used for gas re-injection or gas boosting. However most of

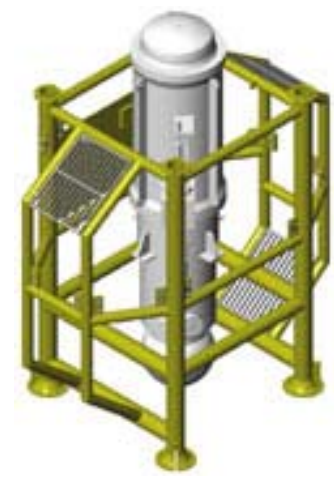

Figure 2.11: Schematic of a subsea gas compressor ${ }^{5}$.

the applications are in the area of gas re-injection into the reservoir for pressure maintenance.

Subsea Multiphase Pumps

Another alternative to increasing transport distances and reducing backpressures 


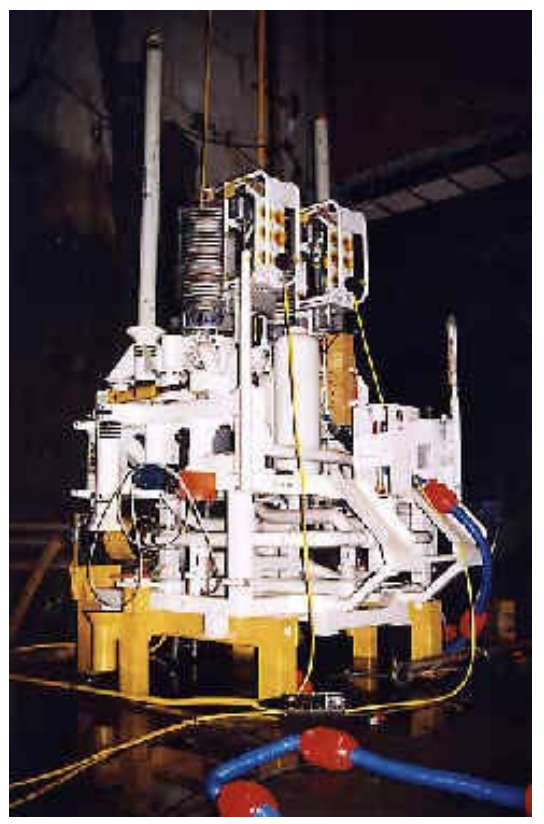

Figure 2.12: A subsea multiphase pump module ${ }^{10}$.

on wellheads ${ }^{2,11,12,13}$ can be by the use of subsea multiphase pumping. Multiphase pumps these days are capable of handling up to $97 \%$ gas volume fractions and up to $100 \%$ for a shorter term. They are also capable of handling slug flow in pipes.

\section{Subsea Wet Gas Compressors}

Wet Gas Compressors (WGC) are designed for applications such as gas transportation to remote onshore or offshore process plants, or for the same applications as for multiphase pumps, though with higher gas volume fraction. Wet Gas Compressors are well suited in high volume, medium to high pressure applications.

Wet Gas Compressors must be able to operate within a wide operating range. The normal operating range is 95 to $100 \%$ gas volume fraction. Wet Gas Compressors can be installed from day one, of a field development or at a later time when the reservoir pressure start to drop. 


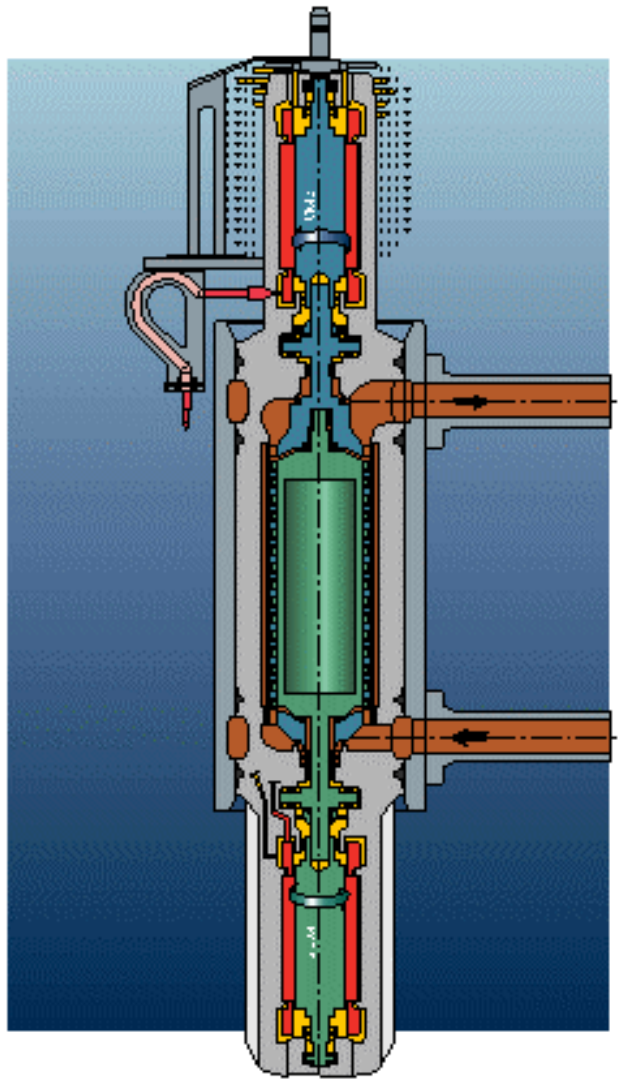

Figure 2.13: Diagram of a wet-gas compressor ${ }^{10}$.

Subsea Liquid Booster

The applications of subsea liquid boosters can be listed as follows:

Water Injection

Produced water injection or raw seawater injection

Crude/Condensate Export 


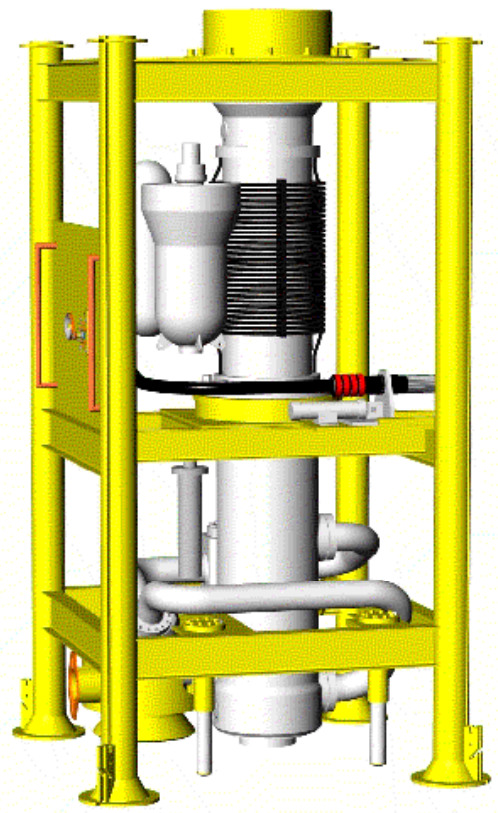

Figure 2.14: A schematic of a subsea liquid booster ${ }^{7}$.

\subsection{Challenges in Subsea Processing}

While there is a distinct need for simplicity of use and maintenance in all subsea equipment, the use of equipment like compressors and pumps, either single phase or multiphase, at the sea floor presents challenges for both performance and maintenance.

A long subsea tie-back and a deeper water depth would require longer umbilicals, which in turn, would require the use of larger electrical power supplies on the surface or the production platform due to the greater amount of power losses sustained over longer distances.

While the space required on board a platform for the processing equipment is reduced, there is a greater need for more space just to house the power supplies. This can mitigate the advantages of having a reduced footprint for the processing equipment. 
Another disadvantage to using subsea processing equipment is the maintenance cost and the expenses for intervention should a failure or leak occur. In most cases, production will have to be shut down and expensive repair jobs carried out or in some extreme cases, it might be found more efficient to replace the failed equipment or in some cases, based on cost studies, there might be reason to provide a backup system in place for all subsea equipment.

\subsection{Buoys for Subsea Fields}

Production control buoys are a fairly new development for subsea production schemes. The development of the production buoys has enabled development of longer distance subsea tie-backs. When installed directly above the subsea field, they can offer huge advantages in terms of cost savings and operational expenses. Mostly designed for smaller applications, these buoys are yet to be categorized as a mature technology area. However there have been two field installations in South Africa and Australia offshore, not in the deepwater area. Companies are currently developing solutions to extend the capabilities of these production buoys to the deepwater area.

Some of the capabilities of these production buoys currently on offer and those that are in development are:

Control of a remote satellite facility through the use of wireless communication offering savings by eliminating the need for communication umbilicals.

Power distribution and generation modules for use in downhole ESPs and multiphase pumps.

Unmanned production processing capabilities, so that the fluids may then be transported to another facility, or into a pipeline system.

Seawater treatment units that offer capabilities for reservoir pressure maintenance by water injection.

Manifold intervention equipment.

Unmanned handling of hydrate inhibitors through remote control aiding in flow assurance. 


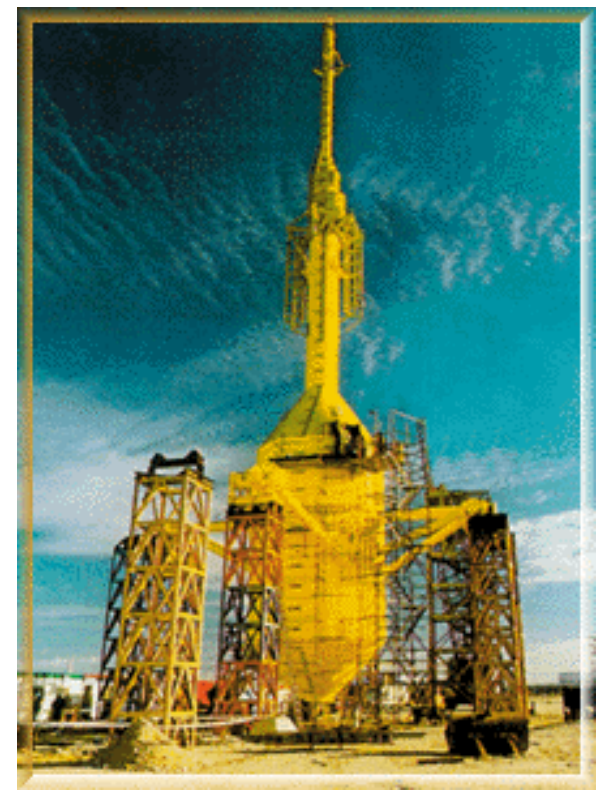

Figure 2.15: A schematic of a production control buoy.

With the capabilities being offered by the use of control buoys and production buoys, it is not a distant possibility that these will be available for cost effective and efficient subsea solutions.

Some of the advantages of the use of buoys are

Reduced capital outlay and a lesser operational expense to operate a deepwater field.

Flow assurance solutions are simplified without the use of complex architecture to incorporate inhibitors into the flow stream.

Control and monitoring of subsea wells becomes easier and probably more reliable.

Power distribution and generation modules allow for more efficient operation and a reduced risk of failure.

This is an area that operators and manufacturers alike should pursue to the fullest of their capabilities since the savings to be realized are huge. Reliability of the buoys and access to the buoys will most likely be non-issues for most cases since they are easily 
reached. With the rapid development of these less expensive buoys to perform a variety of tasks previously handled by long distance umbilicals, support vessels and floating platforms, it is possible to see a rapid growth in the development of more deepwater resources of marginal size.

The only drawback to the use of the production and control buoys currently is a lack of experience and reliability information. Considering that for the cost of one floating platform, many production and control buoys may be obtained, each operating efficiently and controlling production and monitoring it's own field, this is a very promising area of development.

\subsection{The Future}

While subsea processing has distinct advantages over topsides processing due to the greater flow capabilities from individual wells and a possibly greater ultimate recovery from the reservoir, the power requirements and the maintenance costs have not driven the market to consider these options.

Currently few other options are being studied:

The use of salt water cells for power supply at the seafloor

Mini floating platforms to provide power and processing space to each marginal field.

While the use of salt water cells for the supply of hydraulic power has not reached commercial viability, it remains to be seen if these cells can supply the huge amounts of power that multiphase pumping or ESPs demand. At the most these cells currently can supply just sufficient power to energize various gauges and sensors either downhole or on the seafloor.

Some operators are considering the use of mini-floating platforms and there have been cases where these were considered more economical to use. Indeed, the requirement for long flowlines and umbilicals becomes unnecessary and fairly economical recovery of marginal reservoirs is possible. However, these smaller production facilities would have to be economically justified and a thorough weighing of options should be considered before any one type of production facility is installed. 
Other considerations to be kept in mind, is the routine maintenance and stocking of supplies on these smaller platforms. In the case of many marginal fields being produced with the use of mini-floating platforms there would have to be a dedicated work boat for restocking supplies and also for regular maintenance. These all add to the cost of a project.

\subsection{Conclusions}

Subsea separation and boosting offers benefits of cost effectiveness and can help boost production in the early stages of development that can help reduce even OPEX costs by helping reach ultimate recovery scenarios earlier.

Other benefits of subsea separation include reduction of the susceptibility to hydrate formation and the reduction in the usage of hydrate inhibitors.

Subsea boosting offers greater and faster recovery from reservoirs.

There is some resistance to the use of subsea processing technology by operators as these haven't been proven in harsh subsea environments to a great degree yet. The only project right now that utilizes subsea processing is the Troll project ${ }^{14}$. Sand production and disposal is a problem that needs to be reckoned with.

Other problems being faced are the higher power requirements of subsea boosting equipment - either multiphase or single phase boosters.

There is an increasing need to develop solutions in the case of subsea processing equipment failure - would it be better to install a backup or would it be preferable to shutdown and intervene? 


\section{CHAPTER III}

\section{SUBSEA SAND DISPOSAL}

The handling and treatment of sand is a specialized area of process technology. Sand production has a major impact on oil and gas field operating costs. Problems arising from high sand production include erosion, blockage and filling of vessels, pipework and flowlines. Removal of sand, once it has built up in the system, is typically very difficult, especially when it has become bound up with hydrocarbons. Once the sand has been removed from the system, disposal presents a number of process challenges, and is increasingly coming under environmental scrutiny.

It is essential to remove the sand as close to source as possible. Downhole control measures are effective but by their nature also inhibit hydrocarbon production.

The optimum approach to sand management is a combination of several techniques downhole and topsides (or subsea), where some proportion of sand is allowed to flow to surface for optimum hydrocarbon production, but the restrictive so-called "sand-free production rate" is increased.

Some of the common problems associated with sand production are:

Frequent choke replacement

Wear failure in flow line components

Lowering of residence time in separators

Poor injectivity of water

Solids interference with instruments and bridles

Wear and tear of pumps

Some of the questions that arise with managing sand production and disposal ${ }^{15}$ are:

How do I measure sand production?

How do I design my facilities to handle sand?

What are the best materials and equipment to protect against erosion? 
How do I separate the sand?

How do I maintain equipment uptime?

How do I minimize sand damage or interference effects?

What are my options for sand disposal?

What are the regulations regarding sand disposal?

\section{Subsea processing - how the pilot plant may work}

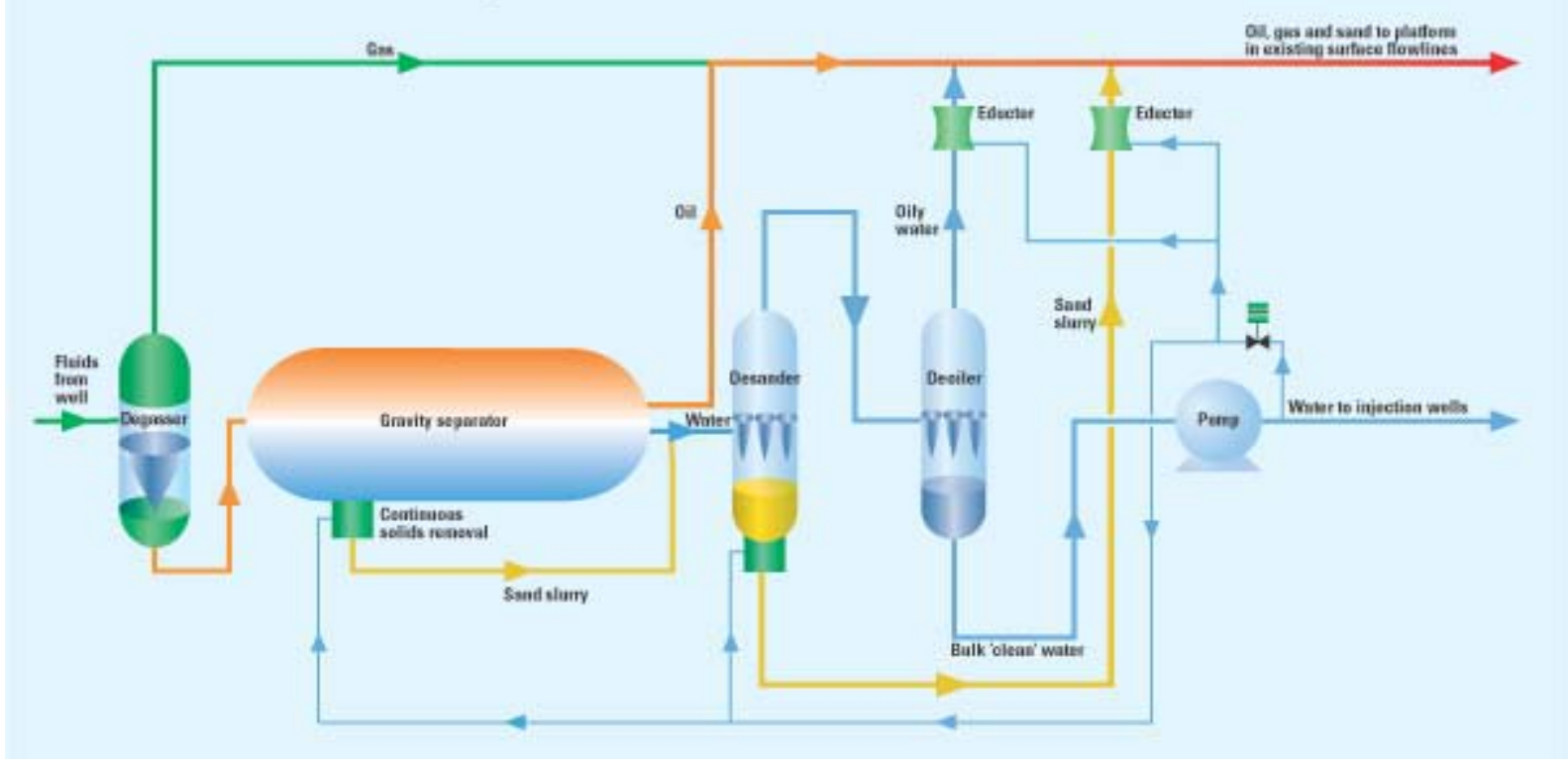

Figure 3.1: An example of how desanding may be carried out in a subsea processing unit $^{16}$.

\subsection{Monitoring Sand Production and Erosion}

There are a variety of companies that offer clamp-on sensors or inline sensors that do the job of monitoring sand production and can quantify sand production. These 
are fairly reliable systems and is a mature area of technology that has been proven in subsea fields in many places.

The problem with solid particle monitoring is the associated noise due to

Gas/Liquid flow

Droplets in high velocity gas wells

Mechanical and structural noise

Electrical interference

However with the latest advancements in increasing the signal to noise ratio of any measurement, these challenges have been overcome.

These sensors can be placed for subsea monitoring and topsides monitoring and both and even for well testing. Almost every susbea project in place today has some form of sand monitoring system to provide information on sand production. However, these days operators are preferring to have the particle monitoring system installed subsea rather than at the topsides facility. This has a few advantages in that the measurements are real time and it allows for accurate measurement of sand production without the sand settling down. Another reason is the improved signal to noise ratios if installed subsea. Problems with failure are mostly uncommon occurrences with the high degree of reliability that these systems are manufactured with. Interference is also a nonissue since these are mostly clamp-on systems that can be retrieved and replaced by ROV.

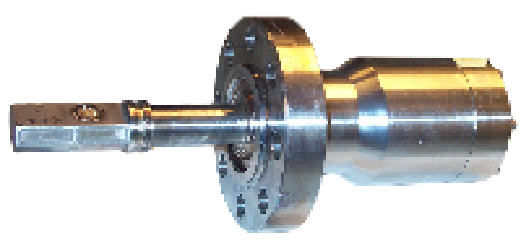

Figure 3.2: Sand/Erosion Sensor ${ }^{17}$. 


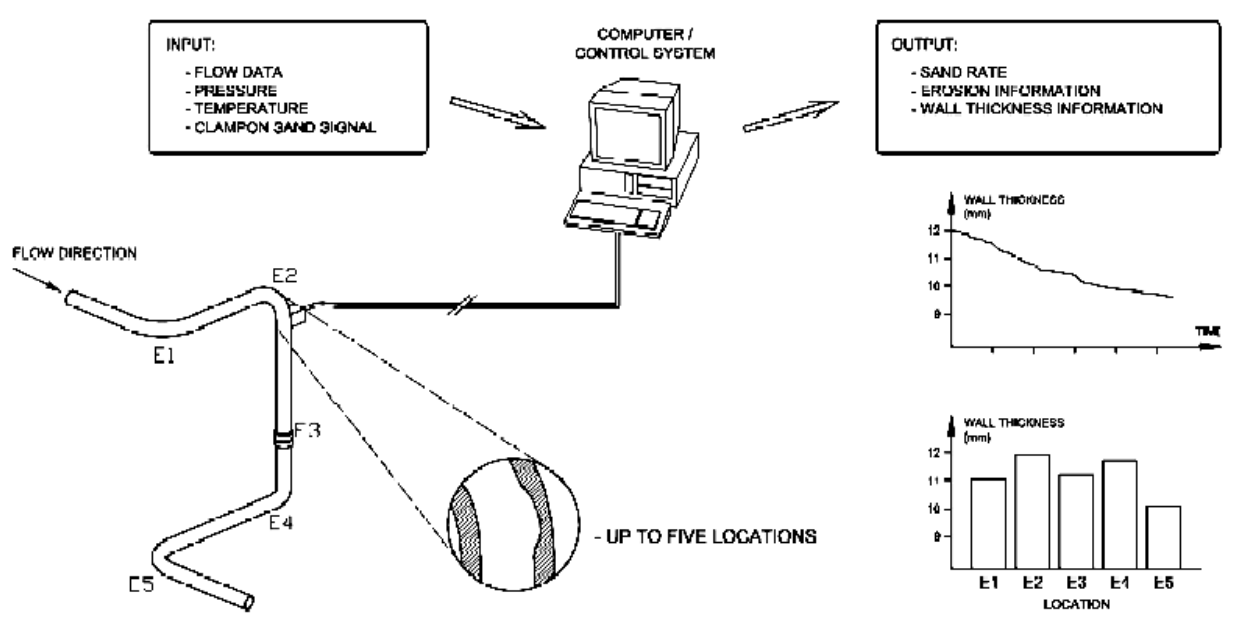

Figure 3.3: Subsea particle monitors are capable of measuring erosion on pipe

$$
\text { walls }^{17} \text {. }
$$

Most of the sand monitoring systems are clamp-on and non-intrusive measurement devices. In the event of a huge unexpected sand production rate, the monitors can set off alarms that will enable the operator to shut down the production or reduce the production rates to prevent further damage to the production equipment and also avoid costly intervention.

\subsection{Sand Management}

Sand management has been extensively researched and the expertise developed due to the harmful effects of sand on pipelines and other production equipment that can have disastrous effects should any of them fail or develop a leak due to corrosion. This is another major mature area in the field of subsea processing and again, many companies 
are providing the expertise and technology for sand management, which is the removal of sand from the wellstream.

Some of the methods in use today for sand separation are discussed below.

\subsubsection{Upstream of the Primary Separator - Wellhead desanding cyclones}

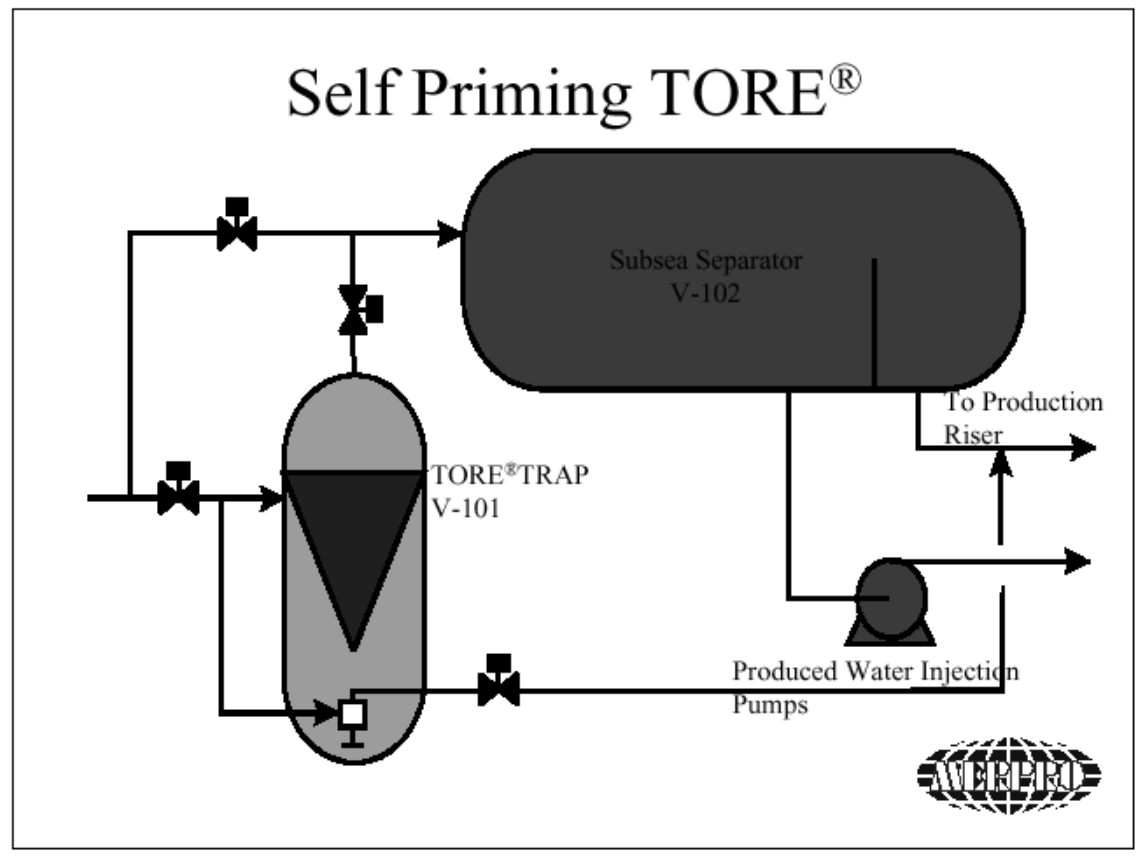

Figure 3.4: Illustration of a desanding cyclone upstream of the primary separator ${ }^{18}$.

Desanding cyclone technology has been developed to remove coarse sand particles from the multiphase wellstream at the wellhead. Problematic solids are removed upstream of any other process system and even ahead of the production choke. At this point the sand is often clean as it is typically water wet in the reservoir. Separated sand can be collected in an accumulator vessel located below the wellhead desanding cyclone and this can be periodically cleaned or flushed. The key elements of the 
application of the technology center around determining the range of volumetric flowrate and phase composition expected from the well or combination of wells in question. Once these ranges have been determined to a satisfactory level of confidence, the nature of the multi-phase flow regime can be determined which in turn dictates the sizing basis for the Wellhead Desanding Cyclones.

\section{Cyclone Operation}

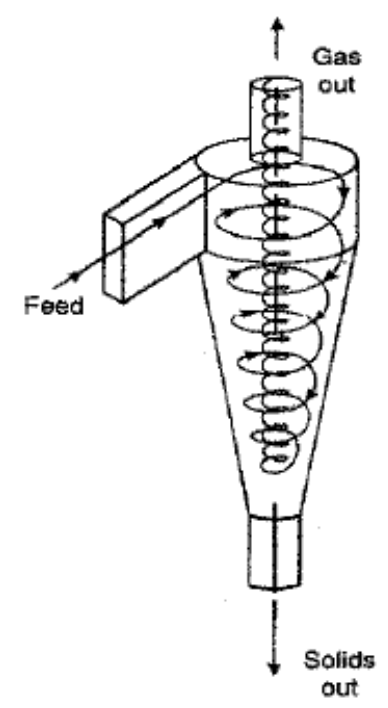

Figure 3.5: A desanding cyclone in operation ${ }^{18}$.

\subsubsection{Downstream of Primary Separator}

Desanding hydrocyclones are used downstream of the main separator for solids removal from produced water, oil or condensate streams. Sand is removed from water streams to protect downstream equipment and to facilitate produced water re-injection. Solids are removed from oil or condensate streams to prevent damage to further downstream equipment. 


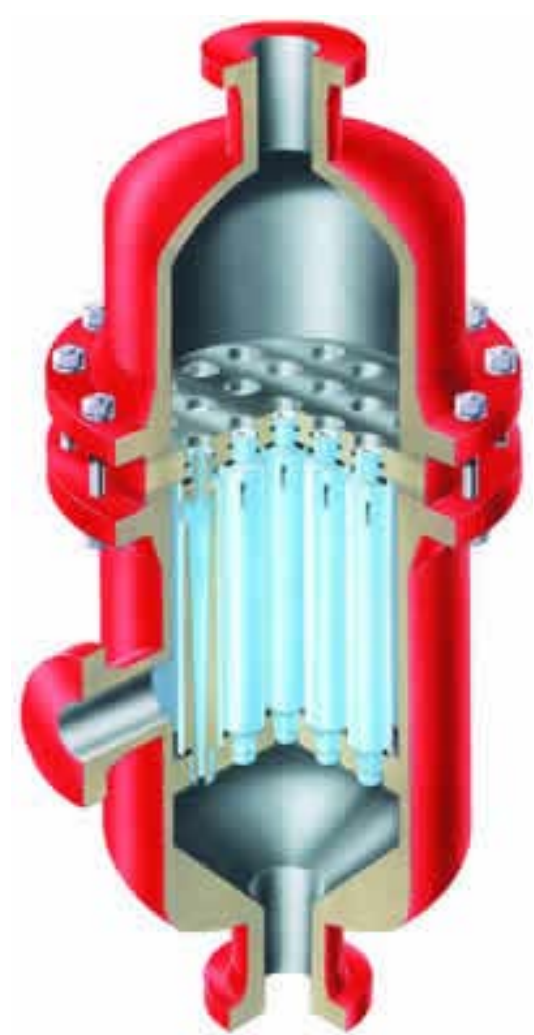

Figure 3.6: Cutout of a desanding multi-cyclone ${ }^{18}$.

With a multi-cyclone system as shown in the figure, the effective separation of particles from 5-25 microns is possible.

The design and flow capacity and the solids handling capacity for each type of desanding hydrocyclone is different for each case of application and mostly these are custom built hydrocyclones that perform for the particular flow parameters of a certain well/field.

The disadvantage of installing the desanding cyclone downstream of the primary separator is that it allows for solids collection in the primary separator and this is not desirable as it reduces the efficiency of the separator and also increases the residence 
time for the separator. This option is used only if sand production is deemed not to be too harmful to the continuous operation of the whole delivery system.

\subsection{Sand Disposal}

With environmental concerns high, it is deemed necessary to clean the sand and rid it of any hydrocarbon or chemical before it is disposed. Environmental regulations require the produced solids to be transported to shore, reinjected or cleaned before disposal.

There are a few options available for sand disposal and each option has to weighed against each other to decide which one would be most suited for a particular application.

The solids collecting under the cyclones could be:

Re-injected into the formation with any produced water being collected in the subsea separator. This would require reduction of sand particle size by the use of ultrasonics.

Storage of solids on the seafloor for periodic removal to the surface.

Re-entrain solids downstream of the separator into the production riser and reseparate the solids at the surface.

Clean solids subsea and directly discharge to the sea.

There are problems and advantages to each method. The last method of cleaning the sand subsea and disposing it is potentially hazardous because there still does not exist a method by which the hydrocarbon quantity in sand can be measured continuously and automatically. Additionally the solids would have to be discharged at pressure to overcome the hydrostatic pressure.

The second option would require a dedicated solids riser or a vessel capable of picking up a sand laden container from the seafloor. The first option is the most environmentally friendly but entails complicated equipment and also the possibility of formation pore plugging. 


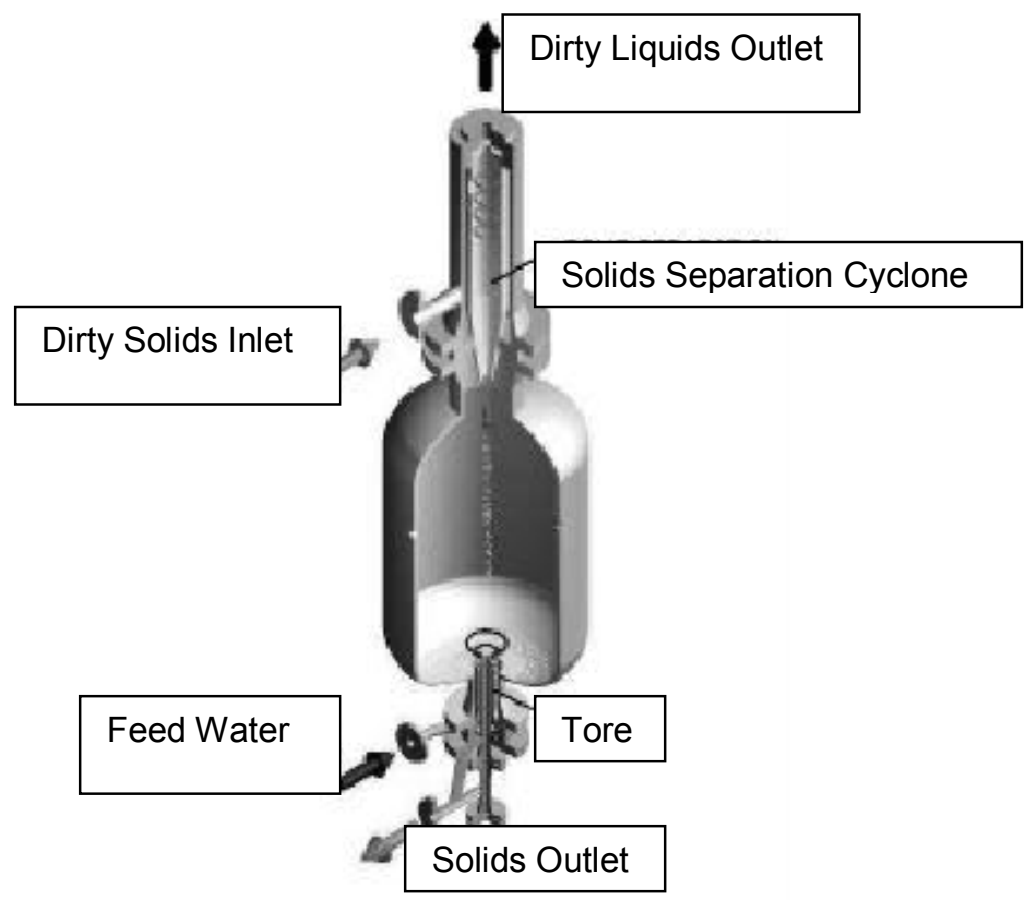

Figure 3.7: A system to clean produced sand ${ }^{18}$.

\subsection{Technology Needs in the Sand Disposal Area}

Problems with sand production faced in the subsea environment:

Sand disposal is a very big issue in the subsea environment as discussed above.

While solid/liquid separator behavior has been understood and has matured as an application, three phase separators that will help separate sand from oil and gas streams have not yet been completely understood. So three phase desanding technology is still in the development stage.

Desanding technology while being widely used for onshore and shallow water applications, haven't yet been widely used subsea because of the problems associated with sand disposal.

Till these problems are sorted, sand disposal and sand management in the subsea environment would continue to be an area where much needs to be done. 


\section{CHAPTER IV}

\section{FLOW ASSURANCE}

\subsection{Introduction}

Unrestricted fluid flow of oil and gas streams is crucial to the petroleum industry. The use of multiphase systems to produce and transport fluids long distances is becoming increasingly common. These fluids, combination of gas, crude/condensate and water together with solids such as scale and sand have the potential to cause many problems including :

Hydrate formation

Wax / Paraffin and asphaltene deposition

Scale deposition

Corrosion and erosion of facilities like pipelines and flowlines due to sand and other solids.

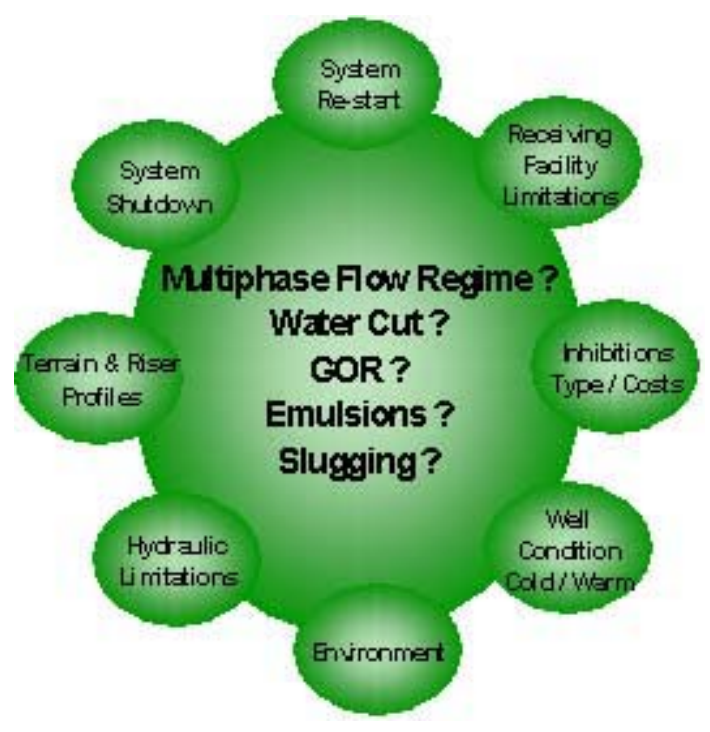

Figure 4.1: Illustration of the considerations for flow assurance monitoring and control $^{19}$. 
We must be able to identify the potential for and quantify the magnitude of any of these anywhere in the system. The difficulties posed are also complicated by changing pressures, temperatures and production profiles over the field life ${ }^{20,21,22}$. Apart from this, it is also necessary to control and predict potential problems during transient periods, which means that the system should be able to shutdown and restart in a controlled manner.

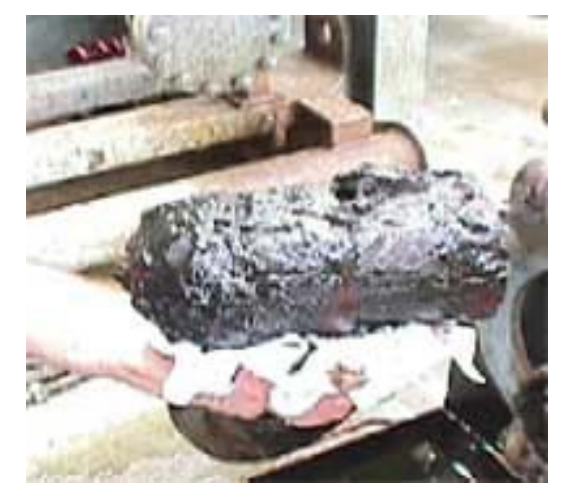

Figure 4.2: An asphaltene plug removed from a pipeline ${ }^{5}$.

The temperatures in the deepwater environment, like in the Gulf of Mexico, at a depth of 2000 feet or more, is around 40F, or $4 \mathrm{C}$, At these temperatures, the transport of crudes becomes a problem in risers and flowlines. Some crudes contain paraffin waxes which when cooled can gel and be deposited on the pipeline wall, gradually choking off the flow through the pipeline. Other crudes contain asphaltenes which can destabilize due to changes in pressure, temperature or oil composition and deposit on pipeline walls, leading to subsequent plugging. Hydrates, which are icy clusters associated commonly with water and methane mixtures can also form within a flowline if the conditions are appropriate and choke the flow. Apart from these issues, there is always the problem of solids/sand production causing flowline and facilities corrosion and blockages. Flow assurance, as a program, should be able to quantify the possible risks due to these effects and also implement sufficient measures to prevent such interventions. In the case of a 
serious blockage, the program should be capable of monitoring the development of a blockage and before it becomes too serious, the problem should be cleared.

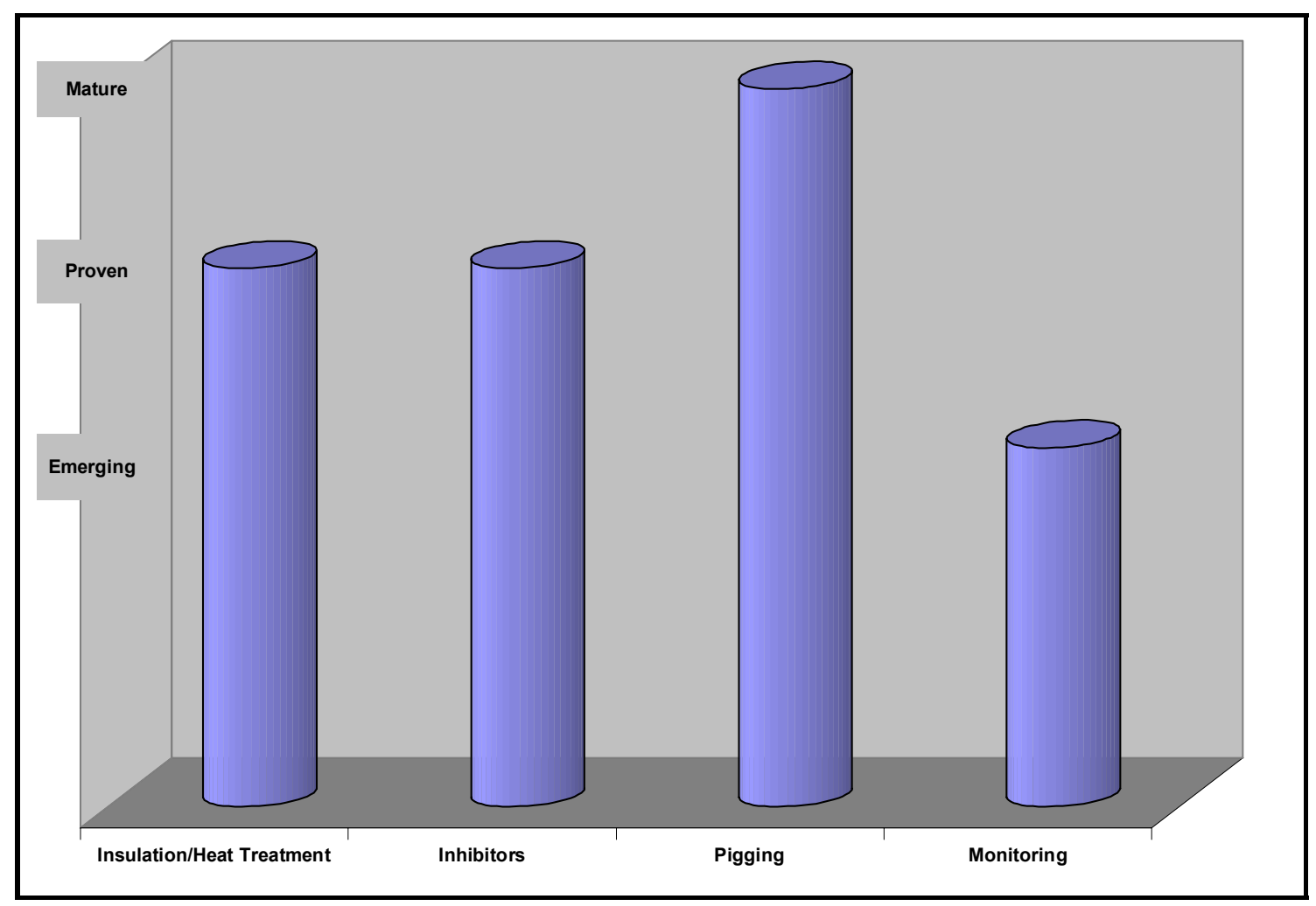

Figure 4.3: Chart showing maturity of various technologies for flow assurance.

There are lots of considerations that go into designing an effective flow assurance program for a field. Flow assurance must consider all the capabilities and requirements for all parts of the system for the entire production life and this would include parameters involved with the overall system design. Some of them are listed below.

Considerations for an effective flow assurance program :

Reservoir characteristics and production profiles

Produced fluids properties and behavior 
Field operating strategies

Flow diameters (tubing and flowlines)

Maximum and minimum production flow rates

Insulation (tubing, wellhead, flowlines, trees and manifolds)

Chemical injection and storage requirements

Host facility requirements (pigging, fluid storage and handling, intervention capability, flow receivers)

Capital and operating costs

\subsection{Blockage Detection}

\subsubsection{Analytical Methods}

Detection and monitoring of pipeline and flowline blockages has always been a problem. Traditional methods have included using the backpressure technique to detect blocks in flowlines.

There are other methods also in the field to detect pipeline blockages. Some of these are described in detail below.

\subsubsection{Gamma Ray Absorption Pipescanner}

The gamma ray absorption pipe scanner uses a weak radioactive gamma ray source to detect and measure blockages in pipelines. While this system hasn't been adopted yet for subsea operations, it could be utilized since it could confirm the presence of wax/hydrate formation and locate the position with great accuracy. An application of this technology would be to detect the position of the buildup once it has been detected by other means. This technology has been used with great success on onshore pipelines till now. For subsea use, it could be deployed by an ROV.

Some of the advantages of this system are:

The Gamma Ray Pipe scanner can detect blockages very accurately. 
It is a non-interfering type device and there are no hassles with instruments getting stuck in the pipeline or flowline.

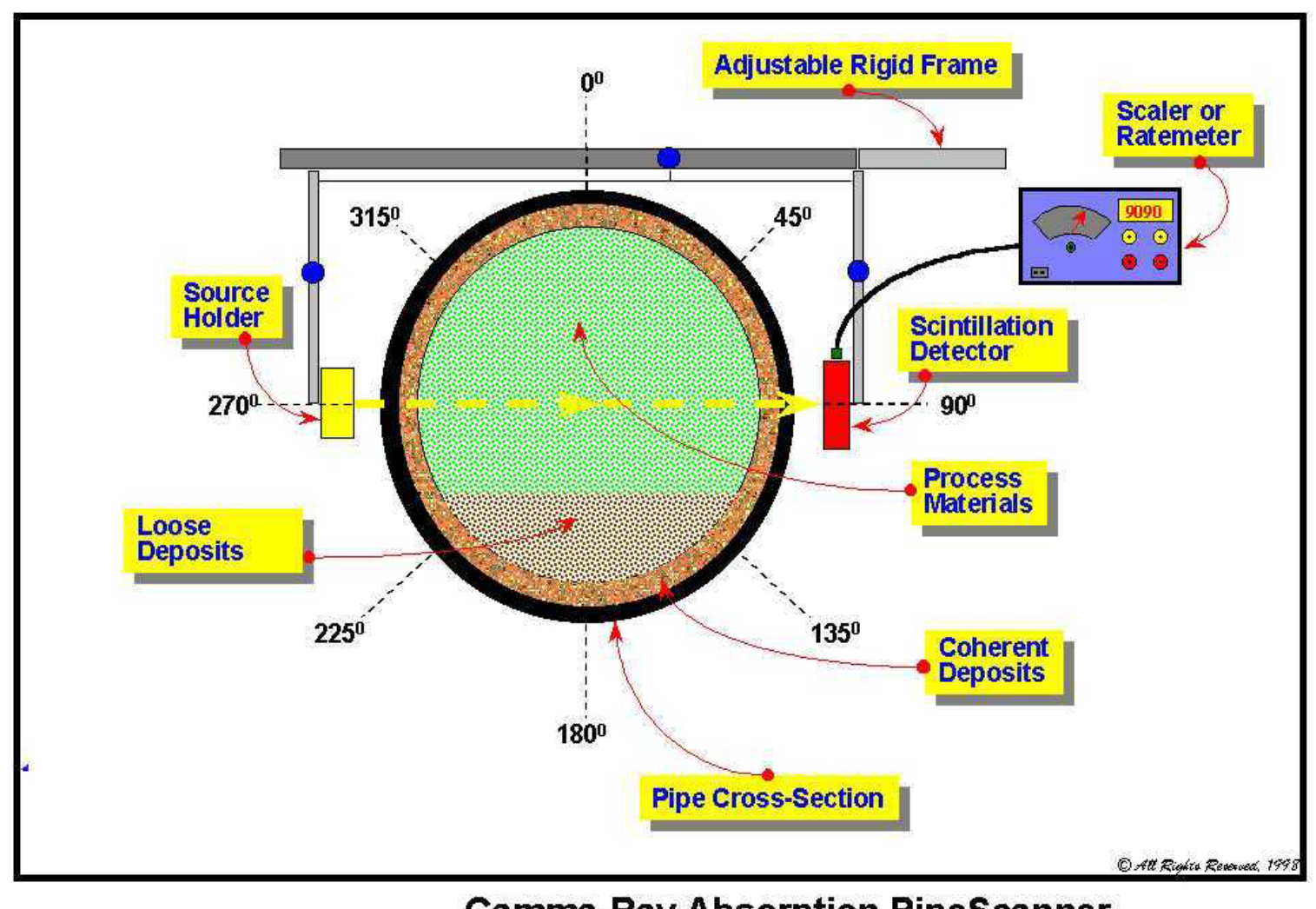

Gamma-Ray Absorption PipeScanner

Figure 4.4: A gamma ray absorption pipescanner

It also provides a repeatable measurement. If in doubt, a second scan can be performed to obtain the extent of blockage.

However there are some challenges while using this technology. Some of them are listed below.

The biggest disadvantage of such a system is the use of a radioactive source. The radioactive containment vessel should be able to withstand such pressures as are 
common in today's deepwater environment. Also retrieval of a source if the ROV has an accident or if the ROV fails is another issue.

It does not provide continuous monitoring capability.

\subsubsection{Fibre Optic Detection of Blockages}

The use of Distributed Temperature Sensing in a subsea flowline bundle will help to monitor and control the flow assurance issues associated with subsea pipelines. This is a more proactive approach to dealing with pipeline blockage and detection. This method of detection will ensure that pigging operations, inhibitor schedules and the use of heating lines is optimized.

This method has been proven in laboratory experiments, however, it's applicability to existing facilities seems rather difficult. The construct of these fibres requires that they be embedded in the pipeline or a special conduit made to house them. This will not be a problem for newer flowlines or facilities monitoring if the operator desires to have the optic fibre cable installed.

The principle behind the operation of distributed temperature sensing systems is the increase of pressure drop across a blockage. This increase in pressure drop will cause an increase of temperature due to the Joule-Thomson effect which can be detected by the optic fibre.

The advantages of such a system are:

Provides distributed temperature sensing - hence a distributed form of pipeline monitoring.

It provides real time data that can be linked to host computers for further analysis with further inputs like flow rates, ambient temperature, underwater currents etc. 


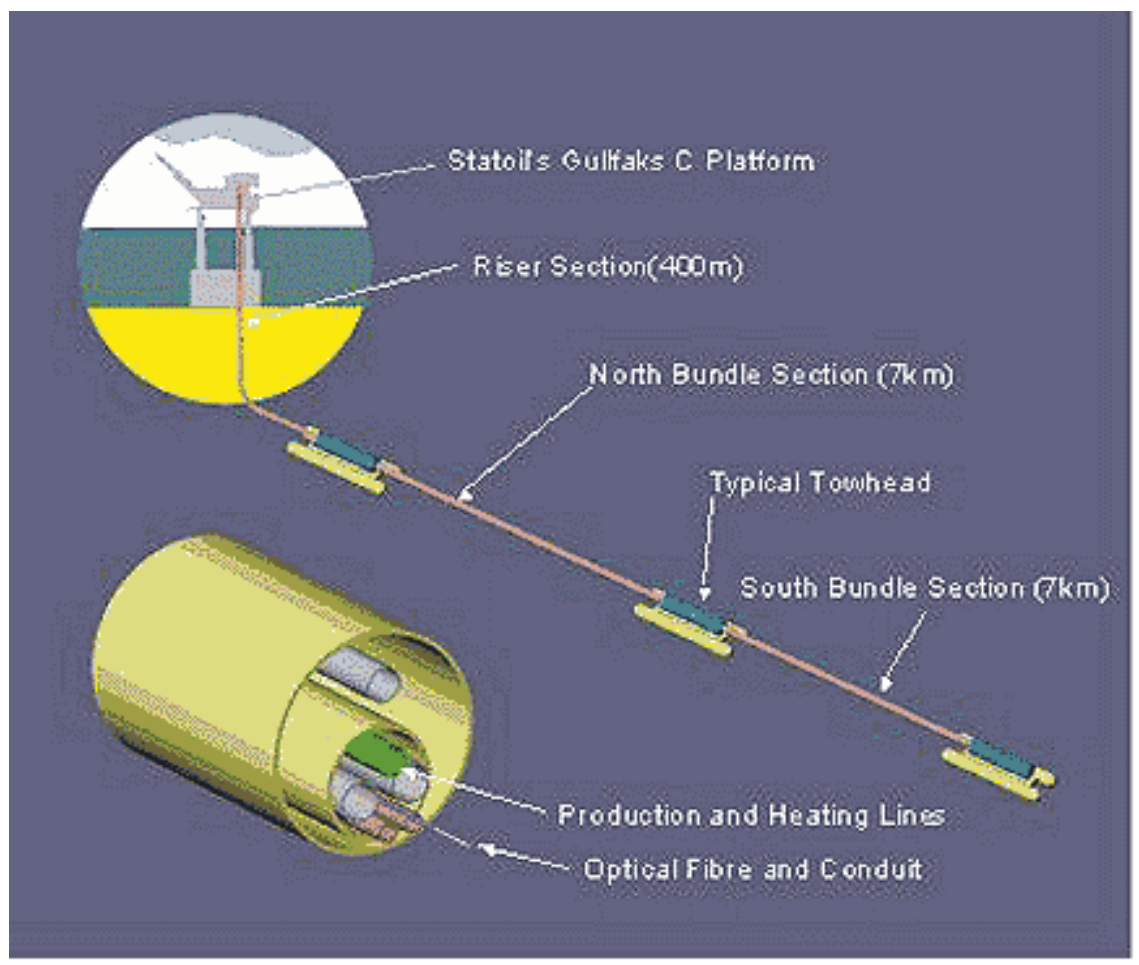

Figure 4.5: Illustration of optic fibre and conduit in a pipeline for monitoring $\operatorname{purposes}^{23}$.

Reduces the use of chemical inhibitors and electrical power since this is a continuous monitoring process. Any time the conditions seem to be getting favorable for hydrate/wax formation, inhibitors can be injected or the heating lines made to provide more heat to the flowline. It optimizes energy delivery to the heating bundle.

In actual practice, there have been noted some disadvantages to the use of optic fibre blockage detection.

Fibre optic cable is still very fragile and although research is being conducted on fibre optic housings to make them more suitable for harsh environments, we still haven't see them on the market.

Reliability is an issue due to the fragility of the optic fibre cables. 
Cannot be installed on existing facilities. The optic fibre needs to be embedded in the pipeline insulation or a separate conduit made for it.

\subsection{Hydrate Control}

Whether heavy hydrocarbons such as crude oil or low molecular weight hydrocarbons such as natural gas, there is gas almost always present in the fluid extracted during production. To varying degrees, the produced stream also contains water. In the presence of water and under a fixed range of pressure and temperature conditions, specific to each hydrocarbon mixture, hydrates of light gases can form. Hydrates have a crystalline structure analogous to that of ice, form solid plugs and can block flow.

Hydrocarbons containing gas, oil/condensate and water will cool to sea temperatures in long tie-backs and inevitably these lines will operate near or inside the hydrate envelope.

Even if, for the entire life of the reservoir, the system can be operated outside the hydrate envelope, which is very unlikely, there are times at shutdown and startup when potential problems cannot be ignored.

Until recently, the much preferred method is not to operate in the hydrate envelope. There are a number of traditional methods to avoid hydrates viz.

Heat retention

Use of alcohols and glycols as thermodynamic inhibitors.

\subsubsection{Insulation/Heat Retention}

Insulation can be used to preserve heat and thus keep operating temperatures outside of the hydrate region. However, whilst these can be effective for short subsea flowlines, they are still inadequate for flowlines of significant length.

Other advanced high performance insulation systems such as pipe-in-pipe systems are being installed subsea. Extremely effective insulation properties can be achieved by packing the annulus with materials like inert gases or silicate beads. However these systems are extremely expensive. Other new developments include 
hybrid flowlines that incorporate a core flowline surrounded by the systems that are normally included in a control umbilical. This has been developed by Kvaerner Inc.

However good the insulation may be, it is to be tested for shutdown/transient behaviour, since cooldown rates and consequently hydrate formation times are influenced by the insulation properties and also the topography of the flowline. Therefore whatever form of insulation is chosen, a complimentary form of remediation is also required.

For ultra deepwater environments also, the transient behavior of the system becomes increasingly important and will often dictate the subsea system design. It has also been shown ${ }^{6}$ that for a subsea system with 3 15 miles flowline length and about a 7000' water depth, the majority of the temperature losses are in the riser and a significant part of this loss of temperature is due to the potential energy loss and not due to a loss to the environment. Environmental losses contribute to less than $10 \%$ of the total heat loss. The insulation for pipelines/ risers /flowlines only accounts for saving the losses to the environment. This may not be the case for shallow water environments. It is also important to note that a system designed for a certain flow rate may fail for a lower flow rate and also if the composition changes as there may be less heat input to the system and also lower thermal mass in the system which may not be able to maintain high temperatures.

\subsubsection{Thermodynamic Inhibitors}

Another way to prevent hydrates is to change the thermodynamic boundary. This can be achieved by using inhibitors such as glycols or alcohols. The quantities of these inhibitors required is a function of the amount of water present in the line. Removing the water at source either in the reservoir or via downhole or subsea separation can significantly reduce the risk of hydrate formation and the quantities of hydrate inhibitor to suppress them.

A new generation of hydrate inhibitor ${ }^{14}$ has been developed which work in much lower concentrations than the thermodynamic inhibitors. These offer significant cost and 
deployment advantages for subsea developments. The other kind of hydrate inhibitor can be categorized as :

Kinetic inhibitors to suppress nucleation

These inhibitors work by extending the meta-stable region allowing operations further inside the hydrate envelope. These can only suppress nucleation and do not prevent it and given sufficient time, hydrates will eventually form. So they cannot be used during an extended shutdown period.

Crystal growth modifiers to control growth rate and prevent agglomeration.

These allow the hydrates to nucleate but control subsequent growth by acting on the crystal surface. The hydrate crystals are then dispersed in the flow preventing agglomeration and deposition.

Emulsification additives to disperse the water phase.

These additives disperse the water phase throughout the multiphase system limiting droplet size and again prevent hydrate agglomeration.

The last two additives can be used during a shutdown scenario provided the hydrates and the water phase are sufficiently dispersed so as to not settle in low lying areas, causing a blockage.

These low dosage inhibitors are probably going to replace the thermodynamic inhibitors. However their action does not cover extreme environments. Reservoirs in environments with temperatures below freezing would require antifreeze even if hydrates weren't a problem. So a combination of thermodynamic and low dosage inhibitor would have to be used. Gas pipelines also present a special case since there is no solvent to carry the inhibitor and some of the inhibitor effects might be lost.

\subsection{Remedying Hydrate Blockages}

\subsubsection{Heat Addition and/or Use of Alcohols}

This method will be effective if only the alcohols and the heating systems are already in place and they are difficult or impossible to apply after the blockage has occurred. 


\subsubsection{Controlled Blowdown}

Controlled blowdown from both ends to reduce pressure and shift the flowline out of the hydrate region is possible. For deepwater scenarios, due to the hydrostatic head, it may not be possible to reduce the pressure sufficiently. So operationally, it may be possible to only depressurize from one end. This can be potentially dangerous as the hydrate can dislodge and travel at high velocities towards the open end. There are reported cases of hydrate plugs rupturing pipes at bends and valves with disastrous consequences. In a multiphase line, the hydrate plug is however, likely to pick up a liquid slug ahead of it and this may decelerate the plug.

\subsubsection{Pigging}

The rapidly expanding development of marginal fields using subsea production systems with long flow lines from the subsea facility to the surface installation has generated the need to consider routine pigging operations as a part of the pipeline maintenance program. With ever increasing lengths of subsea tiebacks, insulation of subsea pipelines alone has proven ineffective in controlling wax and hydrates. Hydrate inhibitors perform the task of reducing hydrate buildup and reduce the risk of blockage, however in the case of extended shutdown periods when the fluid in the flowline may be cooled sufficiently to cause the conglomeration of hydrates or the appearance of wax, pigging operations should be considered and any system should incorporate some sort of pigging philosophy.

Pigging is a process carried out to clear flowlines and pipelines. As of now, there hasn't been any development of any system that monitors flowline/pipeline blocking and the traditional method is still being used, that is a study of inlet and outlet pressures and the rates and how they compare to those of an unblocked flowline.

The rapidly expanding development of marginal fields using subsea production systems with long flowlines from the subsea to the surface facility has necessitated routine pigging operations as an integral part of the pipeline maintenance program.

Some factors to be considered in the design of a subsea pig launcher ${ }^{23}$ are: 
Launcher capacity

Method of deployment, type of installation vessel

Control philosophy

Subsea connection to the pipeline

Pig launch mechanism

Pig drive fluid : For launching and for pig drive.

Structural support

CAPEX/OPEX balance

Guidance system

Environmental and safety issues

Advantages of Pigging Operations:

Controlled and predictable removal of hydrate or wax buildup in pipelines.

It is a mature technology.

With newer intelligent pigs, leaks and other pipeline defects may be detected.

Disadvantages of Pigging Operations:

Pigs are liable to get stuck, this may cause more problems than what the pig was intended to solve. Getting a pig unstuck is a very tedious process.

Pigging operations create large slugs and suitable slug catchers should be available during pigging.

Pigging requires that the pipeline be shut down. This interrupts production and considering that pigs move at around $12-13 \mathrm{ft} / \mathrm{sec}$, in the case of extremely long tiebacks would involve shutdowns for a very long time.

The frequency of the pigging operation is determined by experience with the field and the flowline and the conditions inherent therein. Most operators begin with a more frequent pigging program and this then gradually dwindles to a need-to-pig situation as more is learnt about the wax deposition rate.

There are currently two options open for subsea pigging.

Round trip (two line) pigging using surface launchers and receivers

Subsea Pig launcher (single line) 


\subsubsection{Single Trip Pigging}

When pigging conditions are identified in advance, typical industry practice is to install dual subsea flowlines to establish a round-trip pigging path from the host facility to the subsea well and back. By locating the subsea pig launcher at the subsea wellhead, the launcher can pig the single flowline without the need of intervention at the wellhead

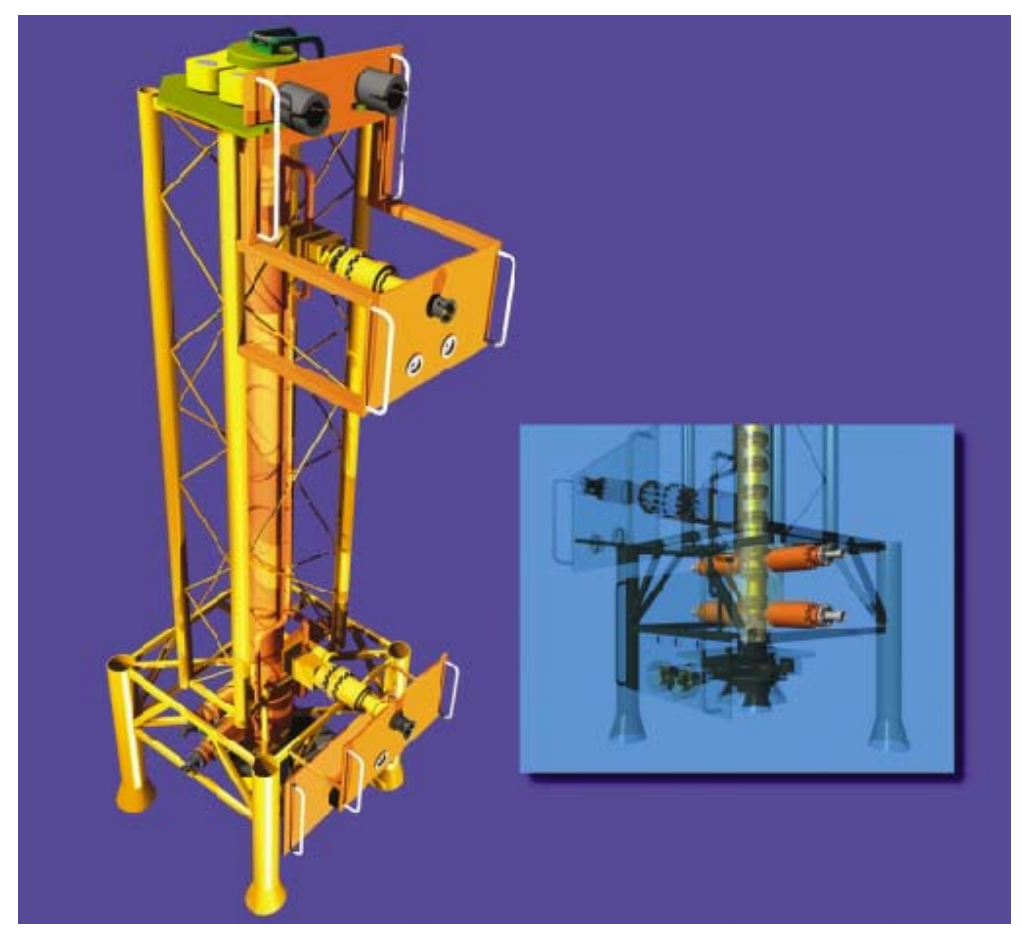

Figure 4.6: Equipment for single trip pigging ${ }^{24}$.

and eliminates the need of the second flowline. This methodology substantially reduces project expenditures associated with installing a second flowline that is typically used only for pigging operations.

With the subsea pig launcher, it is now possible to pig subsea tiebacks in a single trip. This method eliminates the need for round trip pigging and the extra expense of building dual flowlines which could lead to a reduced CAPEX and also a lower OPEX. 
Advantages of Single Trip Pigging

Eliminate a flowline - Reduce CAPEX

Minimize production interruption - Reduce OPEX

Disadvantages of Single Trip Pigging

The subsea pig launcher should be reliable, as it involves long term storage of the pigs and also a high cost of intervention.

Separate chambers for pig storage, parking and launching let you launch or replenish pigs without shutting down production. This not only reduces the cost of intervention, but it also lessens the risk of releasing hydrocarbons to the environment. In addition, it is also possible to use environmentally friendly, water-based hydraulic fluid to store and launch the pigs. This is a more ecologically sound solution that also prevents pig degradation during long-term storage. Most SPL systems in place today use a fieldproven, remotely operated hydraulic pig delivery system for better control of pig placement and release. This feature helps avoid the "pig hang-up" so common in more conventional gravity feed systems.

Halliburton/GD Engineering ${ }^{24}$ developed a subsea pig launching system for BP's Eastern Trough Area Project in the North Sea. The flowline length is 22 mile long and use of a single line subsea pig launcher saved the cost of construction of another 22 miles of return line. These are a few of the details.

1. Applications

Design Pressure 10,000 psi (689 bars)

Water Depth 10,000 feet (3,048 meters)

2. Flowline Size: 6 " to 16 "

3. Pig Type: Conventional polyurethane pigs

4. Pig Storage Capacity: 12 pigs

5. Storage Medium : Water-based hydraulic fluid

Since the DSPL uses water-based hydraulic fluid as storage medium, it can store conventional polyurethane pigs in the launcher barrel for long periods without 
degradation. The launcher stores up to 12 pigs to meet the challenges of subsea tiebacks in ultra-deepwater field developments.

6. Pig Reloading: This is done by a Remotely operated vehicle (ROV) equipped with a specially designed pig reloading tool

7. Pig Launching: Remote Control

8. Pig Replenishment: By ROV

9. Halliburton DSPL features

No need to shut down wells during pig launching or replenishment

No degradation of pigs while stored in launcher barrel

Environmentally "green” by design

\subsubsection{Round Trip Pigging}

With a subsea wellhead conventional pigging operations require the use of two flowlines looped at or near the wellhead and terminated at the surface or platform. The launchers and receivers are installed on the surface in the topsides facility.

Round trip pigging requires two flowlines for the operation to be technically feasible. This may be seen as a disadvantage, however, with two flowlines of reduced diameters as opposed to one flowline of a large diameter, this provides for reduced slug induced problems, since the slug length is reduced.

This is a tried and tested mature technique of blockage removal and has been successfully deployed in all sorts of offshore pipelines to remove blockages. 


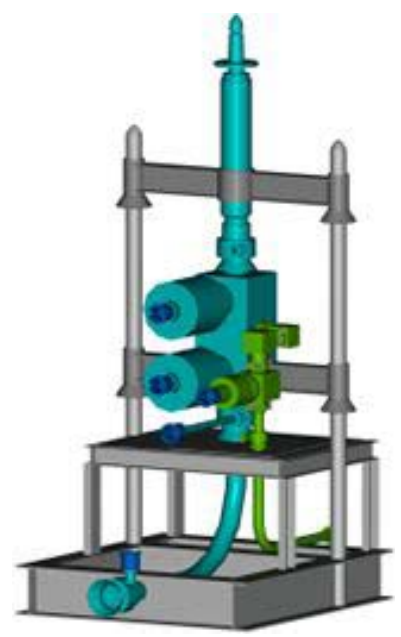

Figure 4.7: Equipment required for round trip pigging

\subsection{Waxes/Paraffin Prediction and Control}

Waxes are a multitude of higher molecular weight paraffinic components mainly soluble in the liquid phase of black oils and condensates. As the fluid cools, each wax component becomes less soluble until the higher molecular weight components solidify. This onset of crystallization is known as the cloud point or wax appearance temperature. As the fluid cools further, even the lower weight molecules also solidify adding to the solid fraction.

The onset temperatures of wax formation are usually higher than that for hydrates and cannot be easily avoided in the field. Intervention to clean a subsea pipeline can be very expensive. So a combination of inhibiting strategies must be used to combat wax formation.

The three methods currently available to deal with wax are:

Thermal: This method keeps the flowing fluids above the wax formation temperature. As in the case of hydrates, this will be limited by greater distances of flow. The thermal method involves the use of insulation systems to prevent temperature loss. And even though, these systems may not prevent fluids from cooling below the wax 
appearance temperature, insulation offers significant benefits since wax build-up rates are proportional to the amount of heat loss which is minimized by insulation. During long shutdowns, the improved insulation can extend the period before a restart issue owing to galled or gelled fluids occurs.

Also if the line is not totally blocked, it is also possible to clear the line by pumping hot fluids to melt the deposit. The hot flushing of pipelines is feasible if the flush fluid can maintain a reasonable temperature over the entire distance it is pumped. For this method, twin flowlines are required and care must be taken not to flush the waxes down into the tubing or the reservoir.

Another approach is by the use of an exothermic reaction in a partially blocked flowline. Significant quantities of heat and gas are developed which melt and agitate the deposit. This process was developed by Petrobras ${ }^{9}$.

Mechanical: These systems are used to scrape the wax out of the wellbore or flowline. Typical systems include wireline scrapers and flowline pigging. However, depending on the magnitude of the problem, the frequency of intervention may not be economic. This is especially true for subsea systems where the cost of intervention is high.

Chemical : Inhibitors are available which can modify the wax deposition rate and the rheology of the fluid.

When used to modify the viscosity or restart characteristics, these additives are called "Pour Point Depressants". Wax crystal modifying additives can also be used to reduce the rate of solid wax build up onto surfaces. These are called deposition or wax inhibitors.

\subsection{Erosion Due to Sand Production}

The production of sand and solids in oil and gas can represent a major problem in terms of erosion and damage to fittings, pipings and valves. Sand production can lead to a degradation or, in the worst case, collapse of the reservoir. Unexpected breakdown of the reservoir can occur with a water breakthrough resulting in increased sand content in the well fluid. Process equipment could also fill up due to the settling of sand. 
There are many methods to control sand production and some of them include using a Gravel pack, screen or a frac-pack job on the well.

Controlling sand production is best achieved by the use of desanding cyclones that can be installed near the wellhead. This is dealt with in greater detail in the "Subsea Sand Disposal" chapter.

Another method to control sand effects is to use a Sand Monitoring System. During a well test, the maximum sand free rate can be estimated and this maximum can be used for periods of production. However, the downhole conditions could change and this would require continuous downhole measurements. There are many companies that provide sand monitoring devices that can be used to monitor sand production rates so that timely intervention may be performed to prevent any further increase in sand rates.

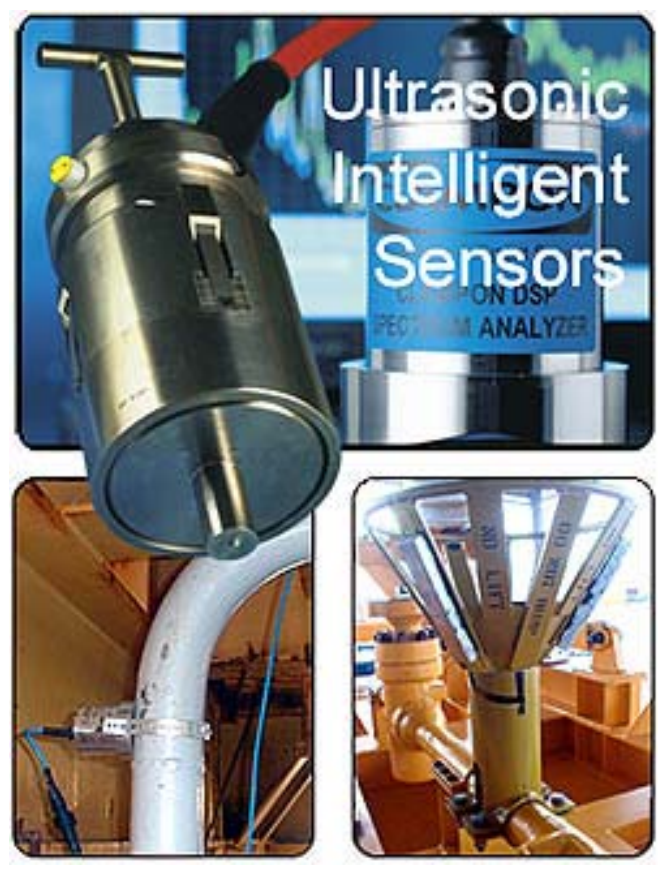

Figure 4.8: Subsea sand monitors ${ }^{17}$. 


\subsection{Other Methods of Ensuring Flow}

\subsubsection{Magnetic Flow Assurance}

MagWell's Magnetic Fluid Conditioner ${ }^{24}$ is a proven treatment for removing and preventing the build-up of solid scale and paraffin deposits in oil wells, and is currently being used in over 1,300 wells worldwide. The MFC is a magneto hydrodynamic generator specifically designed for the magnetic treatment of precipitating fluids in producing wells. Fluids are directed across extremely powerful controlled magnetic fields, which alters the growth of paraffin crystals and scale, thereby inhibiting the formation of solids in the well and in the surface equipment The body and shell of the MFC are constructed with 300 series stainless steel. Titanium is used for highly corrosive atmospheres.

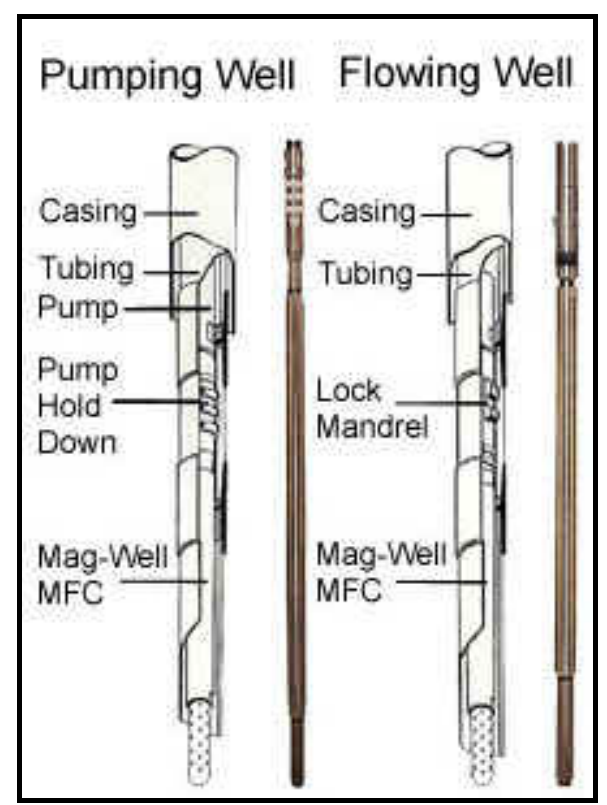

Figure 4.9: Installation of magnetic flow assurance devices ${ }^{24}$.

Inside the tool are a series of neodymium-iron-boron magnetic circuits creating flux densities in excess of 8000 Gauss. One hundred percent $(100 \%)$ of the fluids 
produced pass across the magnetic circuits, which prevent the crystallization of paraffin and scale deposits inside the venture.

Some of the advantages of magnetic flow assurance are :

Significantly reduces the need for hot oil, mechanical, or chemical treatments

Helps improve production due to lack of paraffin scale and asphaltene congealing on pump rods, tubing, flowlines, and other equipment

Helps remove existing scale and inhibits the formation of new deposits in pumps, tubing, heaters, separators, and other equipment

Keeps system free of the scale that causes under-deposit pitting-can reduce corrosion

No power supplies required - so reliability is not an issue here.

Pressure drop is minimal as the fluid is treated.

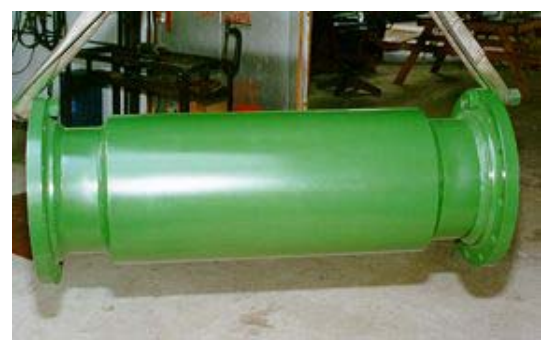

Figure 4.10: North Sea MFC designed for $10000 \mathrm{BOPD}^{24}$.

Some of the disadvantages of this system are that:

It has not been adequately demonstrated in the deepwater environment

Each project requires a unique design of the MFC and one MFC may not work for all conditions. Changing conditions could prove to cause an MFC failure in preventing scaling/hydrate deposition.

However, this is still an emerging technology still in the nascent stage and further field trials are required before it can become popular. 


\subsection{Other Design Issues}

\subsubsection{Wet Tree Versus Dry Tree}

Typically shallow water dry tree risers are not well insulated. Primarily, due to warmer seabed temperatures and to a lesser degree, lower shut-in pressures, they can provide adequate cooldown times without requiring an expensive insulation scenario. In ultra-deepwater, however, dry trees are extremely susceptible to hydrate formation upon shutdown due to the increased shut-in pressures and the lower temperatures, reducing the time to reach hydrate formation in less than a few hours.

Also considering the fact that multiple dry trees may be used in a development (as opposed to a single subsea tieback), mitigating hydrates for an unplanned shutdown in this conventional scenario becomes nearly impossible without some sort of active heating strategy.

Traditional insulation schemes for dry tree risers in ultradeepwater may not be sufficient to provide adequate cooldown times to prevent hydrate formation in the event of an unscheduled shutdown. Better insulators with a greater thermal mass may be added to all of the risers, thus increasing cooldown times, however this may be expensive and the capital expenditures associated with multiple dry tree risers may be substantial as compared to that of a single subsea tieback. 


\section{CHAPTER V}

\section{SUBSEA WELL INTERVENTION}

\section{1 "Intelligent" Completions}

The principal driving force behind intelligent completions is the need to manage today's highly leveraged designer wells, which challenge the technical capabilities and economic assumptions of conventional, intervention-based production management.

Among key drivers of intelligent well technologies are:

Fewer, larger (tubulars and production rate) well completions which complement advanced directional drilling capabilities

Pre-completion of primary, secondary and tertiary pays to exploit multiple reservoirs within the same primary wellbore, favoring commingled production.

Overall increasing sensitivity to unplanned OPEX, driving reliability (availability) requirements.

Early confirmation/contradiction of preliminary assumptions about reservoir response can provide valuable insights regarding reserves estimation; adequacy/inadequacy of capital infrastructure plans; number, placement and design of subsequent development wells, etc.

Intelligent Well Technology (IWT) encompasses two primary concepts ${ }^{25}$

Surveillance in real time - making measurements of downhole flow and/or reservoir conditions. Measurement is achieved by electronics or fiber optics. Measurements commercially available today are pressure, temperature and flow rate. Downhole pressure/temperature has been available since the 1980s.

Control in real time - the ability to remotely control zones, by on/off control or choking. Real-time production control has been commercially available only since about 1998. Control is achieved by electric, hydraulic or electro-hydraulic (hybrid) actuation of a valve or sleeve.

Conventional (non-intelligent) well designs require intervention via wireline, coiled tubing, or rig to make measurements or alter zone flow. By installing downhole well 
measurement and control devices connected to the surface (i.e., "intelligent technology"), measurement and control become possible without intervention.

\subsection{Intelligent Well Systems - Reliability Issues}

Intelligent Wells have evolved with developing technology like downhole safety valves, sliding sleeves, downhole gauges, and other components that are becoming more and more reliable. With the extension of these components, Intelligent Wells can serve many purposes like flow control, downhole monitoring, and communication from the wellbore to the platform. The benefits are certainly desirable for most fields, but although close to $86 \%$ of all Intelligent Wells have experienced no failure, the number should be closer to $95 \%$ to call Intelligent Wells "mature". The most critical part that most often fails is the downhole electronics. One major technology gap is designing electronic gauges that can withstand severe downhole conditions because these components are the most sensitive to high temperatures. Another learning experience is from the initial installation of an Intelligent Well System. Finally, hydraulic systems are considered the most reliable, but from time to time a mishap has occurred caused by extreme downhole conditions. Until Intelligent Well Completions have acquired optimal reliability, not many companies will be able to call their products "mature". 


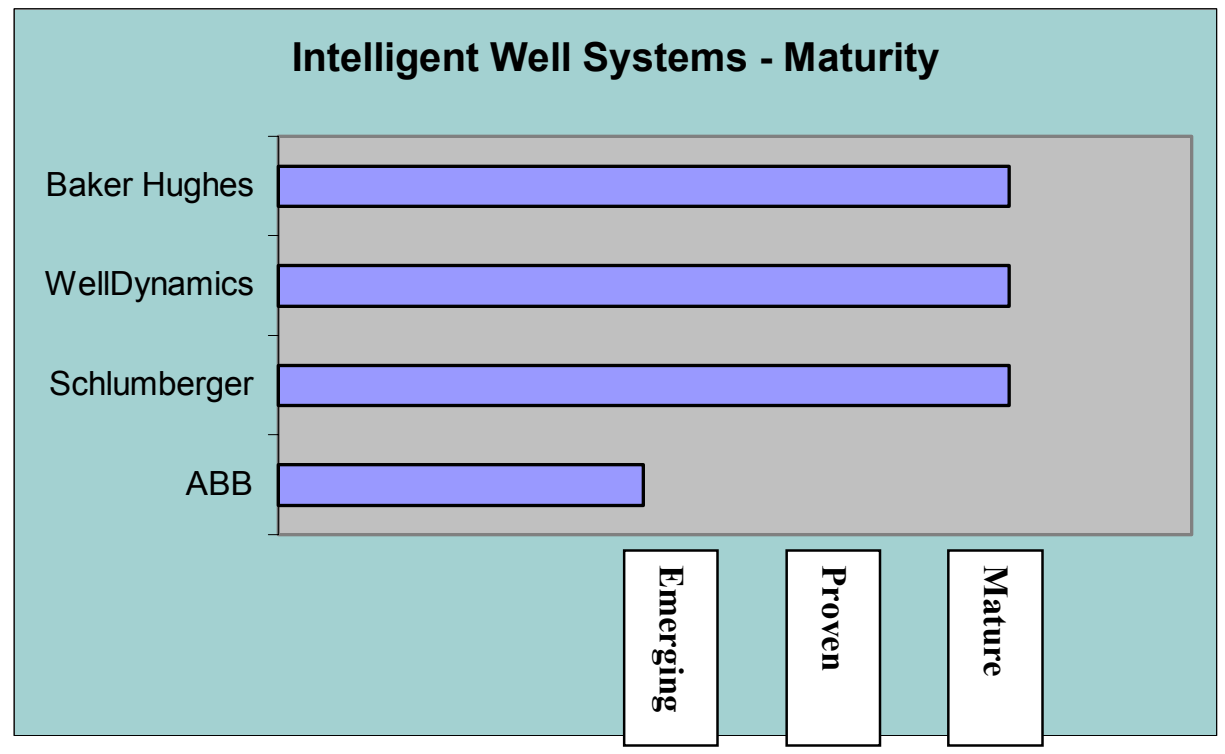

Figure 5.1: Maturity of IWS offered by various companies

As shown by Figure 5.1, ABB is the only company out of the four listed above that has not proven their Intelligent Well System in an oil field environment, but their technology is emerging to the scene. Intelligent Well Systems are a fairly new technology and companies are constantly learning more information about them on a daily basis. It is hard to tell when Intelligent Well Systems will reach the mature stage or have close to $95 \%$ redundancy, but lessons are being learned to change the tool design and the procedures. $100 \%$ redundancy is very much possible in the near future. 


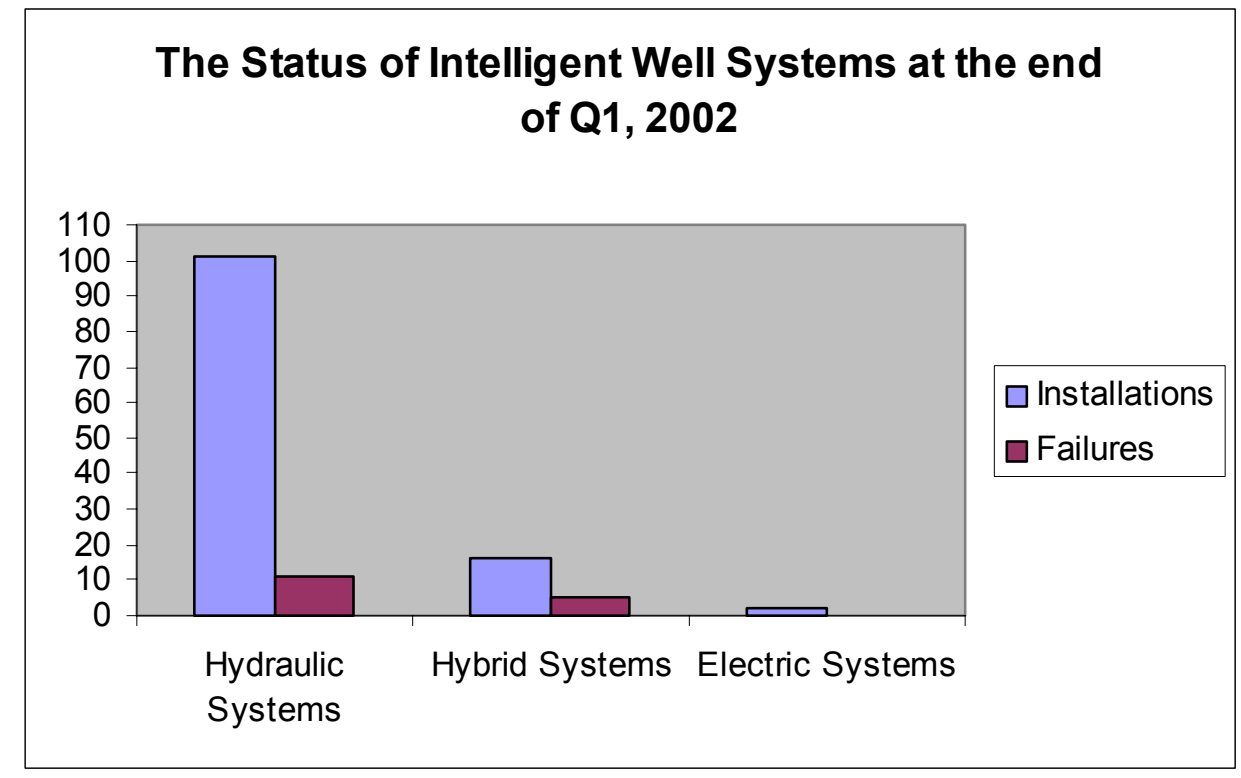

Figure 5.2: Intelligent well systems worldwide

As shown by Figure 5.2, about 10 percent of the hydraulic Intelligent Well Systems worldwide have experienced failure and approximately 30 percent of the Hybrid systems have failed. The electric Intelligent Well Systems have only been installed twice worldwide (1 by Baker Oil Tools and 1 by Schlumberger) because they are perceived as less reliable than the hydraulic systems, but they are much easier to install. The limited number of installations for electric systems is reflected by the limited success of the hybrid systems, but lessons have been learned from the installations of the hybrid systems. Bas Wolters, an Applications Engineering Manager at Baker Oil Tools, says "most failures took place in the early implementation of the new technology". He went on to add, "Reliability has much improved since. Unfortunately the image of intelligent well systems still has to catch up with these improvements". Baker Oil Tools strongly believes that these numbers will most definitely improve over time because the learning curve is forever increasing. There are a number of reliability studies going on to assess the risks when deploying Intelligent well systems.

As of now the failure rates are such: 
Hydraulic systems: 11 failures in 101 installations

Hybrid systems: 5 failures in 16 installations

Electric systems: 0 failures in 2 installations

As per the end of Q1, 2002 there were 22 intelligent well systems on land wells, 61 in offshore platform wells and 36 installations in subsea wells.

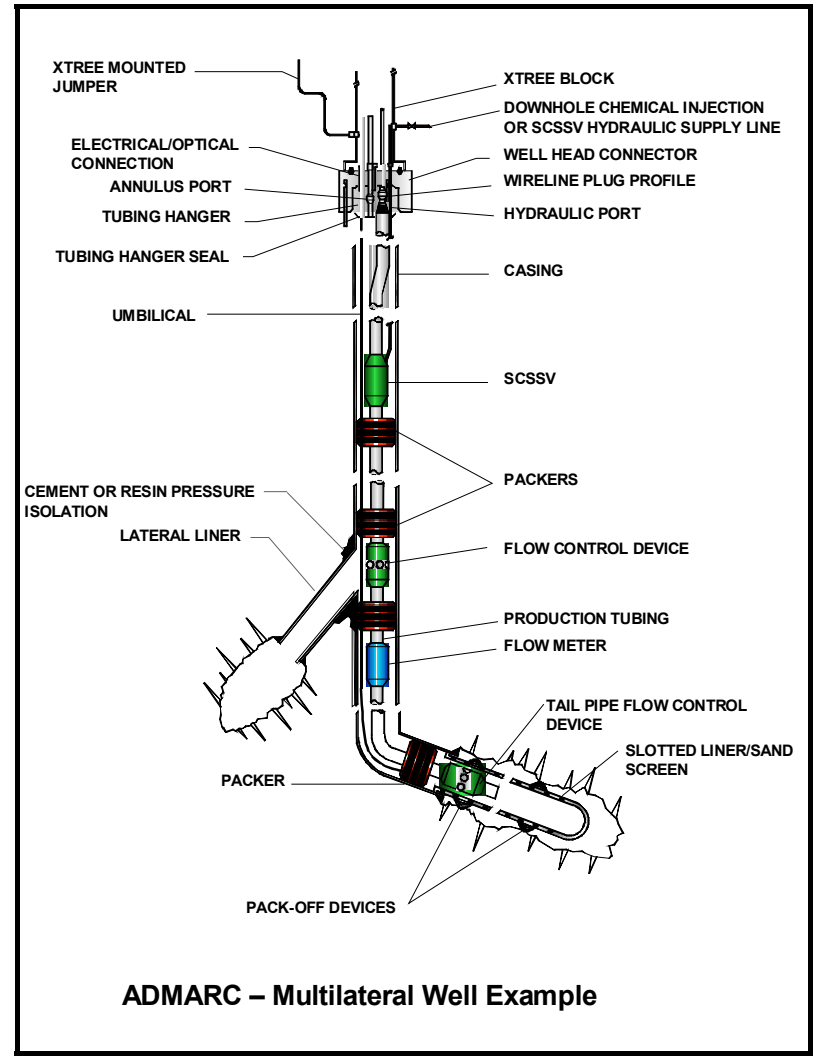

Figure 5.3: An illustration of an intelligent well system ${ }^{26}$.

\subsection{Downhole Monitoring From an Onshore Facility}

The downhole optical gauge system (DOGS) might be the most important element in ADMARC. It uses fiber optic sensors to monitor temperature and reservoir 
pressure. Shell Petroleum implemented the first pilot installation of DOGS in March 2000 off the coast of Brunei. First, the system works by transmitting broadband light from a source on the platform to the downhole environment using a fibre optic cable. Next, the downhole sensor reflects back to the surface two separate wavelengths of light, which are dependent on the pressure and temperature being applied to the sensors. Then, the wavelengths can be converted to the proper Engineering units at a topside interrogation unit. Finally, Shell Petroleum is able to control and operate the downhole sensors in an office at the Netherlands. After the installation was complete, they found out that the system was operating efficiently at a water depth of 2000 meters and $100{ }^{\circ} \mathrm{C}$.

\subsubsection{Description of an Intelligent Well System, DOGS (ABB)}

Uses intrinsic sensor technology with specially designed optical cable and connector system

10 sensors can be installed on a single fibre for exceptional accuracy

Ideal for high temperature applications

Hydraulically actuated

Can perform effectively in up to three zones

On-off control

Suited for vertical, deviated, and horizontal wells

Conventional electronic or fiber optic permanent gauge systems can be used

\subsubsection{InCharge Intelligent Well Systems (Baker Hughes)}

The InCharge intelligent well system also reduces/eliminates intervention and pilot monitoring, but it has some distinct advantages over the InForce intelligent well system. The InCharge system is better suited for subsea applications with multiple hydrocarbon zones because only one feed-through is required to penetrate the wellhead and the packers. The all-electronic design eliminates any hydraulic mishaps, and allows the operator to control the flow rates of up to 12 hydrocarbon-producing zones at a 
single control station. Also, permanent downhole quartz sensors are used to read the pressure and temperature in real time.

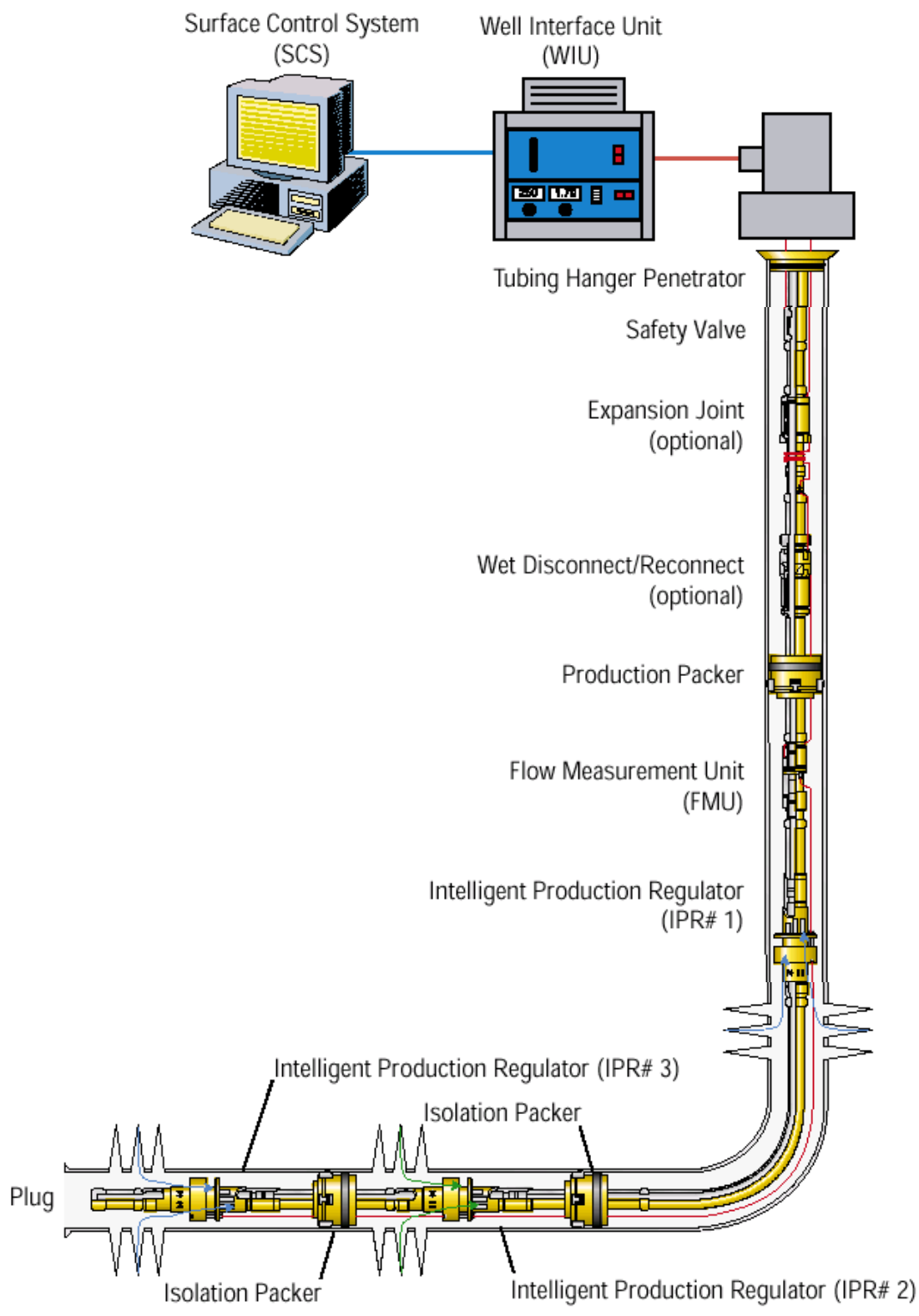

Figure 5.4: Schematic of the Incharge well system ${ }^{5}$. 


\subsection{The Significance of Safety Valves}

In order to explore into deeper waters and changing well conditions, safety valves are essential to improve the performance and the safety of dangerous subsea operations, but they have to meet several conditions. First of all, the flapper closure mechanism, rod piston, power springs, and other components must be reliable for water depths up to $3000 \mathrm{ft}$ of water. In addition, the design of the safety valve must be short length in order to ensure through-flow-line deployment. Next, just about every safety valve supplied by major oil tools companies like Baker Hughes and Halliburton have metal-to-metal seals. Metal-to-metal seals ensure that wellhead pressure is isolated from the topside hydraulic system when the valve is open and isolates the control line from the well fluids when the valve is closed. Also, the designers of these valves have to precisely construct them so that the safety valves can last close to 20 years in repeated tests. Finally, if a mis-run were to occur or a piece of equipment needed to be fished out of the wellbore, the safety valves need a temporary confinement center so that the running tool can bypass the safety valve and fish out whatever piece of equipment that needs to be looked at.

Safety valves that are manufactured today serve two main purposes that help improve overall safety and restore reliability in the wellbore. First of all, safety valves are the last resort to save the environment and human life because they automatically secure the wellbore safely when pressure integrity is lost. Whenever there is any loss of signal or the hydraulic controls are not operating effectively, safety valves are designed to automatically lock up and ensure a strong closure mechanism. Secondly, safety valves help maintain the same pressure between the control line and the wellbore. In 2000, BP Amoco's Pompano Phase II subsea development team in the Gulf of Mexico ordered a full investigation to find out the cause for several leaks between the production tubing and the control line. They soon found out that excessive pressure differential between the wellbore and the control line due to reservoir pressure decline was the central cause. After intensive engineering problem solving and thorough testing, they designed a through-flow-line deployed insert surface-controlled subsurface safety valve that 
revitalized production and restored pressure integrity. Finally, companies like Baker Hughes and Halliburton have designed and implemented safety valves that can be integrated into their Intelligent Well Systems that monitor and control downhole flow, which is an added bonus.

\subsection{IWS and Intervention Avoidance}

Operators use intelligent well technologies for three primary reasons:

To reduce or eliminate intervention costs

To accelerate production and reserves and improve reservoir management

To allow for additional recoverable reserves.

The single most-often-cited reason for running Intelligent Well Systems is intervention avoidance. Intervention to change zone flow will accomplish one or more of the following objectives:

Bring on production for a non-producing zone

Reduce or shut off flow of unwanted gas or water

Shut off a zone permanently.

Intervention carries with it a high cost, including rig cost, workover fluids, completion equipment, etc. In addition there is an opportunity cost that includes lost production for the duration of the intervention. Ancillary risks include environmental and safety issues.

Eliminating or reducing interventions by using IWS has the potential in some areas to add many millions of dollars to well net present value (NPV). Rig and workover costs alone may range from less than $\$ 50,000$ in low-rate onshore areas to more than $\$ 10$ million in offshore deepwater environments. Delayed revenue must also be considered. Thirty days of production delayed by a workover at, say, 10,000 bopd and $\$ 15$ per barrel, is equivalent to $\$ 4.5$ million delayed revenue.

Integrating intelligent well technology into subsea well architecture is actually a complex task since that would involve more dedicated support systems like power lines 
in umbilicals and additional power requirements for their usage. Intelligent well completion systems can be energized by:

Entirely electrical means

Electro-hydraulic systems

Hydraulic systems

Each of these systems offers its own benefits and advantages and the applicability of each is to be determined by the cost/reliability/frequency of maintenance/cost of intervention.

\subsection{Intervention}

When one speaks of intervention, it is not only intervention or routine maintenance or workover programs on existing subsea wells, but also a damage control or a repair or maintenance job on any one of the several components that make up a subsea system, including umbilicals, trees, flowlines and downhole gauges, subsea processing equipment etc.

The thrust in subsea architecture development has been to develop failsafe and reliable equipment that will require very little intervention. However, this is yet to be seen even as of today and constant equipment failures are commonplace. With increasing water depths that are seen these days, the cost of intervention is becoming prohibitively expensive. Traditional methods of intervention on offshore wells in shallow water are not applicable to fields where the water depth may be in excess of a 1000 feet.

Another problem being faced by industry in the GOM is the lack of precedent in well intervention at depths of 3000-4000 feet. While in the North Sea environment, subsea systems are in place and are being operated, the scenario is very different from that of the GOM. For instance, the water depths are greater. While offshore development in the GOM has always been in shallow water, the deepwater environment is a radical change from that previously encountered in the shallow waters of the GOM. Where once water depths were 500 feet, now in deepwater environments, the depth has plunged to an 
average of 5000 feet which induces reluctance to adopting any new technology until it has been tried and tested and this is a Catch-22 situation.

\subsubsection{Remotely Operated Vehicles (ROVs)}

Current trends in the offshore oil industry are placing increased demands on the capability, productivity, and reliability of remote intervention tools and techniques. Remotely operated vehicles (ROVs) and their tools are already changing to meet these demands, and this evolution is now poised to accelerate and intensify.

Offshore oil operations have long been dependent on remote intervention, but its methods are now coming under closer scrutiny than ever before. Remote intervention is a critical issue partly because it has a broad effect on total oil field costs. While intervention activity accounts for only 2 to 3 percent of the total cost of offshore oil production, it frequently paces other operations on the critical path during oil field construction and operation. Because the operation of very costly equipment (such as supply vessels, drill rigs, and derrick barges) depends on the success of ROV operations, making those operations more efficient and reliable will produce a large, cost-saving ripple effect throughout all aspects of offshore production.

Two of the most important trends now apparent in the offshore oil industry are (1) the need to establish oil wells in deeper water, and (2) the presence of economic incentives to move traditionally platform-based process systems to the sea floor. Both trends have important consequences for the future development of intervention methods.

Operating in deeper water increases demands on both ROVs and the tools they deliver to the work site. For electrical operations performed at the sea floor, longer umbilicals must be capable of more efficient power transmission and conversion.

Because greater depths mean longer ROV travel time between the vessel and the work site, it is advantageous to decrease the total number of missions. One approach would be to design more capable ROVs that could execute multiple tasks on a single mission. Operations in deep water are generally more costly for all aspects of oil exploration and production. But, by making major tooling packages smaller, many other costs can be reduced. (For example, ROV size can be decreased, which in turn allows 
use of smaller winches, smaller support vessels, etc.) Universal interfaces for underwater operations will also allow smaller tooling packages.

As oil wells are drilled in deeper water, the components and technologies routinely used at current operating depths will require enhancement. The most profound change, resulting from longer umbilicals which place a premium on system efficiency, may be the transition from ROVs with electro-hydraulic systems to all-electric systems.

\subsubsection{Expansion of Sea-floor Operations}

The movement of some traditionally platform-based process systems to the sea floor has shown that current "surrogate diver approach" (an ROV with two manipulator arms) has evolved to its useful limits. Because these formerly topside process systems were designed for human intervention rather than remote intervention, the tasks required to install and maintain the systems are inherently difficult or even impossible to perform with traditional ROV tools and techniques.

The presence of new operational requirements on the sea floor will require intervention equipment that can perform new tasks and solve new problems. Electrical systems will require battery replacement. Connectors will have to be connected and switches will have to be changed out. Instruments and sensors will require service and replacement, and entire communication and control modules will need to be replaced. Water separation systems and reinjection pumps with motor units, high-voltage connectors, and switch gear will need to be installed. Filters and metering systems will require servicing. Plans for riserless drilling operations (and future drilling from the seabed itself) raise concerns about whether current ROVs and manipulators could efficiently perform required intervention tasks.

How will new seafloor-based process systems be powered? A crucial step in the next phase of deep-water oil production will be the high-voltage electrification of sea floor equipment. GEC Alsthom's Subsea Power Electrical Equipment Demonstrator (SPEED) project has shown that an 11-KV electrical supply can be taken underwater, transformed near the wellheads, distributed through a load-switching module to various services at $3.3 \mathrm{KV}, 480 \mathrm{~V}$ and $415 \mathrm{~V}$, and controlled remotely. 
The task of maintaining components of subsea power systems (connectors, stepdown transformers, load distribution centers, variable-speed drives, etc.) will itself put additional demands on intervention systems and methods. The design of these power systems will dictate the degree and type of intervention they will require, and a fundamental choice of approach is looming. Should all components be designed for a 30-year life to minimize required maintenance? Should equipment be designed so that component failure requires the removal of large subsystems for topside repair? Or should failure-prone components be put into easily replaceable modules that can be installed or replaced by ROVs and remotely operated tools?

\subsubsection{Improving Capability, Productivity and Reliability}

Improving the capability, productivity and reliability of ROV systems has received increasing attention over the past few years for subsea oilfield uses.

As stated earlier, current trends in the offshore oil industry have placed increasing demands on the capability, productivity, and reliability of remote intervention tools and techniques. Innovative techniques for enhancing ROV performance are already taking shape. Dramatically increased reliability can be achieved by design changes in critical ROV systems, while capability and productivity can be increased by emphasizing equipment modularity, reducing equipment size, instituting universal interfaces, and automating intervention tasks.

\subsection{Riserless Intervention}

This is a fairly new technology area and involves the use of Coiled tubing or wireline units that are put to the job of replacing downhole valves and other subsea tree equipment. This will have to be accomplished by a dynamically positioned vehicle that will be capable of performing intervention services with the use of CT and/or wireline units.

Benefits / gain:

Dramatically reduces well intervention costs on subsea wells 
No workover riser during operation

The system can be operated from a cost effective intervention vessel

Ideal intervention method on deepwater wells.

Increased subsea well availability.

Modular design with full flexibility to run either Wireline or Coiled Tubing

Some companies that are offering this technology are:

FMC Kongsberg Subsea ${ }^{27}$

ABB Offshore systems ${ }^{26}$

Cal Dive International ${ }^{28}$

This is a mature technology area and the systems have been tried and tested for operational success.

\subsection{Dynamically Positioned Vessels and Riser Based Intervention}

There are very many needs for minor maintenance in the case of well workover/intervention for which the requirement is for light intervention vessels that would be capable of handling routine jobs like:

Logging operations

Perforation operations

Coiled tubing operations

Subsea tree change outs

Pumping services for cementation to control water production by sealing off layers.

Installing mechanical plugs in the wellbore to control the fluid production.

Installation and replacement of downhole safety valves on subsea trees.

These services can be performed by light intervention dynamically positioned vehicles with a riser that can be guided and connected to the subsea tree.

This type of service is currently being provided by Coflexip-Stena Offshore. This type of intervention service has also matured into a viable alternative with success rates remaining high. 


\subsection{Choice of Intervention System}

The choice of an intervention system would be primarily dictated by the

Kind of equipment that has failed and requires replacement/maintenance.

Maintenance or replacement jobs

Availability of intervention resources

Cost of intervention method

Depth of water/severity of the environment

Based on all these factors, there is not one intervention method that can be recommended over the others for all sorts of intervention jobs.

\subsection{Lacunae in Intervention Systems}

There are still problems with deployment of intervention systems in rough sever environments (storms etc) which can cause considerable delays in startup.

The time between equipment failure and it's replacement is still long as the intervention vessel needs to be deployed to site and it is expensive to maintain a dedicated vessel unless the cost is justified or there are many fields near by which require intervention often.

\subsection{Environmental Concerns}

Intervention will play a major role in the case of a hydrocarbon leakage ${ }^{29}$ or hydraulic fluid leakage from the pipelines or the umbilicals that carry them. While we have been fortunate in that no major accident in subsea wells has occurred, nevertheless such an eventuality has to be prepared for. While this should be the thrust of all operators concerned with offshore oil and gas development, in subsea systems, this has been found to be lacking. And even till now, subsea safety valves were not being considered for seafloor and well equipment that would detect or monitor leakages and alert the concerned personnel.

The main reasons for this are

The high cost of subsea field development 
Reliability issues of safety valves and equipment

However with increased pressure from regulatory bodies and environmentalists, there are measures in place to protect against oil spills and leaks. For instance, the BP Northstar project has incorporated some measures to prevent and detect the presence of leaks and spills. Some of these measures are increasing the pipeline wall thickness to three times the normal size, reduction in the number of underwater valves and fittings that are susceptible to leaks, anticorrosion coating and cathodic protection programs and the installation of state-of-the-art leak detection systems.

It should be noticed that the preventive measures for the subsea enviroment tend to be very expensive compared to the standard equipment used elsewhere. A pipeline three times thicker than the standard wall pipeline would send costs increasing exponentially. However, this is a required measure until newer materials are available that can reduce the risk of a major spill. It is to be noted that even with such measures in place, the BP Northstar project is capable of providing only a 1 in 1000 chance of a major spill each year, which is still not an acceptable figure for subsea or arctic environments.

\subsubsection{Spill and Leak Prevention Methods: Emerging Technology ${ }^{29}$}

Other options for environmental protection are damage control methods once a leak or spill has occurred. These systems are very much in use today, however they do not guarantee the containment and control of $100 \%$ of all the harmful effluents. So till this is done, the environment still suffers from considerable danger owing to subsea field development. There are many companies that do provide these damage control technologies and services all around the world.

Other factors that are currently high interest topics are

Waste water /Produced water disposal

Sand disposal

Some people are in favor of seafloor disposal of both waste water and the produced sand with the conviction that the pollution caused by such dumping after 
suitable subsea processing has been performed is negligible. Others however view this with concern as there are no controls present and regulations available as to safe limits on pollutants in produced water and sand, because it is not only a function of quantity but also an issue of the total project time during which such produced effluents would have to disposed of at the seafloor.

Environmental disasters from subsea wells have the potential of becoming extremely unmanageable and with the current technology limitations and the nonavailibility of failsafe systems that can detect, control and eliminate any well effluents, we have a long way to go before we can be comfortable in the knowledge that if a leak or spill occurs, there will be complete control over the situation.

Requirements:

Adequate failsafe systems to prevent leaks and spills

Failsafe monitoring systems that can immediately sound the alarm in case of a spill or a leak.

In the case of a leak or a spill, equipment and personnel should be capable of handling the load with a close to $100 \%$ recovery of the effluents.

Regulatory bodies to conduct studies on efficient methods of waste water and sand disposal and their effects on the environment. 


\section{CHAPTER VI}

\section{SUSTAINED CASING PRESSURE}

This chapter reviews and discusses the problems associated with sustained casing pressure and investigates options available currently and those in development to aid in monitoring and remediation of sustained casing pressure for subsea wells.

Sustained casing pressure is any measurable casing pressure at the wellhead that

Will rebuild to the original casing pressure after being bled off

Attributable to causes apart from artificially applied annular pressure that remains isolated from all other annuli ${ }^{30}$.

All wells must be monitored for casing pressure by using a pressure gauge with the appropriate range on all casing annuli, so that pressure can be detected at all times.

Studies conducted by the Wojtanowicz ${ }^{30}$ et al. document the existence of over 11000 sources of casing pressure in over 8000 wells in the GOM.

\subsection{The Dangers of SCP}

Pressure leaks in wellhead or in downhole tubulars or equipment can lead to the development of an annular gas pressure that can, in turn, lead to ${ }^{3}$

Inoperable subsurface safety valves

Casing pressure damaging cement integrity

Environmental pollution

Loss of production

Extreme cases - blowout

It is essential to the safe and environmentally sound operation of a well that such leaks be identified and cured. 


\subsection{SCP Occurrence}

Annular gas pressure, also known as sustained casing pressure (SCP), is a common problem and a potential threat to the safety of personnel and equipment, as well as, to the environment. SCP is a growing problem among offshore wells, leading to expensive shutdowns and remediations on many wells. Poor primary cementing, inadequate cement coverage, gas/water influx during or after cement placement, mud cake shrinkage and the development of stress induced microfractures and microannuli are all sited as causes for SCP.

While there are many reasons for SCP, the pressure and temperature cycles are the most significant. Casing growth and contraction that result from production cycles and stimulation operations can de-couple the bond between the cement and the casing. These forces can stress crack the cement. Both scenarios provide small pathways for high-pressure, low-volume communications of annular gas to the surface. The inaccessible nature of these pathways limits remediation options.

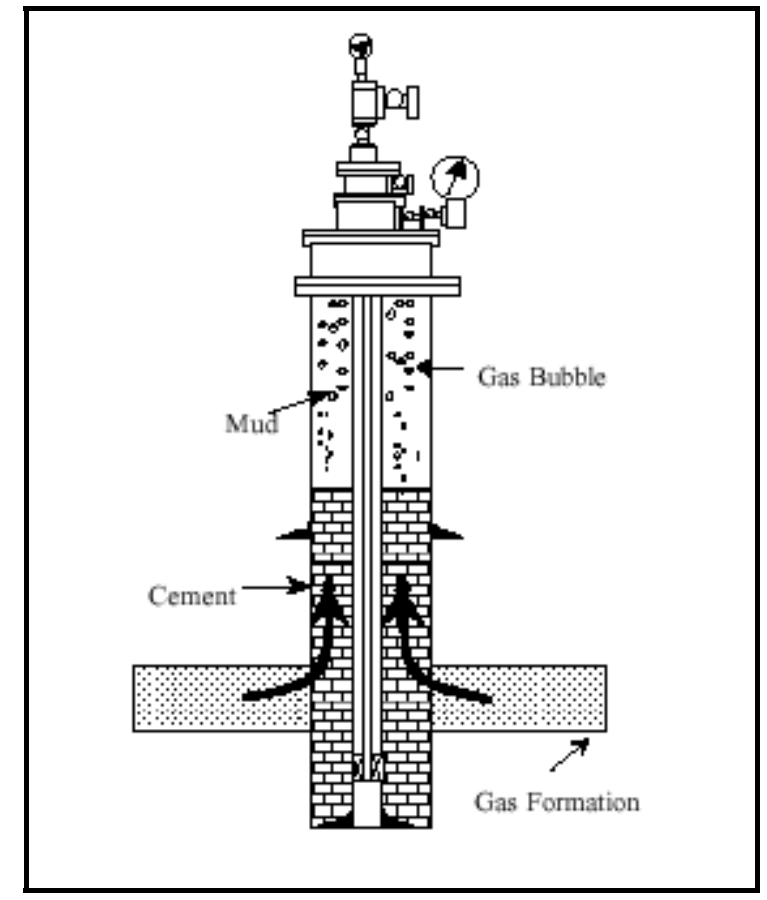

Figure 6.1: Mechanism of $\mathrm{SCP}^{30}$. 
Early onset mechanisms can include:

Gas cutting of the cement

Gas movement through a free water channel

Casing/Tubing connection leaks

Inadequate cement coverage

Late onset mechanisms include:

Channels of bypassed mud

Stress cracks in the annular cement sheath

Shrinking or drying of the mud filter cake

Casing/Tubing connection leaks

\subsection{SCP Diagnostics}

Diagnostic methods are used to determine the source of the SCP and the severity of the leak. Most of these methods use data (such as fluid sample analysis, well logs, fluid levels, or wellhead/casing pressure testing) obtained from routine production monitoring performed by operators. In addition, MMS has specified a standardized diagnostic test procedure to assist in this analysis when SCP is detected. These tests include pressure bleed-down and pressure build-up.

In the bleed-down test, MMS requires recording the casing pressure once per hour or using a data acquisition system or chart recorder. Also, the pressure on the tubing and the pressure on all casing strings are to be recorded during the test to provide maximum information. The recorded data are used to see how much of the initial pressure can be bled down during the test. Also, the recorded pressures from other annuli would indicate whether there is communication between different casings in the well. However, no analytical method to analyze these tests quantitatively has previously been developed. 


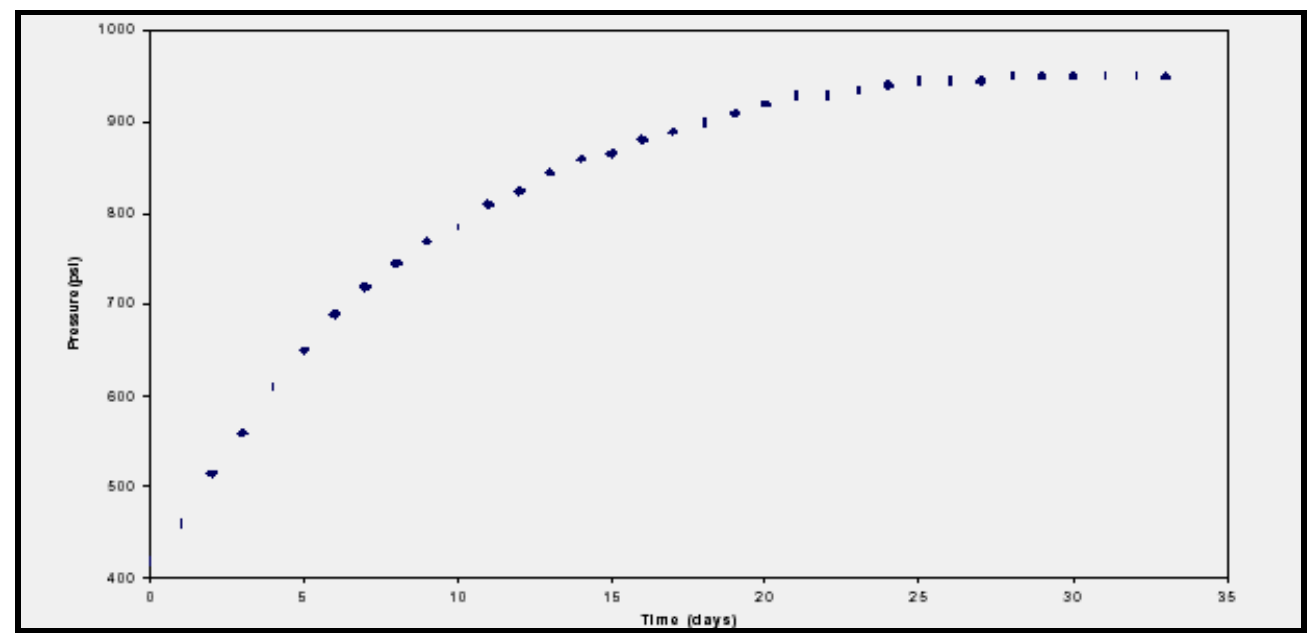

Figure 6.2: Typical SCP build up plot ${ }^{30}$.

A similar situation exists for pressure build-up tests. MMS requires the pressure build-up period to be monitored for 24 hours after bleeding off SCP. The pressure buildup test is especially important when the SCP cannot be bled to zero through a 0.5 -in. needle valve. The rate of pressure build-up could provide additional information about the size and possibly the location of the leak. However, no method for interpreting the test has previously been developed.

\subsection{SCP Remediation}

Remedial treatments of wells that have SCP are inherently difficult because of the lack of access to the affected annuli. Since there is no rig at the typical producing well, the costs and logistics involved in removal of SCP are frequently equivalent to a conventional workover. Moreover, there are additional casing strings between the accessible wellbore and the affected annulus. Methods for SCP removal can be divided into two categories:

Those using a rig

Rigless method 


\subsubsection{SCP Remediation Using a Rig}

The rig method involves moving in a drilling rig, workover rig or, in some cases, a coiled tubing unit and performing some kind of cement bridge or cut-and-squeeze operations in the well. Generally, this method is most effective when SCP affects the production casing string. However, the rig method is inherently expensive due to the moving and daily rig costs.

When the SCP affects outer casing strings, the rig method usually involves squeezing cement. These procedures involve perforating or cutting the affected casing string and injecting cement to plug the channel or micro-annulus. Both block and circulation squeezes have been attempted. The success rate of this type of operation is low (less than 50\%) due to the difficulty in establishing injection from the wellbore to the annular space of the casing with SCP and getting complete circumferential coverage by the cement. As a last resort, the rig method may involve cutting and pulling the casing. This complication generates additional expense due to the time it takes to recover the casing, since it often must be pulled in small segments.

\subsubsection{SCP Remediation Using Rigless Methods}

In principle, the rigless methods involve injecting high density fluid into the casing annulus to kill the pressure. The fluid is injected either at the surface directly into the casing head (Bleed-and-Lube method) ${ }^{30}$ or through a flexible tubing inserted to a certain depth in the annulus (Casing Annulus Remediation System, CARS) ${ }^{30}$. The concept of these two methods is to replace the gas and liquids produced during the pressure bleed-off process with high-density brine, such as Zinc Bromide. The goal of these techniques is to gradually increase the hydrostatic pressure in the annulus.

Sometimes however, completion of the job would have required months, or years, of pressure "cycling" application since the volumes injected at each cycle were extremely small. Other operators have observed incomplete reduction in surface casing pressures when this method was employed. In some cases, several iterations of 
pressuring up to high levels and bleeding off (or pressure "cycling") has been proven to worsen the casing pressure problem, probably due to opening a micro-annulus in the cement or breaking down previously competent cement.

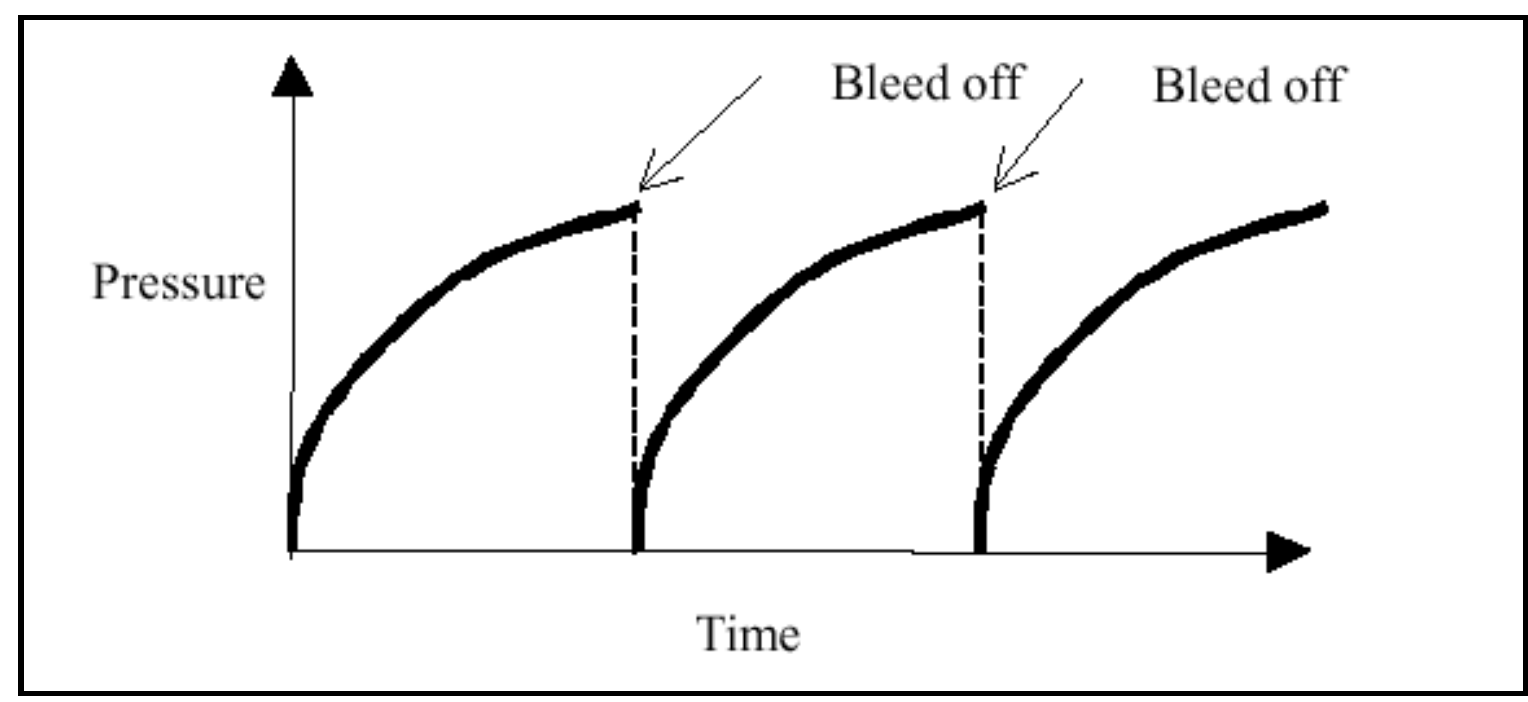

Figure 6.3: The bleed and lube technique ${ }^{30}$.

To date, field experience with CARS showed that the maximum injection depth could not exceed 1000 feet, while in most wells the injection depth was less than 300 feet and could not be increased. Thus, injection depth has become one of the major barriers for widespread use of CARS.

A search continues for techniques that would eliminate very expensive and unreliable workovers involving rigs. The Bleed-and-Lube technology has already proved feasible but not consistently effective for a variety of reasons.

\subsubsection{SCP Remediation Using Other Rigless Methods (Sealants)}

Research conducted by Texaco, Inc and Halliburton Energy Services ${ }^{24}$ led to a method that would compensate for the drawbacks of the above options and has shown promise on small field-scale physical models. The solution involves placing palletized 
alloy metal into the well's annulus, heating the alloy metal above the melting point and then allowing the alloy metal to cool. These steps form a continuous alloy-metal plug in the well's annulus.

The alloy metal pellets are placed and activated with the drilling fluid present in the annuli. Currently, the temperature is limited to 200F. The length of the final alloymetal plug affects the quality of the final seal.

Another method developed and that is commercially available is the use of pressure activated sealants to cure sources of casing pressure. This unique hydraulic sealant developed by Seal-Tite, $\operatorname{LLC}^{31}$ is designed to seal leaks in severe environment hydraulic systems. This sealant is pressure activated and will remain as a fluid in any system until the sealant is released through a leak site. At that point of differential pressure, the sealant reaction will occur and bridge across the leak.

The remainder of the sealant remains in the fluid phase and can be flushed out. The sealant can be custom blended to the particular conditions of the leaking system and can tolerate temperatures of up to $350 \mathrm{~F}$ and pressures up to $17000 \mathrm{psi}$.

It can be used to seal leaks across:

Subsurface safety valves

Wellhead tubing hanger and casing hanger seals

Casing and Tubing pinholes and connections

Umbilical lines

Subsea well control systems.

The disadvantages to this system are that it requires accurate data for the leak since the mixture is custom made for each job. The other problems associated with this method is the fact that narrow leaks regardless of the number or length can be cured easily, but larger circular holes are not very easy to seal and it is possible that a high pressure differential could blow the seal away. 


\subsection{Conclusions and Recommendations}

SCP is a common occurrence in the Gulf of Mexico and has been identified as a serious problem undermining safe and environmentally sound operations of subsea fields ${ }^{32}$. The conclusions of this study are:

SCP remediation using rigs is not only time consuming, but also expensive and can be ruled out as an option for curing wells of SCP unless and until other methods fail or the annular pressure is of a severe enough nature to warrant the extra expense and time.

For the bleed and lube and the CARS method, further studies and research is required to ensure that these techniques provide the required timely and cost effective solution to containment and reduction of SCP.

It is entirely possible that SCP might worsen due to the application of the bleed and lube and CARS methods as they might aggravate the casing leakage problem.

Injection of fluids and re-circulation of annular fluids (bleed and lube and the CARS methods) require a greater understanding of the fluid mechanics behind the casing in the annulus and a greater knowledge of the interaction between the injected fluid and the existing fluid.

The bleed and lube and CARS methods have met with limited success in offshore fields. A greater understanding of the process and further research will enhance the probability of successfully taming SCP in offshore wells.

Other rigless methods that are essentially sealants have proven to be cost effective, safe and reliable in most cases, however they require greater knowledge of the leak parameters before these solutions can be applied. In most cases, this information is not available.

Sealants are also not very effective at sealing larger leaks since the pressure differential between the casing and the annulus might blow open the seal. 


\subsection{The Difficulty of Sustained Casing Pressure Remediation}

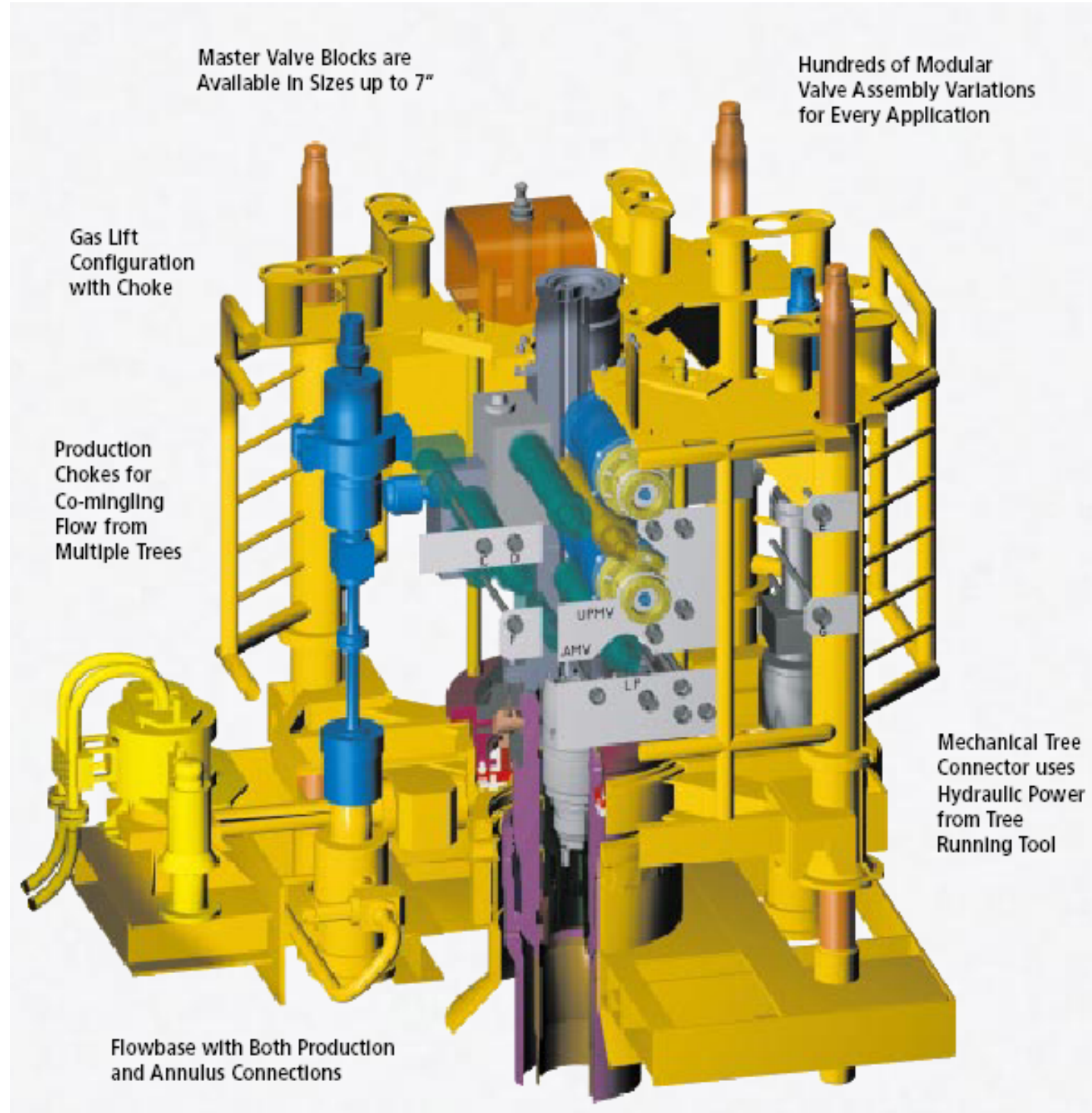

Figure 6.4: Complexity of a subsea tree.

The figure shows the complexity of subsea wellhead architecture. This complexity does not lend itself well to mediation and intervention, especially in the case 
of sustained casing pressure. While there are efforts being made to reduce the complexity of subsea wellheads and to improve the monitoring and access problems currently being faced, there is much scope for improvement.

To remediate sustained casing pressure problems, an easy and efficient way of being able to access the casing and annulus must be provided. Pressure monitors for all annuli between casing should be a standard feature of all wellheads, since it is required by the Minerals Management Service.

However, the sheer complexity of subsea wellhead design requires huge amounts of time, effort and expense to be able to tackle the problem to satisfaction. Most of the intervention techniques do require the presence of a rig to allow for adequate access to the affected annulus. This not only makes the process time consuming but also expensive. This is the reason why in spite of many occurrences of SCP in the GOM, the problem has not been mitigated sufficiently since the costs and the effort involved are prohibitive. 


\section{CHAPTER VII}

\section{THE GLOBAL ENERGY BALANCE}

In this chapter the fundamentals of the energy losses in a production system are reviewed and analyzed. The reservoir is treated as an expansion chamber similar to a cylinder and piston arrangement and the waste of reservoir energy due to high backpressure imposed by long flowlines is estimated. Starting from first principles, the work and energy relations that can be used to characterize a reservoir and the production facility are analyzed and presented. This chapter proposes a new concept of a global energy balance to evaluate energy usage in a production system.

\subsection{Introduction}

A subsea and deepwater production facility usually require the use of long flowlines especially in the case of long subsea tiebacks to existing production facilities.

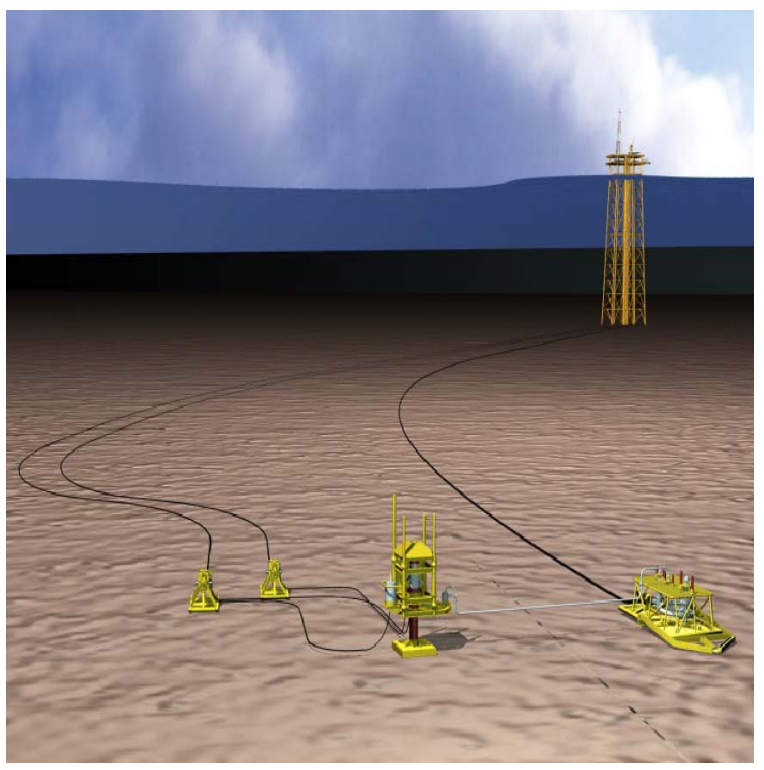

Figure 7.1: Schematic of deepwater architecture for a tieback ${ }^{14}$. 
With rapid development of larger fields in the Gulf of Mexico and other deepwater fields worldwide and the use of large process facilities, most operators are now exploring and developing lesser and more marginal fields. These smaller fields do not justify the additional expense of a separate process facility or the use of a Floating Production and Storage Offshore (FPSO) system. Consequently, these marginal fields are developed with subsea production equipment and subsea process facilities and the field tied back to an existing larger surface facility where excess capacity is available or if not, additional process capacity is made available to enable the economics of the project. This entails the use of long flowlines from the subsea marginal field to the process facility, a distance that could, at times, be as much as a 100 kilometres.

While this use of long pipelines and flowlines allows for better project economics, it imposes higher backpressures on the well and hampers flow. The succeeding sections in this chapter discuss, using energy and work equations, how such tie-backs tend to under-utilize reservoir energy. These equations show that energy that could be used to improve ultimate recoveries from the reservoir are now being wasted transporting fluids through the long flowlines.

Other losses encountered in a system are the energy losses suffered in pipe fittings and chokes and valves. Gravitational losses can become significant for higher density fluids in an ultra-deepwater environment.

While these energy losses are significant, it is interesting to note that some form of energy input to transport fluids will improve ultimate recoveries and reduce wastage of non-renewable natural resources in deepwater fields. The energy input to the fluids can consist of some form of subsea processing that can be, depending on the fluid, the available capital and the enthusiasm or reluctance to the use of a certain technology, one of many options. Some of them are listed below:

Multiphase Pumping 2,11,12,13,33,34

Subsea Separation and Boosting ${ }^{4}$

Wet Gas Compression

Dry Gas Compression 
Downhole Oil-Water Separation and Pumping 5,7

Vertical Annular Separation and Pumping Systems(VASPS) ${ }^{9}$

Artificial lift techniques, like gas injection ${ }^{35,36}$.

This chapter considers only the energy losses suffered due to pressure drops across the elements of the production facility. Other energy losses due to cooling arising out of inadequate insulation or the Joule-Thomson effect are ignored to prove that in spite of not havng the losses due to cooling, substantial energy is wasted in just moving fluids over long distance subsea tie-backs.

\subsection{Energy Losses in a Production Facility}

Conventional production operations routinely drawdown wellhead pressures to about 100-200 psig. In the case of subsea wells in marginal fields located at the end of long flowlines, these abandonment pressures may be as high as 1000-2000 psig due to the backpressure added by the long flowline. These wells also operate under a constant backpressure for the life of the field and this has been shown to reduce ultimate recovery.

Consider the energy balance in a gas pipeline ${ }^{37}$. Some assumptions made are:

Isothermal flow, that is the temperature changes in the fluid are negligible.

The change in kinetic energy of the gas is negligible.

The friction factor, $f$ is a constant over the flow rates encountered.

The pipeline is horizontal.

The energy balance can be written as:

$$
\frac{d p}{.}+v d v+g d h+\frac{f v^{2} d l}{2 d}=0
$$

that is, the sum of the changes of kinetic energy and potential energy and the pressure work done and the loss of energy due to friction is zero.

Due to the assumptions made above, the equation reduces to

$$
\frac{d p}{.}=-\frac{f v^{2} d l}{2 d}
$$


and using the relations

$$
=\frac{p M}{z R T}
$$

and

$$
v=\frac{P_{b}}{T_{b} \pi / 4} \cdot \frac{Q_{b} T z}{D^{2} p}
$$

we get

$$
\frac{R T z}{M p} d p+\sin \alpha \cdot d l+\left(\frac{P_{b}}{T_{b} \pi / 4}\right)^{2} \frac{Q_{b}^{2}}{2 d^{5}} \frac{f T^{2} z^{2} d l}{p^{2}}=0
$$

Solving this equation, we get

$$
P_{1}^{2}=P_{2}^{2}+\frac{1}{(\pi / 4)^{2} R} \frac{P_{b}^{2}}{T_{b}^{2}} L M Q_{b}^{2} \frac{T z f}{D^{5}}
$$

Equation (7.6) relates pipeline outlet pressure to the inlet pressure based on flow parameters like the gas flow rate, friction factor, pipeline length and mean temperature. This equation illustrates the well-known fact that the pipeline inlet pressure increases with pipeline length. This increase in inlet pressure is known as backpressure and this backpressure influences the reservoir performance.

Assuming the gravitational drop and frictional drop in the wellbore are negligible, the wellhead pressure, which is the pipeline inlet pressure, is the bottom hole flowing pressure.

The reservoir deliverability equation for gases is ${ }^{38,39}$

$$
Q_{b}=J\left(\overline{P^{2}}-P^{2}{ }_{w f}^{n}\right.
$$

and

$$
P_{w f}=P_{1}
$$

This means that any increase in the bottom hole flowing pressure reduces the flow rate from the reservoir. Since the reservoir is under this continual backpressure for the life of the field, the production rates are lower than what they would be without any backpressure. 
With this application of the continual backpressure on the reservoir, the economic limit for production is also reached sooner. The combination of reduced production rates and shorter life of field, in effect, reduce the ultimate recovery from the reservoir.

The same energy equation can be used to illustrate the same effect of long pipelines on liquid flowrates. For an oil above the bubble point, the density variations with pressure can be written as

$$
\text { . = . }{ }_{b} \exp \left(c\left(p-p_{b}\right)\right)
$$

The compressibility of the oil above the bubble point at a certain temperature is represented by ' $c$ '. This equation of state can be used to predict pressure losses in a flowline flowing oil above the bubblepoint. However, since the compressibility values of oil above the bubble point are very low, it may be safe to assume that the density changes of the oil with pressure are negligible for this particular study. It can be shown then that the pressure losses suffered by the oil in moving through a flowline are

$$
P_{3}-P_{2}=\frac{f v^{2} L}{2 d}
$$

The gravitational loss in the wellbore and riser can be significant for liquids and this can be written as

$$
P_{2}-P_{1}=\cdot g h
$$

These pressure losses are in addition to the losses suffered across pipe fittings, chokes and other valves that make up the production system.

The equation governing flow from the reservoir into the wellbore can be written as

$$
Q=J\left(P-P_{1}\right)
$$

So the above equations estimating pressure losses in a pipeline and a riser for an oil above the bubble point indicate greater losses for a longer flowline and a deeper water depth. This directly relates to a higher backpressure at the sand face inhibiting productivity and reducing flow rates. 
From equation (7.1), assuming the kinetic energy changes of the gas in the pipeline are negligible, then the net energy loss to friction in the pipeline per unit mass can be represented by the equation

$$
l w_{1}=\frac{f v^{2} L}{2 D}
$$

As the pipeline length increases, for a given friction factor, the frictional losses increase. This energy loss to friction is a waste of reservoir energy that could be used to improve production rates and ultimate recovery from the reservoir.

Other losses are incurred in fittings, chokes and valves and this can be represented by the equation, which sums up all the losses on all such obstacles.

$$
l w_{2}=\sum_{i=1}^{n}\left(\frac{1}{2} v^{2} e_{v}\right)_{i}
$$

where $e_{v}$ is the friction loss factor for each fitting. The value of the friction loss factor varies from 0.2 for open gate valves to $0.45(1-\downarrow \downarrow)$ for sudden contractions, where $\Downarrow$ is ratio of the smaller cross sectional area to the larger cross sectional area ${ }^{40}$.

There are further gravitational losses suffered by the fluid in the riser. The energy loss per unit mass is $g$. $h$, where $\mathrm{g}$ is the gravitational acceleration and $h$ is the height of the riser.

Energy losses to the environment also include heat losses in the pipeline and riser system. ${ }^{23}$ The amount of heat loss is a function of the flow rates, insulation and/or heating strategy, pipeline length and pipeline and riser diameter.

The heat loss can be represented by the equation

$$
Q=U A . T
$$

where $U$ is the overall heat transfer coefficient, $A$ the area available to transfer heat which is in the case of a pipeline proportional to the pipeline length and pipeline diameter and $T$ is the temperature difference between the surroundings and the fluid.

The net energy loss from the fluid can be estimated using the equation

$$
l w_{T}=\frac{f v^{2} L}{2 D}+\sum_{i=1}^{n}\left(\frac{1}{2} v^{2} e_{v}\right)_{i}+g . h+\pi D L U . T
$$


This equation shows that energy losses from the fluid are directly proportional to the pipeline length and water depth (riser length) and the number of fittings on the pipeline.

So it is necessary, in the case of marginal fields tied back to existing production facilities to have some form of subsea processing to improve ultimate recoveries. Subsea separation and boosting and multiphase pumping and artificial gas lift are some of the means by which energy can be added to the well stream or by which the energy loss can be mitigated.

\subsection{The Global Energy Balance}

This section estimates the amount of reservoir energy remaining unused due to the high backpressure imposed on the sandface. The backpressure could be due to a variety of reasons including long flowlines and deep water depths as discussed in the previous section. The reservoir fluids flow into a wellbore and the entire process is assumed to be adiabatic. This assumption is valid for an instantaneous process that can be replicated many times over to understand the exact processes leading to an injudicious use of reservoir energy.

For an adiabatic system, the equation of state can be written as

$P V=C$, where $\mathrm{C}$ is a constant. This is a feature of adiabatic systems.

The work done in expanding from pressure, $\mathrm{P}_{1}$ to pressure $\mathrm{P}_{2}$, where $\mathrm{P}_{1}$ is the initial pressure is given by

$$
W=\frac{P_{1} V_{1}}{\cdot-1}\left(1-\left(\frac{P_{2}}{P_{1}}\right)^{\frac{.-1}{\cdot}}\right)
$$

and

$$
P_{1} V_{1}=P_{2} V_{2}
$$

Therefore,

$$
\frac{P_{2}}{P_{1}}=\frac{V_{1}}{V_{2}}
$$

Consequently, the work done by the system in expanding from $\mathrm{P}_{1}$ to $\mathrm{P}_{2}$ is given by 


$$
W=\frac{C V_{1}^{1-}}{\cdot-1}\left(1-\left(\frac{V_{1}}{V_{2}}\right)^{\cdot-1}\right)
$$

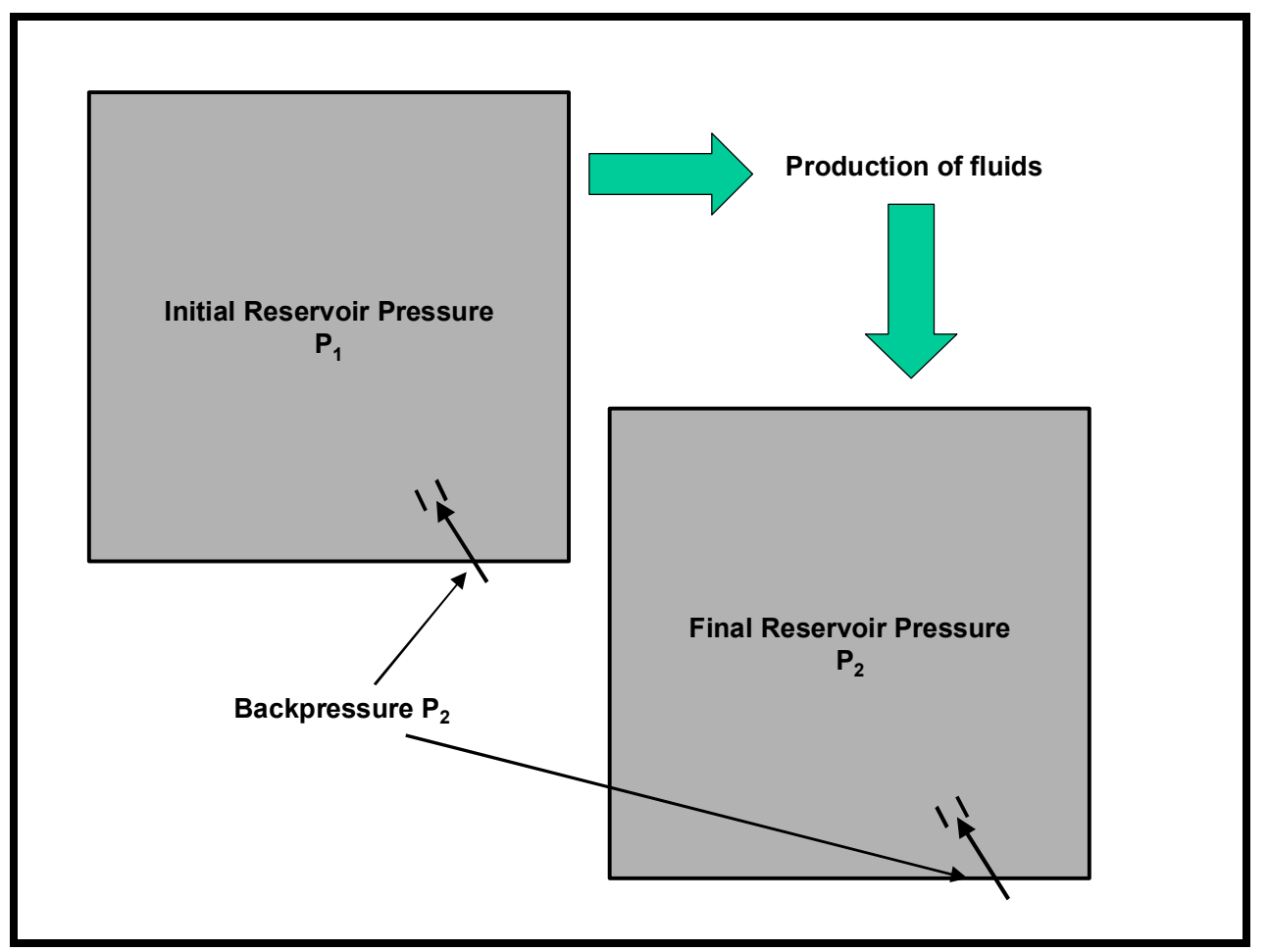

Figure 7.2: Depiction of the process involved during production under backpressure. The reservoir produces till it attains the value of backpressure imposed on it.

Since the volume of the reservoir is given by

$$
V=A h .,
$$

the work done can be expressed as

$$
W=\frac{C V_{1}^{1-}}{\cdot-1}\left(1-\left(\frac{.+.}{.}\right)^{-1}\right)
$$

The change in porosity arises due to rock compressibility. The volume at a higher pressure, $\mathrm{P}_{1}$ being lower than the volume at a lower pressure, $\mathrm{P}_{2}$. 
Using the following numerical approximation, that is, $(a+b)^{k}=a^{k}+k a^{k-1} b$ if $\mathrm{b}<<\mathrm{a}$, then we have the work done by the system approximated to

$$
W=C V_{1}^{1-} \stackrel{\cdot}{\cdot}
$$

This equation represents the adiabatic work done by the reservoir in expanding from pressure $\mathrm{P}_{1}$ to pressure, $\mathrm{P}_{2}$. This work done is converted to kinetic energy of the fluid released into the wellbore. The kinetic energy imparted to this mass of fluid allows the fluids to move up through the wellbore and through the production system.

Now we can also rewrite

$$
\dot{\cdot}=\frac{V_{1}-V_{2}}{V_{2}}=\left(1-\left(\frac{P_{2}}{P_{1}}\right)\right)
$$

Given the equation for the work done by the reservoir, equation 7.23 and the equation 7.24, we can rewrite the work done as

$$
W=C^{\frac{1}{\cdot}} P_{1}^{\frac{--1}{\cdot}}\left(1-\left(\frac{P_{2}}{P_{1}}\right)\right)
$$

where $\mathrm{P}_{2}$ is the final pressure and $\mathrm{P}_{1}$ the initial pressure.

A reservoir can deplete only until both the reservoir pressure and the bottomhole pressure are the same. Once this condition is reached, there is no fluid flow from the reservoir to the wellbore. Consequently, the kinetic energy imparted to the fluid flowing into the wellbore would be different with different bottomhole pressures. These varying values of bottomhole pressures can arise due to backpressure added by pipelines, valves, chokes and other fittings.

Consider a case where the flowing bottomhole pressure is $\mathrm{P}_{2}$ and another case where the pressure is $\mathrm{P}_{3}$, where $\mathrm{P}_{3}>\mathrm{P}_{2}$. Then the work done by the reservoir can be evaluated using the above equation and it can be seen that $\mathrm{W}_{2}<\mathrm{W}_{3}$. This difference in energy imparted is the energy that remains unused in the reservoir. 


$$
W_{3}-W_{2}=C^{\frac{1}{-}} P_{1}^{\frac{--1}{-}}\left(\frac{P_{3}^{-}-P_{2}}{P_{1}}\right)
$$

For an isothermal system, following the same argument as above, the work done can be approximated by the equation

$$
W=n R T_{i} \ln \left(\frac{P_{1}}{P_{2}}\right)
$$

where

$$
P_{1}=P_{2}+. P
$$

Therefore, for small values of. $\mathrm{P}$, the work done can be written as

$$
W=n R T_{i} \frac{\cdot P}{P_{2}}
$$

where $\mathrm{P}_{2}$ is the final value of the reservoir pressure, or the backpressure imposed on it.

For a case where the backpressure imposed is higher, it can be seen that the total work done by the reservoir is smaller, suggesting that there is left over energy in the reservoir that is not being utilized to move fluids from the reservoir to the wellbore. Both, the isothermal and the adiabatic processes suggest that there is energy left behind in the reservoir when there is a higher backpressure. Since all thermodynamic processes lie between an isothermal process and an adiabatic process, the above conclusion definitely supports the theory that reservoir energy is not being completely utilized.

The difference in energy imparted to the reservoir fluid is the reservoir energy that is unavailable to withdraw more fluids from the reservoir owing to a higher backpressure on the wellbore. If this backpressure is released, then the energy difference can be used to extract more fluids out of the reservoir aiding in an improved ultimate recovery.

This reduction of backpressure can be achieved by the use of some subsea processing strategy. Some of these options are multiphase pumping, subsea separation and boosting, VASPS, gas compression etc. These means of aiming at a reduction in backpressure also add energy to the reservoir fluids in the wellbore and pipeline. Consequently, the energy not available for extraction of fluids can be made available 
through extraneous means by the use of some form of subsea processing, helping improve ultimate recoveries and helping increase production rates, thereby improving project economics.

\subsection{Other considerations}

The reservoir can deplete from a certain initial pressure to a final abandonment pressure in many such pressure steps, the recovery from the reservoir being dependant on the backpressure imposed on the sand face.

Now consider an isothermal process. The ratio of the number of moles leaving the reservoir to the work done by the reservoir in losing those same number of moles can be written as

$$
R T_{i} \frac{m}{E}=\frac{1}{\ln \left(\frac{P_{1}}{P_{2}}\right)}
$$

where the reservoir pressure falls from a pressure $P_{1}$ to a pressure $P_{2}$. The reservoir is also under the influence of a backpressure, $\mathrm{P}_{\mathrm{bh}}$ that is essentially the bottomhole pressure. So the reservoir undergoes a series of isothermal processes till finally there is no flow and this occurs when the reservoir average pressure is the same as the bottomhole pressure, or when there is no pressure gradient.

Consider two cases for reservoir depletion, one case where the bottomhole pressure, $\mathrm{P}_{b h}=0.1 \mathrm{P}_{\mathrm{i}}$ and another case where $\mathrm{P}_{\mathrm{bh}}=0.5 \mathrm{P}_{\mathrm{i}}$, where $\mathrm{P}_{\mathrm{i}}$ is the initial reservoir pressure and let us call them Case A and Case B respectively. Case B with the higher bottomhole pressure could be a situation in a long distance subsea tieback to a reservoir, while Case A could be the same situation, but with some additional means of reducing reservoir backpressure, like multiphase pumping or a subsea booster. In either case, the reservoir will be capable of producing fluids only until the reservoir pressure remains higher than the imposed backpressure. 
The source of energy for the fluids from the reservoir would be the pressure energy in the reservoir. If the work done by the reservoir at each time step be a constant and the change in pressure at each time step be denoted by . $\mathrm{P}$ then

$$
R T_{i} \frac{m}{E}=\frac{1}{\ln \left(\frac{P_{1}}{P_{2}}\right)}=\frac{1}{\ln \left(\frac{P_{2}+. P}{P_{2}}\right)}=\frac{1}{\ln \left(1+\frac{\cdot P}{P_{2}}\right)}
$$

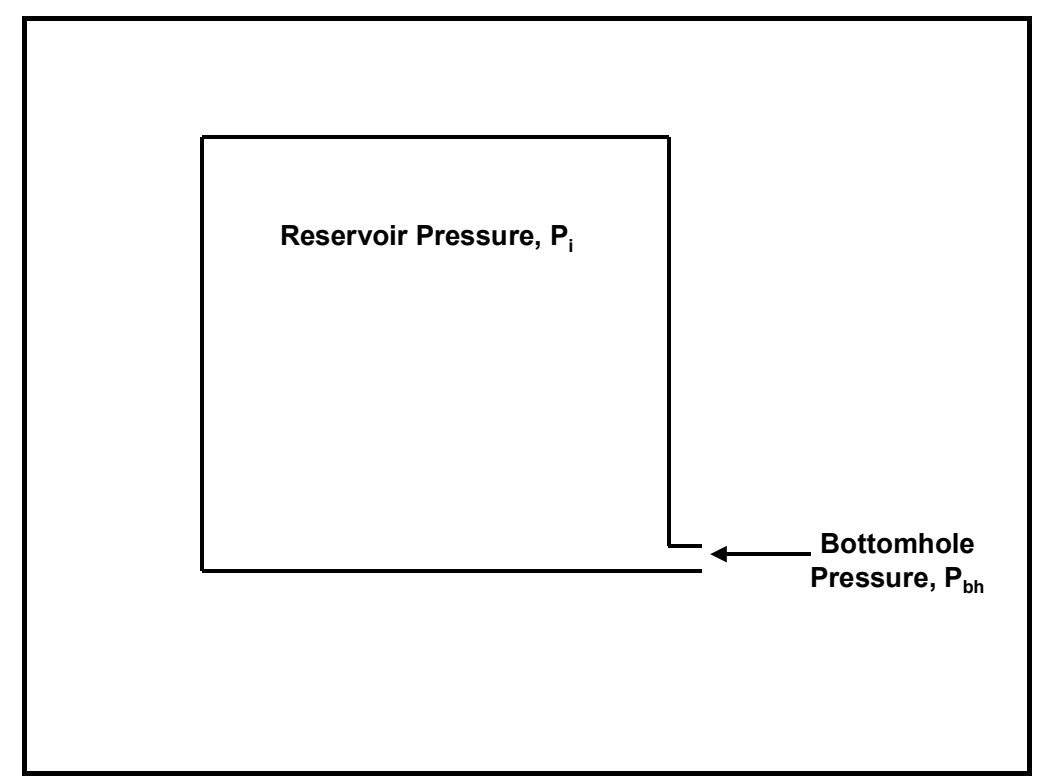

Figure 7.3: Illustration of reservoir and the borehole and the pressures therein.

For small values of. P,

$$
\frac{1}{\ln \left(1+\frac{. P}{P_{2}}\right)}=\frac{1}{\cdot P / P_{2}}=\frac{P_{2}}{P}
$$

This is for the first step. For consecutive steps, if the reservoir pressures be denoted as $\mathrm{P}_{3}, \mathrm{P}_{4}, \mathrm{P}_{5}, \mathrm{P}_{6}, \ldots \ldots \ldots . . .1 \mathrm{P}_{\mathrm{i}}$, then the ratio of the net mass flow from the reservoir to the energy supplied to the fluids at each time step would be 


$$
\frac{R T_{i} M_{T 1}}{E}=\frac{P_{2}+P_{3} \ldots \ldots+0.1 P_{i}}{. P}
$$

and the net energy supplied by the reservoir would be

$$
E_{T 1}=n_{1} E
$$

where $\mathrm{n}_{1}$ is the number of steps.

If the value of the backpressure is higher, say for instance, $0.5 \mathrm{P}_{\mathrm{i}}$, then the net mass flow from the reservoir would be the same as equation except that the final pressure would be $0.5 \mathrm{P}_{\mathrm{i}}$.

$$
\frac{R T_{i} M_{T 2}}{E}=\frac{P_{2}+P_{3} \ldots \ldots+0.5 P_{i}}{. P}
$$

A higher value of backpressure would imply fewer steps $n_{2}$, so the total work done by the reservoir would be

$$
E_{T 2}=n_{2} E
$$

It is clear that $\mathrm{M}_{\mathrm{T} 2}<\mathrm{M}_{\mathrm{T} 1}$ and that $\mathrm{E}_{\mathrm{T} 2}<\mathrm{E}_{\mathrm{T} 1}$ since $\mathrm{n}_{2}<\mathrm{n}_{1}$. This not only implies that the net mass of fluids recovered from the reservoir is lower with a higher backpressure imposed on it, but it also suggests that there is energy left over in the reservoir unused. This conclusion ties in with the conclusions from the previous section. With the net mass of fluids extracted being lesser, this leads to the conclusion that ultimate recovery from a reservoir suffering from a higher backpressure would be lower.

\subsection{Comparison of Pressure Energy and Heat Energy}

Gas from a reservoir can be put to use two ways, either the pressure energy can be made use of by the means of a turbine or the gas can be used for thermal energy by burning. Figure 7.4 below compares the energy to be derived from both of these cases for methane.

The calorific value of methane is taken to be $0.39771 \mathrm{HP}$ hour/cu. Ft. The reservoir productivity index, $\mathrm{J}$ is taken to be $0.4 \mathrm{MMscf} / \mathrm{psi}^{2}$. The values of the gas formation volume factor were used to compute the respective flowrates in MMscf/D. 


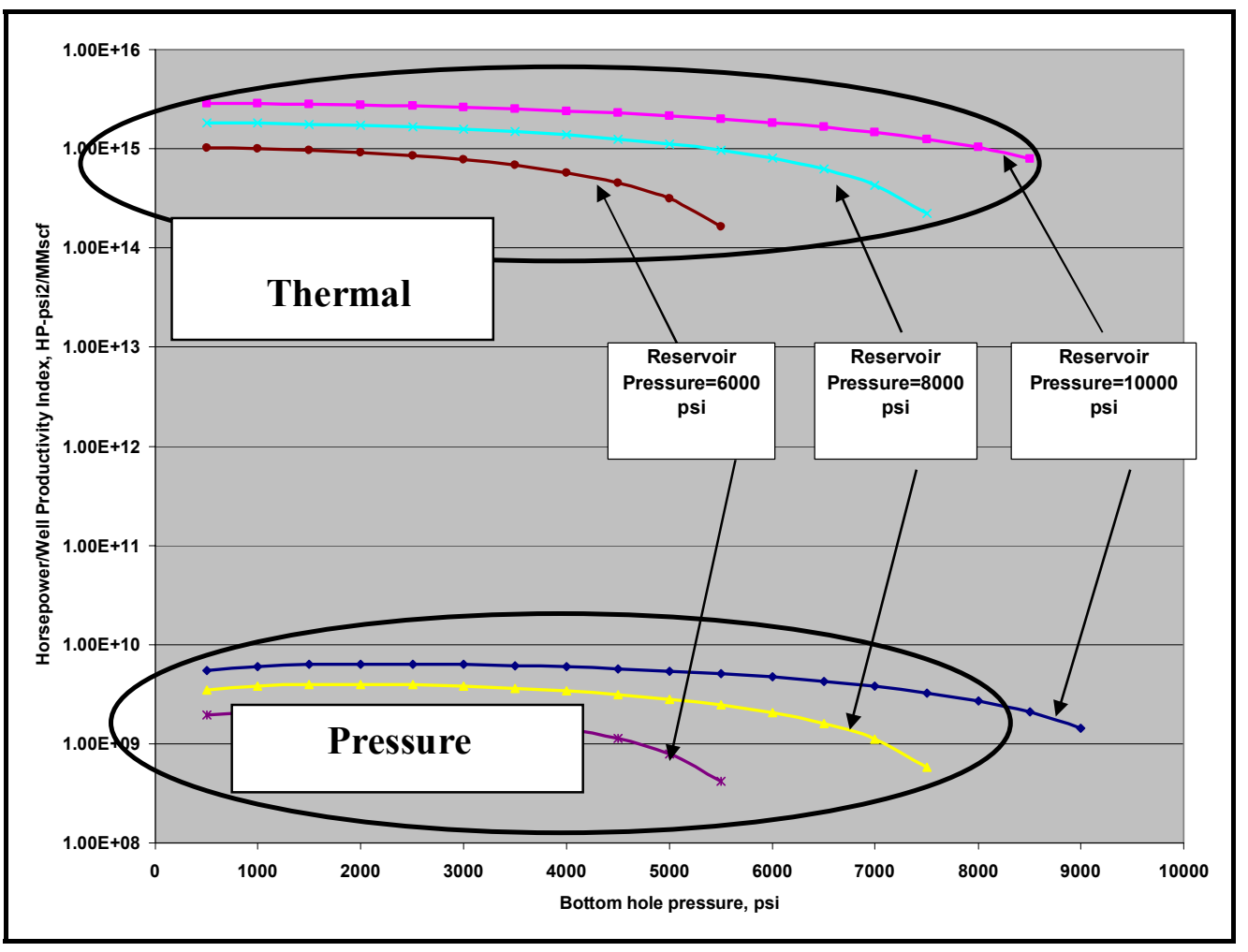

Figure 7.4: Chart showing a comparison of the pressure energy to be tapped from a gas reservoir versus the thermal energy available.

Figure 7.4 uses the flow rates from a reservoir to calculate the net horsepower available for use. In the case of a turbine, the gas is taken in to the turbine at the bottomhole flowing pressure and ejected at atmospheric pressure-which gives an idea of the maximum work that can be done by the gas flowing from the reservoir. The turbine efficiency is also assumed to be unity. The chart shows that in spite of assuming such ideal conditions for gas expansion through a turbine, the pressure energy available for use from the gas is only a minute fraction of the total energy available and a very small percentage of the thermal energy contained in the gas. The thermal energy available is orders of magnitude higher than the pressure energy available.

In fact, whatever be the reservoir pressure, the available power from pressure is less than a percent of the thermal or total power available while burning the gas as a fuel. 
This conclusion will have many ramifications, firstly that it is more inefficient to use the gas to run a turbine than it is to burn the gas and use the energy thus obtained. This conclusion should be kept in mind when using the reservoir fluid as a source of power for the various subsea processing blocks and control systems sometime later on when such subsea power sources are being developed. 


\section{CHAPTER VIII}

\section{THE PHYSICAL MODEL}

\subsection{Physical Model}

Figure 8.1 shows a schematic picture of a gas producer: a subsurface reservoir connected to a surface wellhead assembly by a vertical cased borehole equipped with production tubing.

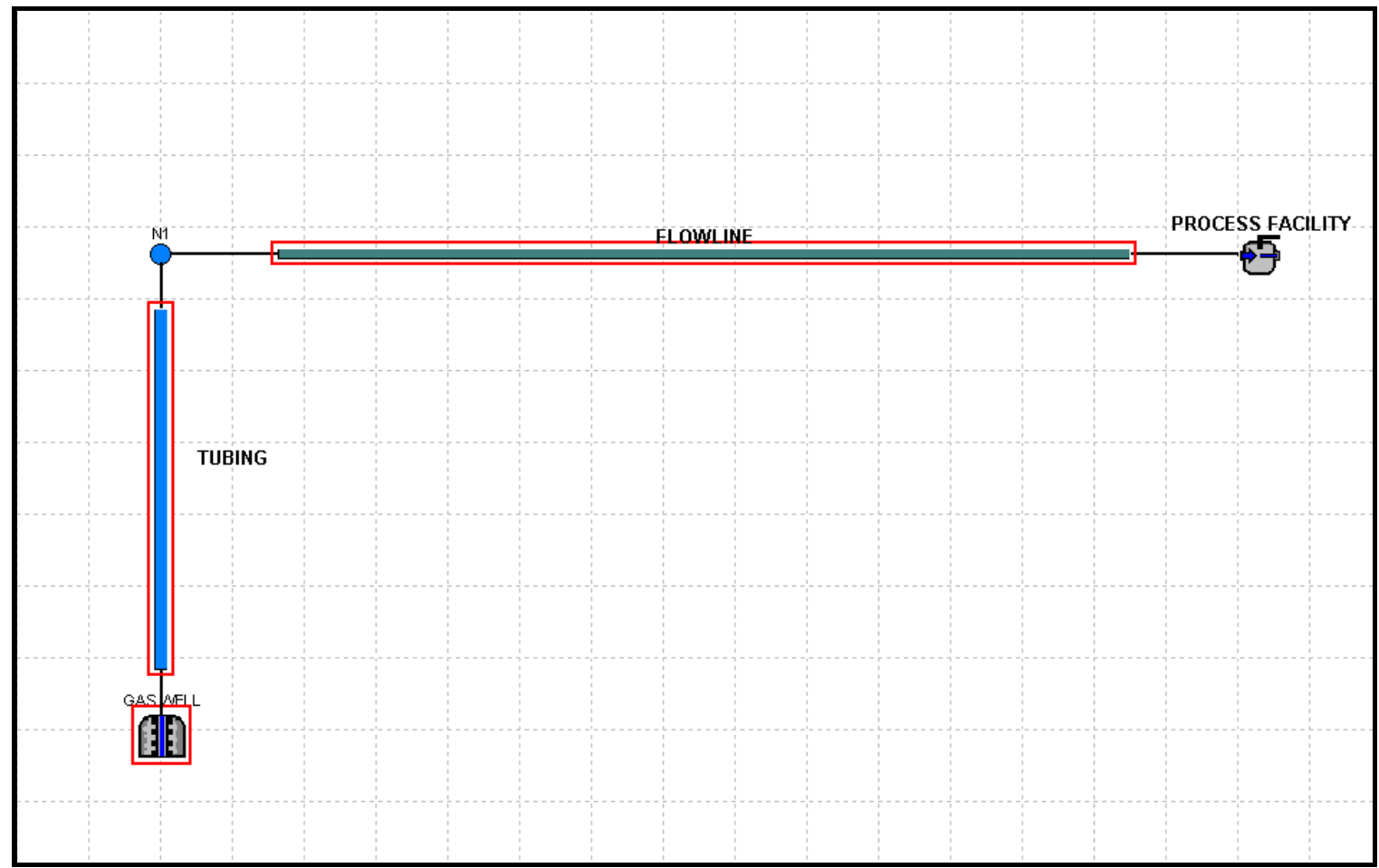

Figure 8.1: Gas well and process facility

The reservoir contains a dry natural gas. We assume a uniform pressure and temperature of the gas in the reservoir at all times. The reservoir pressure and reservoir temperature change over time as a result of gas production and of heat exchange with the 
surrounding formation. During production the gas expands which is accompanied by a decrease in gas temperature.

Heat transfer also occurs at the outer boundaries of the formation with the surrounding formation. However this is not modeled in this study for simplicity purposes. This heat transfer may be modeled by the use of dimensionless heat influx and dimensionless times based on the water influx equations developed by Van Everdingen and Hurst.

Flow within the tubing and the flowline is assumed to be steady-state and isothermal. This assumption is fairly valid for high gas rates and considering that most subsea flowlines of today are accompanied by fairly efficient insulation and heating methods, the temperature of the gas in the flowline may be assumed to be a constant. Hence temperature variations within the wellbore and flowline due to compression and expansion of the gas are not incorporated and heat exchange with the well environment is ignored. The latter simplification is justified considering the high flow rates of the gas in the wellbore and flowline during production. Friction losses in the flowline may be incorporated by empirical friction factors, which depend on Reynolds number and roughness of the tubing wall. For this study a friction factor of 0.0142 is assumed.

The storage gas in the reservoir is an ideal gas. That is, the pressure, volume and temperature behavior of the gas is described by the Ideal Gas Law, which does not include the gas deviation factor or z-factor.

The well operating constraints in the model are a prescribed minimum pressure at the entry to the surface facility-this being the requirements of most process facilities to allow operation of the system determined by the minimum intake pressure of the gas plant at the surface. If this minimum pressure is reached the well is shut in and further operation becomes uneconomical.

\subsection{Reservoir Equations}

The pressure and temperature of the gas in the reservoir are governed by the mass balance and the energy balance applied to the reservoir at large. 


\subsubsection{Mass Balance ${ }^{41}$}

The mass balance states that at any time the amount of gas in the reservoir must be equal to the amount of gas initially present minus the amount of gas produced. In combination with the Ideal Gas Law this mass balance reduces to the following relation for the pressure and temperature of the gas in the reservoir:

$$
\frac{P}{T}=\frac{P_{i}}{T_{i}}\left(1-\frac{G_{p}}{G}\right)
$$

\subsubsection{Energy Balance B1 $^{4}$}

The energy balance applied to the reservoir states that at any time the internal energy of the gas-in-place must be equal to the internal energy of the gas-initially-inplace minus the efflux of enthalpy by convection through the tubing plus the influx of heat from the surrounding rock. The energy balance reads ${ }^{41}$ :

$$
n U=n_{i} U_{i}-\int H_{g} \frac{d n_{p}}{d t} d t+\text { Heat } t_{\text {formation }}
$$

The internal energy and the enthalpy depend on the gas composition and are functions of both pressure and temperature. In the model they are calculated internally by means of the basic thermodynamic relations for molar enthalpy and internal molar energy.

The ideal-gas molar enthalpy is given by

$$
H_{g}=\int C_{p} d T
$$

where $\mathrm{C}_{\mathrm{p}}=$ isobaric heat capacity.

However, there are correlations that estimate the ideal gas molar enthalpy as a function of the temperature and this can be represented by the following relation:

$$
H_{g}=\sum_{1}^{8} a_{n} \frac{T^{n}}{1000^{n}}
$$

The internal molar energy is related to the molar enthalpy by 


$$
U_{g}=H_{g}-R T
$$

\subsection{Wellbore Equations}

Flow in the pipeline can be described by the Weymouth equation that essentially is an energy balance on the gas.

\subsubsection{Weymouth Equation}

The Weymouth pipe flow equation relates gas flow rates at standard conditions and the pressure drops over a length element along the flowline by assuming (1) a constant average temperature, (2) a constant average z-factor, and (3) a constant average friction factor. The following equation is the Weymouth Equation.

$$
Q_{s c}=433.5\left(\frac{T_{s c}}{P_{s c}}\right)^{1}\left(\frac{P_{1}^{2}-P_{2}^{2}}{\overline{T Z} L}\right)^{0.5}\left(._{g}\right)^{-0.5} d^{2.667}
$$

Given the pressures at the inlet and outlet ends of the flowline, the above equation allows the calculation of the gas flow rate, provided the average temperature, $z$ factor and friction factor are known.

The friction factor is taken to be 0.0142 for gas flows in the flowline which is a commonly accepted value for the friction factor.

\subsection{Numerical Solution}

The primary variables that characterize the behavior of a gas reservoir are: Reservoir pressure, $\mathrm{P}$

Reservoir temperature, $\mathrm{T}$

Bottomhole temperature, $\mathrm{T}_{\mathrm{bh}}$

Bottomhole pressure, $\mathrm{P}_{\mathrm{bh}}$

Flowline outlet pressure, $\mathrm{P}_{\mathrm{wh}}$

Production rate, $\mathrm{Q}_{\mathrm{sc}}$

During a production cycle the minimum reservoir pressure is prescribed. The production occurs at a certain rate dictated by the reservoir pressure, the flowline outlet temperature and the flowline length. As long as the reservoir pressure exceeds the 
minimum reservoir pressure, the reservoir produces at declining rates at a constant flowline outlet pressure.

There are 5 equations: two reservoir relations, one flowline relations and the two equations that couple the reservoir equations to the tubing relations:

$$
\mathrm{P}_{\mathrm{bh}}=\mathrm{P}_{\mathrm{R}}
$$

$$
\mathrm{T}_{\mathrm{bh}}=\mathrm{T}_{\mathrm{R}}
$$

Here for simplicity the reservoir pressure (at the midpoint reservoir depth) is assumed to be equal to the bottomhole pressure (at the bottom of the tubing).

To solve the unknown variables at successive timesteps this model uses a Newton-Raphson iteration scheme for the two reservoir equations. The flowline equation is solved within an iteration loop of this Newton-Raphson scheme. The iteration scheme for the solution of the reservoir and wellbore equations consists of the following steps.

1. Estimating reservoir pressure and temperature

The temperature is taken equal to the converged temperature of the previous timestep. The pressure is estimated from the converged pressure of the previous timestep corrected for the efflux of gas based on the well production rate of the previous timestep.

2. Calculation of flow rates

Calculate the pipeline flow rate for the given conditions of reservoir pressure, process facility inlet pressure and reservoir temperature.

3. Calculate the corrections for the estimated reservoir pressure and temperature.

The reservoir mass balance and the energy balance can be written symbolically as, respectively ${ }^{41}$ :

$$
\begin{aligned}
& M B\left(T^{n}, P^{n}\right)=0 \\
& E B\left(T^{n}, P^{n}\right)=0
\end{aligned}
$$

According to the Newton-Raphson iteration scheme the pressure and temperature corrections of the $\mathrm{n}+1$ th iteration cycle are then given by ${ }^{41}$ :

$$
\frac{. M B^{n}}{. T} \cdot T^{n+1}+\frac{. M B^{n}}{. P} \cdot P^{n+1}=-M B^{n}
$$

and 


$$
\frac{. E B^{n}}{. T} \cdot T^{n+1}+\frac{. E B^{n}}{. P} \cdot P^{n+1}=-E B^{n}
$$

The pressure and temperature corrections for the new $n+1$ timestep are computed from the previous two linear equations, the coefficients of which are evaluated by taking the values of the pressure and the temperature at the old iteration cycle $n$.

4. Calculate new reservoir pressure and temperature and check for convergence The new estimates of the reservoir pressure and temperature are given by:

$$
P^{n+1}=P^{n}+. P^{n+1}
$$

and

$$
T^{n+1}=T^{n}+. T^{n+1}
$$

If the pressure and temperature changes calculated in step 3 are greater than some certain prescribed tolerances (e.g. 0.1 bar and 0.1 degree $\mathrm{K}$, depending on the time step chosen) return to step 2, else proceed with the next timestep.

\subsection{Case Studies}

The reservoir and production facility simulated with this program have the following characteristics.

Table 8.1: Table of reservoir and production facility characteristics

\begin{tabular}{|l|l|l|}
\hline Reservoir and Production Facility & Case I & Case II \\
\hline Reservoir Fluid & Dry Gas(air) & Dry Gas(air) \\
\hline Initial Pressure & $10,000 \mathrm{psi}$ & $10,000 \mathrm{psi}$ \\
\hline Well Depth & $2000 \mathrm{~m}$ & $2000 \mathrm{~m}$ \\
\hline Pipeline ID & $0.102 \mathrm{~m}$ & $0.102 \mathrm{~m}$ \\
\hline Pipeline length & $\mathbf{1 0 0} \mathbf{~ m}$ & $\mathbf{1 0 0 0} \mathbf{~ m}$ \\
\hline Reservoir Final Pressure & $1450 \mathrm{psi}$ & $1450 \mathrm{psi}$ \\
\hline
\end{tabular}


Table 8.2: Coefficients used to calculate enthalpy for air $^{42}$.

\begin{tabular}{|c|c|}
\hline Coefficient Number & Value \\
\hline $\mathrm{A}_{1}$ & -54.2 \\
\hline $\mathrm{A}_{2}$ & 29438.65 \\
\hline $\mathrm{A}_{3}$ & -805.41099 \\
\hline $\mathrm{A}_{4}$ & -3997.2481 \\
\hline $\mathrm{A}_{5}$ & 17207.096 \\
\hline $\mathrm{A}_{6}$ & -19647.986 \\
\hline $\mathrm{A}_{7}$ & 10813.917 \\
\hline $\mathrm{A}_{8}$ & -2987.0543 \\
\hline
\end{tabular}

Following the simulation runs, the results obtained were those that were expected. A longer flowline added more backpressure to the reservoir and the ultimate recovery took longer than the case where the pipeline was a $100 \mathrm{~m}$. Also in the case of the $1000 \mathrm{~m}$ pipeline, the flow rates were reduced as compared to the one with the shorter pipeline.

The same results were obtained changing other features of the reservoir and production facility. The reservoir initial pressure and final pressures were changed, the well depths were changed and the pipeline ID was changed. The results obtained were the same. Cases with the longer pipeline had a detrimental effect on reservoir performance and led to reduced rates and a longer time for the same ultimate recovery.

The results from the simulation runs are presented below in the next section. 


\subsection{Simulation Results}

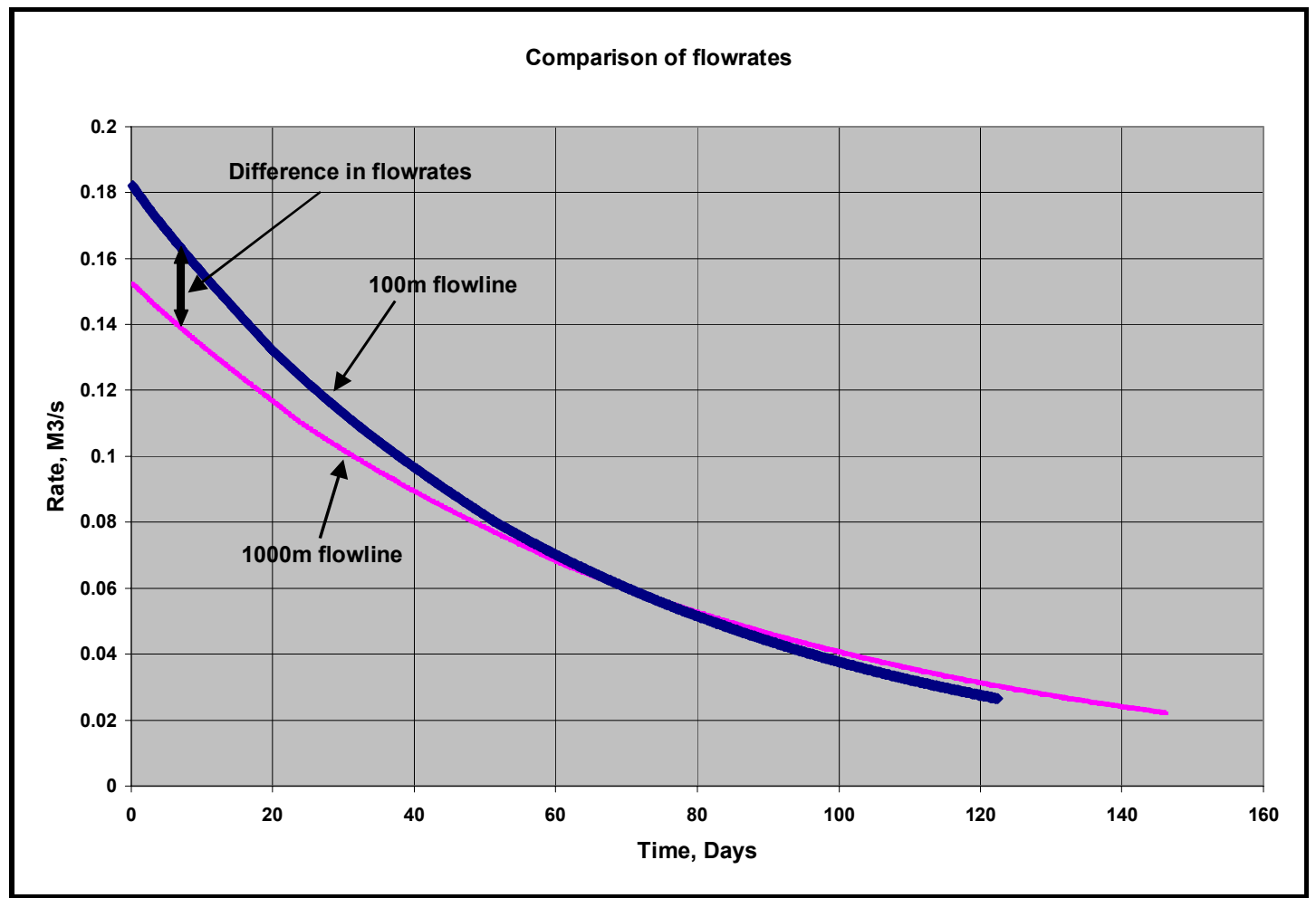

Figure 8.2: Chart showing difference in production rates owing to differences in backpressure caused by two different flowline lengths. 
Time taken to Ultimate Recovery

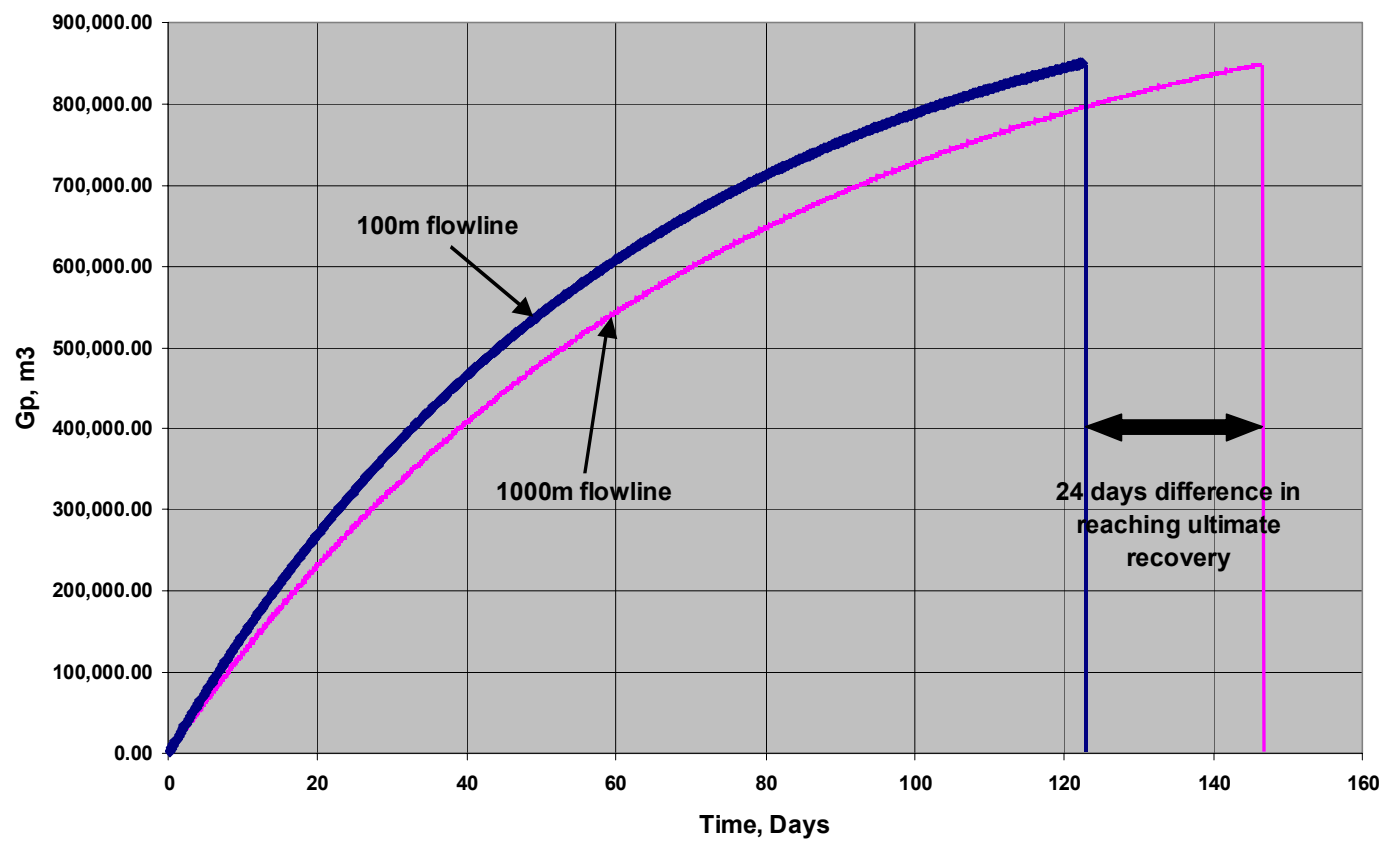

Figure 8.3: Chart showing earlier recovery achieved with a shorter flowline. 


\section{CHAPTER IX}

\section{RESERVOIR AND PRODUCTION FACILITY INTERACTION}

\subsection{Introduction}

While there has been sufficient work done in simulating the responses of the production facility alone to flow rates and pressures, there has been little work done in studying the interaction of an actual reservoir with the production network and how both of them impose constraints on each other.

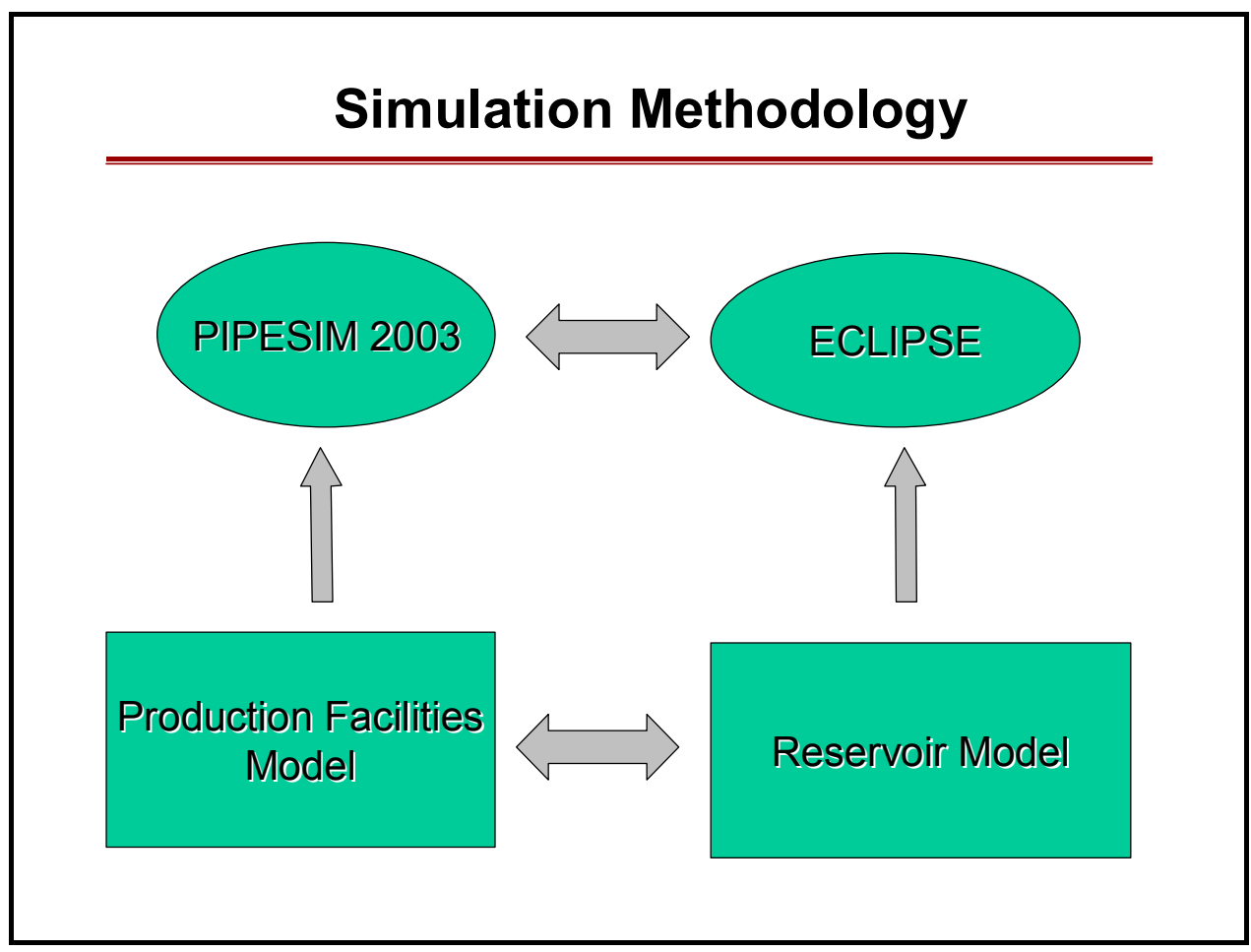

Figure 9.1: Interaction between the reservoir and facilities model 
To model the interactions between the reservoir and the production facility, I used PIPESIM 2003 to build the facilities model and ECLIPSE, a reservoir simulation software to build the reservoir model. Using a link called the FPT (Field Planning Tool), it is possible to study how one affects the other and in turn have a bearing on reservoir performance.

FPT uses an approximation method called Successive Steady State to model time-dependant surface facility behavior. So the user needs to specify time steps at which the steady state simulation is carried out. At each time step, since the boundary conditions (namely, the reservoir pressure) changes, FPT directs PIPESIM to perform a simulation run for the particular timestep using a constant value of the boundary conditions and hence gives a constant flow rate for steady state flow under those conditions.

The reservoir model now uses the flow rates predicted by PIPESIM to compute a new material balance and estimate pressure decline using the value of the constant flow rate for the particular timestep. The new reservoir pressure is then passed on to PIPESIM as a boundary condition for the next timestep.

In this manner, it is possible to approximately model the entire network from the reservoir all the way to the separator and predict the effects of the production facility on reservoir performance in terms of production rates and ultimate recovery.

\subsection{Simulation Model}

The simulation study consisted of two parts, the reservoir model described in Eclipse and the production facilities model described in PIPESIM. The characteristics of the reservoir is detailed below and so are that of the subsea tieback network.

The 3 cases studied for illustrating the value of subsea processing are:

The base case, where flow occurs under natural gradients.

Using a multiphase pump at the subsea manifold.

Using a separator and a liquid booster at the subsea manifold. 
Table 9.1: Reservoir properties

\begin{tabular}{|c|c|}
\hline Reservoir Property & Value \\
\hline Fluid Type & Black oil \\
\hline Reservoir model gridblock design & $1000 * 1000 * 1$ \\
\hline Reservoir gridblock size & $10 * 10 * 100$ feet \\
\hline Permeability, x-direction & $500 \mathrm{md}$ \\
\hline Permeability, y-direction & $500 \mathrm{md}$ \\
\hline Porosity & $20 \%$ \\
\hline Depth of the wells & $6000 \mathrm{feet}$ \\
\hline Number of wells & 3 \\
\hline
\end{tabular}

Table 9.2: Subsea tieback design

\begin{tabular}{|c|c|}
\hline Tieback Facility & Value \\
\hline Pipeline length & 52,800 feet \\
\hline Pipeline ID & 5 inches \\
\hline Multiphase pump, delta-P & $1000 \mathrm{psi}$ \\
\hline Centrifugal pump, delta-P & $1000 \mathrm{psi}$ \\
\hline Water depth & 500 feet \\
\hline Number of wells & 3 \\
\hline
\end{tabular}

\subsection{Simulation Results}

After running the simulation, the results agreed with what has been proposed in the global energy balance chapter. The ultimate recoveries and the flow rates are indeed 
seen to be higher for cases where there is energy input into the system. The base case shows lower oil and gas rates and also shows a lower recovery in the same time.

However, with energy input, the subsea multiphase pumping option shows a greater recovery and a higher production rate and so does the subsea separation and boosting option. I have not included gas flow rates for the subsea separation and boosting case, since the gas flows through another flowline and is not under the influence of any boosting.

So a higher flowrate and a higher ultimate recovery will help the economics of the project and offset the capital investment in multiphase pumping and separation and boosting.

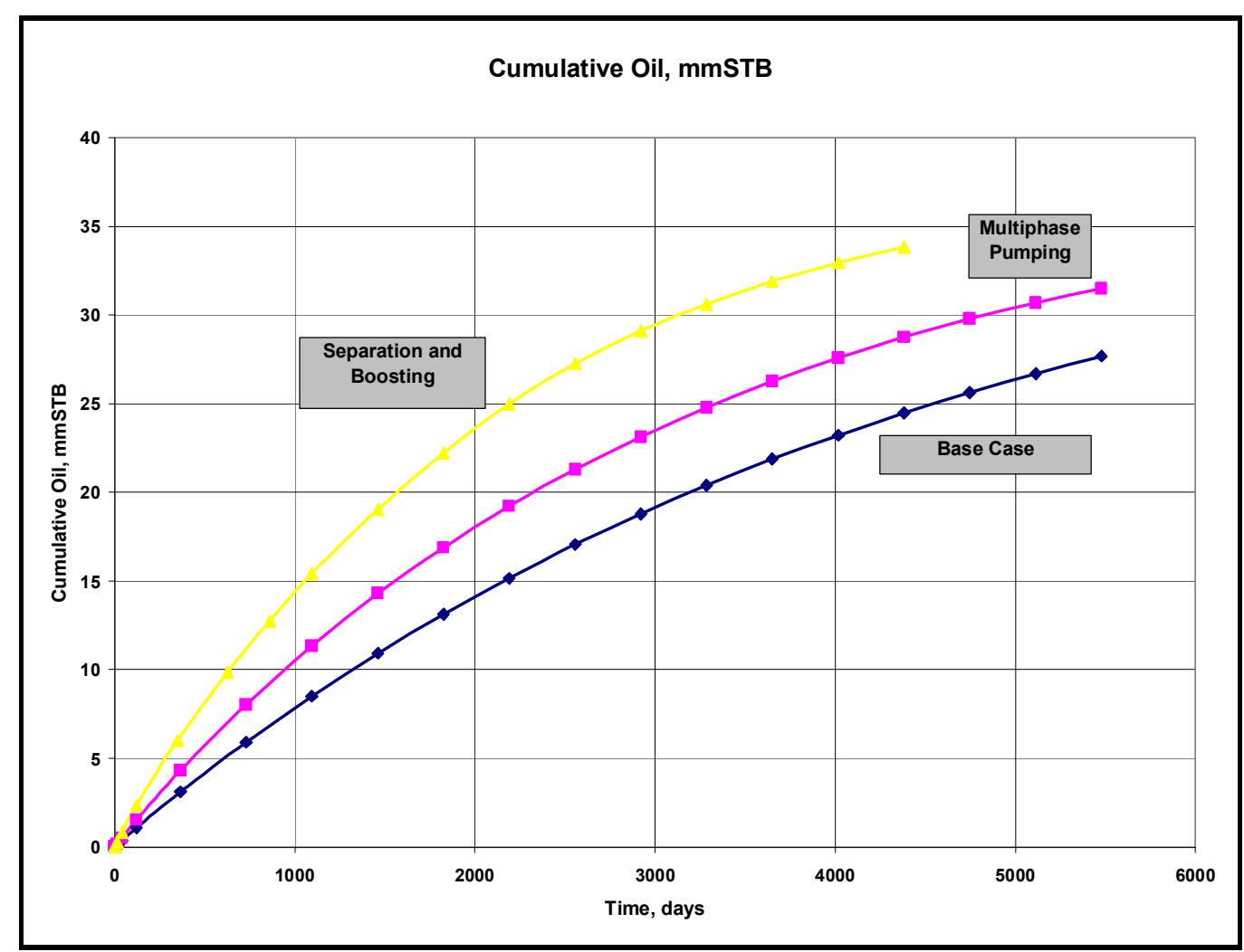

Figure 9.2: Chart comparing cumulative oil. 


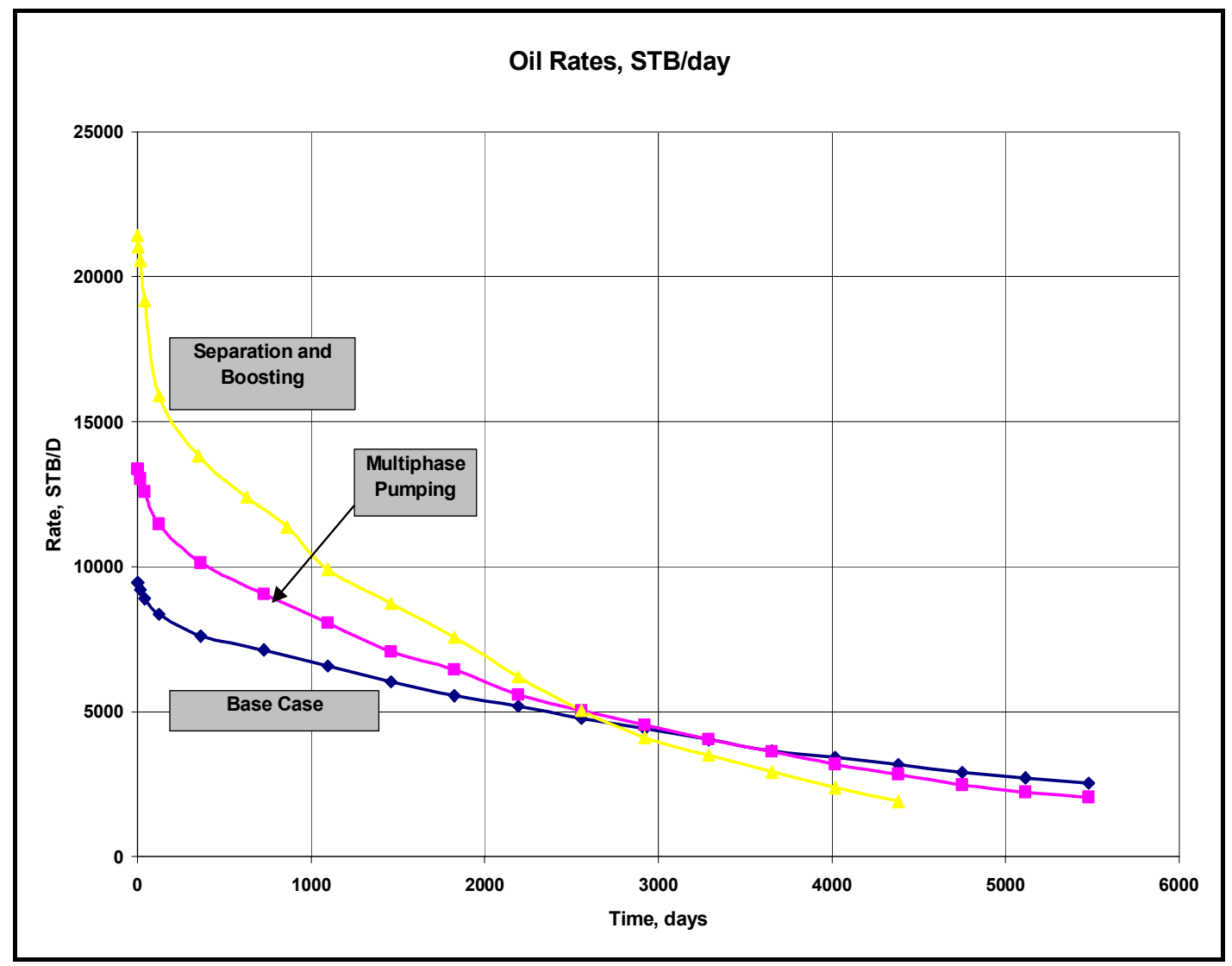

Figure 9.3: Chart comparing oil rates 


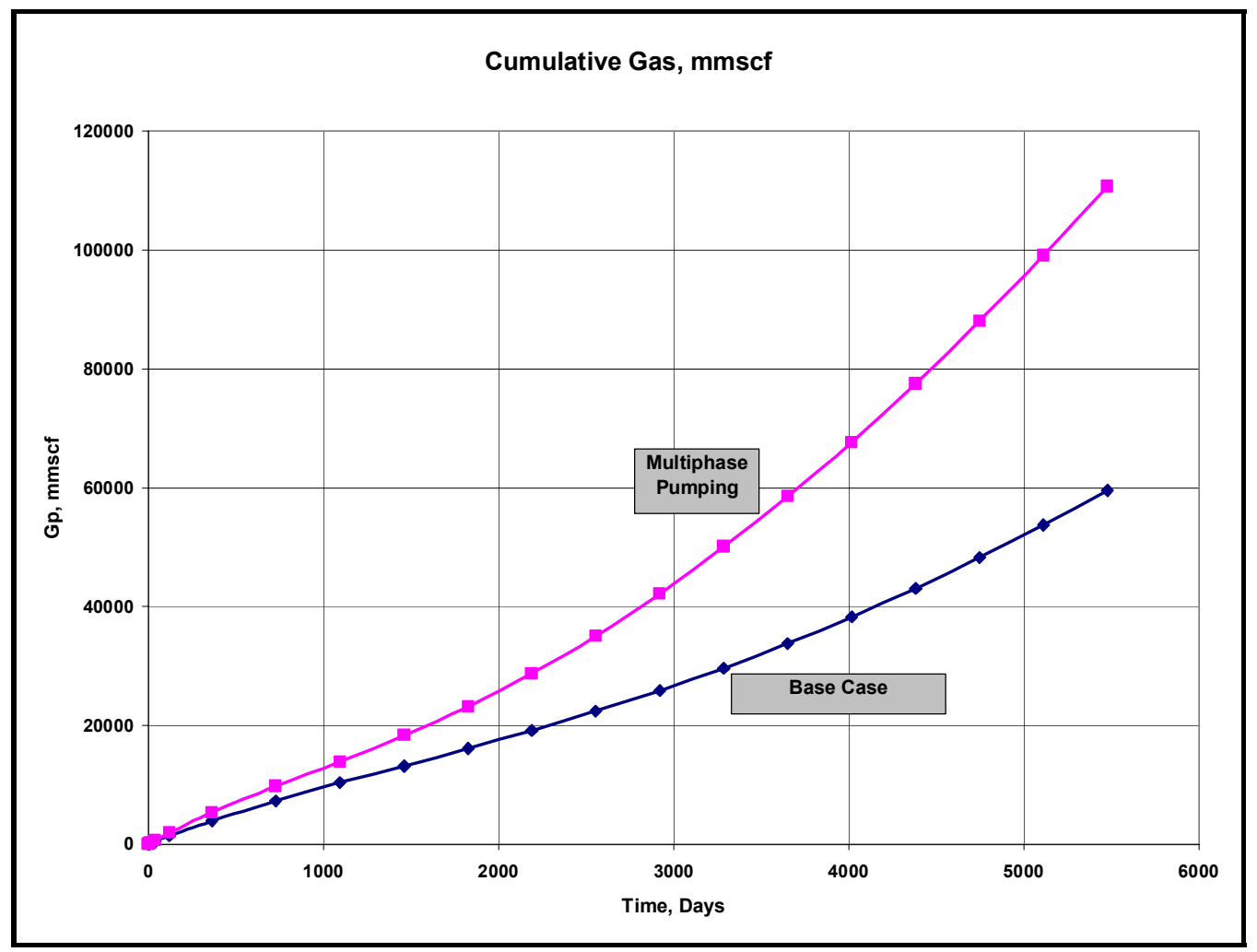

Figure 9.4: Chart comparing cumulative gas. 


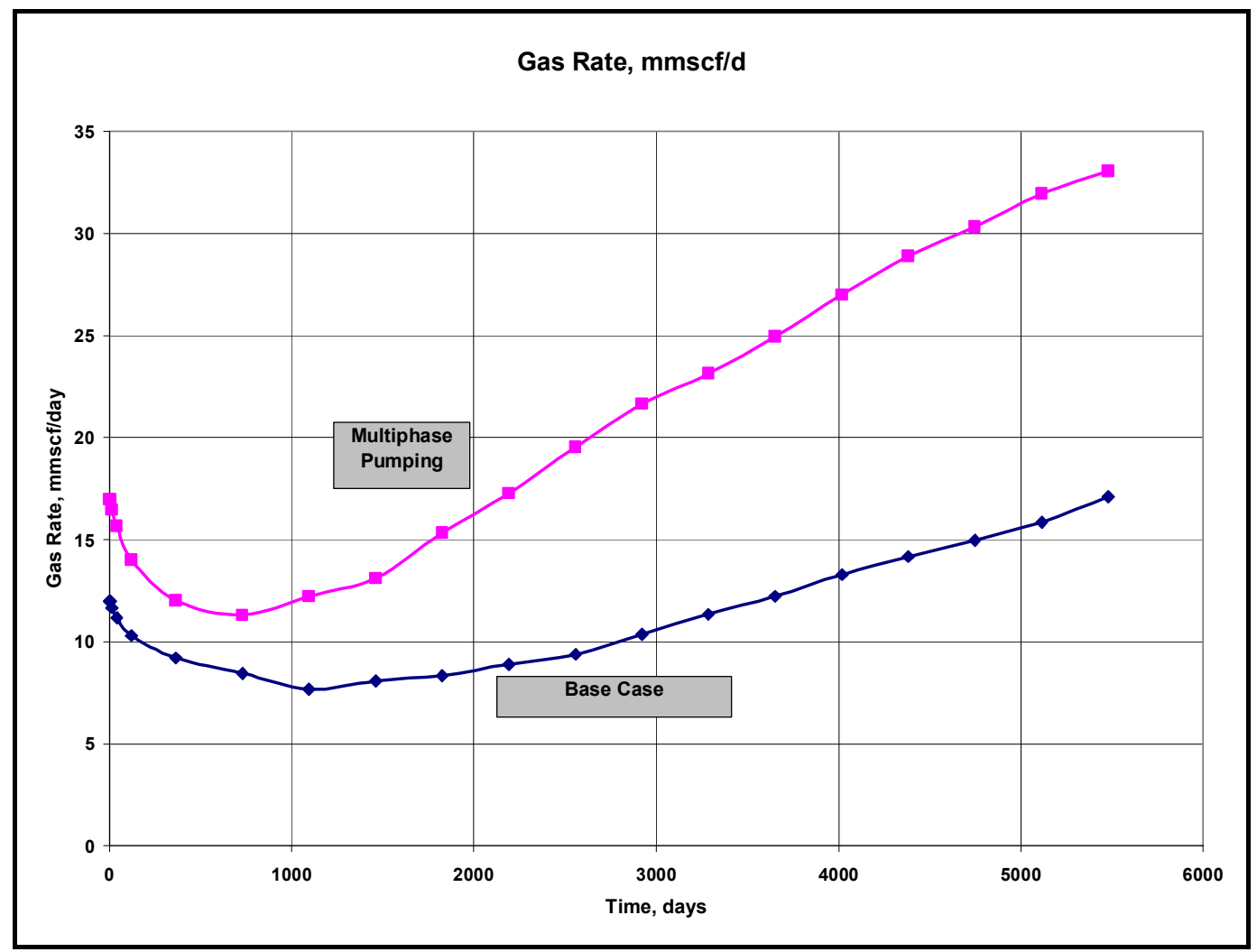

Figure 9.5: Chart comparing gas rates

\subsection{Economic considerations}

The figures above may depict the considerable advantages of using subsea separation and boosting over subsea multiphase pumping. While this may be true in terms of ultimate recoveries and production rates, this completely ignores economic considerations. Taking into account the cost to benefit ratio of both the boosting schemes, it might be advantageous to be using a multiphase pump over a subsea separation unit. Using approximate figures for the capital outlay involved with both of the schemes, the table below highlights the fact that multiphase pumping is a less expensive option. 
Table 9.3: Comparison of the cost of subsea separation and boosting versus subsea multiphase pumping.

\begin{tabular}{|l|c|c|}
\hline & $\begin{array}{c}\text { Subsea Separation and } \\
\text { Boosting }\end{array}$ & $\begin{array}{c}\text { Subsea Multiphase } \\
\text { Pumping }\end{array}$ \\
\hline Tie-back distance & $60 \mathrm{miles}$ & $60 \mathrm{miles}$ \\
\hline \# Flowlines & 2 & 1 \\
\hline Barge costs & $500,000 \$ /$ day & 300,000 /day \\
\hline Support vessels & $300,000 \$ /$ day & 0.8 of the above \\
\hline Material and Installation & 0.8 of the above & $1,440,000 \$ /$ mile \\
\hline Cost/mile of pipeline & $1,440,000 \$ /$ mile & $10,000,000 \$$ \\
\hline Multiphase pump & - & 1 mile/day \\
\hline Separation/Boosting & $35,000,000 \$$ & $182,800,000 \$$ \\
\hline Lay rate & 1 mile/day & - \\
\hline
\end{tabular}

A subsea separation and boosting scheme would require the use of two flowlines at least, one to transport the gas and the other to transport the liquids. This compares to only one flowline for a multiphase pumping scenario. Also the expenses involved with setting up a separation unit are considerably higher. A look at the above table suggests that the separation and boosting option could be as much as 2 to 3 times higher than the subsea multiphase pumping option. Aside from the capital outlay, separators tend to require more maintenance and this involves a higher OPEX, due to solids production and other maintenance requirements.

Figure 9.6 illustrates the increasing difference in capital outlay between subsea multiphase pumping and subsea separation schemes. The increasing difference arises 
due to the extra pipeline that needs to be added for a separation scheme to transport gas to the surface facility.

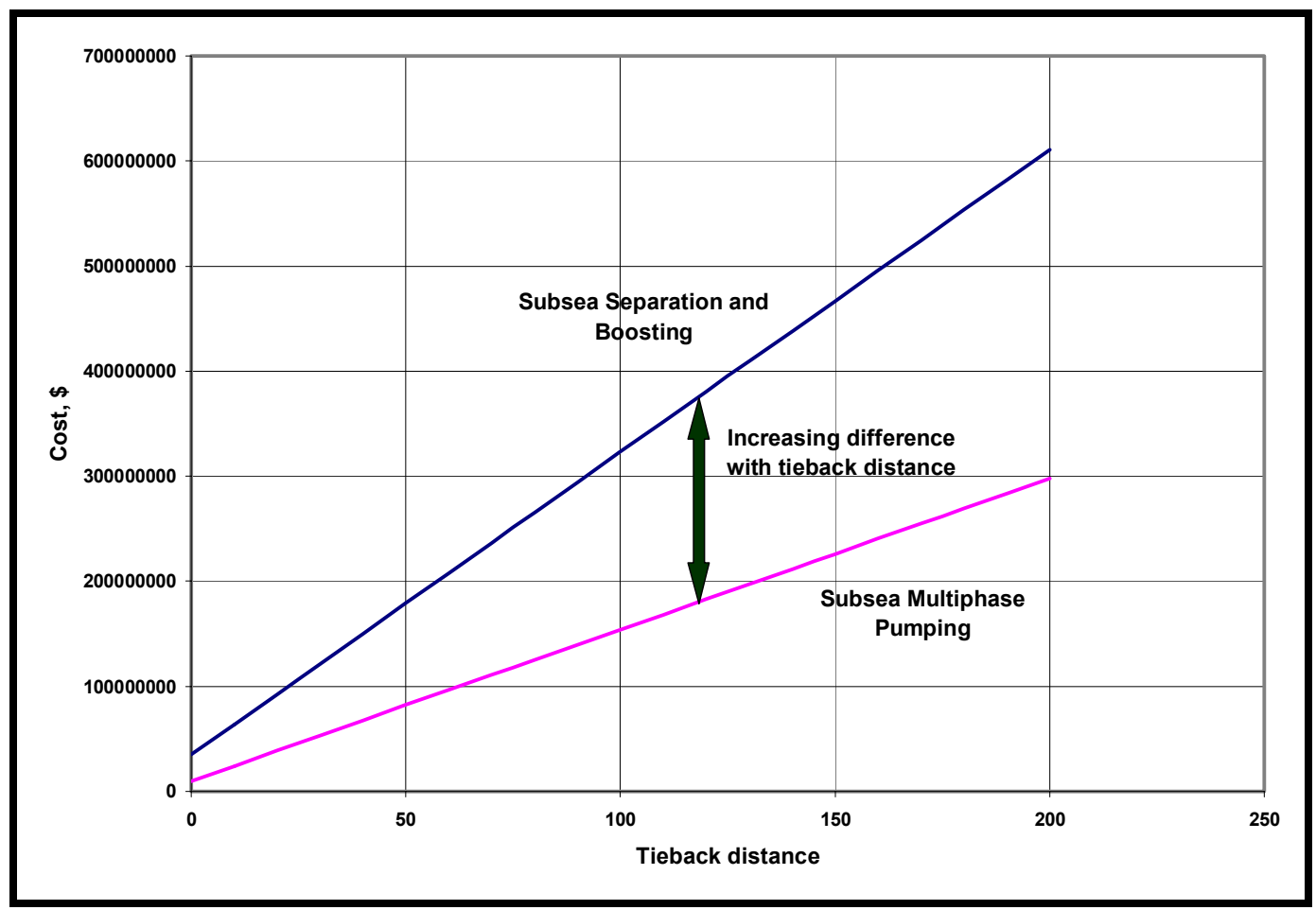

Figure 9.6: Costs of subsea multiphase pumping compared with subsea separation and boosting. 


\section{CHAPTER X}

\section{CONCLUSIONS AND RECOMMENDATIONS}

This chapter details the conclusions and recommendations from this study. The summary of the conclusions and recommendations are listed below.

\subsection{Conclusions}

Subsea separation and boosting, multiphase pumping and other artificial lift options offer benefits of cost effectiveness and can help boost production in the early stages of development that can help reduce even OPEX costs by helping reach ultimate recovery scenarios earlier.

Higher backpressure owing to long flowlines result in a waste of reservoir energy and this in turn reduces ultimate recovery from subsea reservoirs and reduces production rates from the reservoir.

Subsea processing schemes allow for reduced hydrate occurrence and a reduced footprint on surface facilities.

Desanding technology while being widely used for onshore and shallow water applications, haven't yet been widely used subsea because of the problems associated with sand disposal.

Subsea well and facilities intervention technology is in the developing stage and there are more challenges to be overcome currently than the technology is capable of.

Sustained casing pressure is a prevalent problem in subsea wells and remediation of these problems is risky, inefficient, unreliable and expensive.

Environmental and safety concerns still present a problem with leak detection technology and blockage monitoring techniques lacking all the capabilities to inform the operator of changing conditions under all operating environments.

Power requirements and delivery are challenges being faced by the petroleum industry for longer distance subsea tie-backs due to wastage in transmittal. 
Flow assurance monitoring techniques are still primitive and more analytical techniques and instrumentation needs to be developed for better detection.

Reliability of most subsea equipment is a matter of great concern to all operators. Until some certain level of availability is demonstrated, then operators will not embrace a new technology.

Standardization of equipment is the need of the hour to enable easier intervention, replacement and cost effectiveness.

\subsection{Recommendations}

Deploying some form of subsea processing requires an in-depth study of the economics of the project, the cost to benefit ratio and intervention options.

Smaller floating platforms like production buoys and mini-TLPs to be deployed more extensively to eliminate some of the disadvantages of subsea production schemes.

Flow assurance techniques and instrumentation to be developed to allow for greater ease in detecting blockages in existing pipelines.

Solid handling and disposal procedures and technology needs to be researched more for cost effective and environmentally sound practices.

More options for power delivery and distribution to be investigated for subsea production facilities.

Resource allocation and multiphase metering is an emerging technology-more studies and development is required to make this a mature area of application.

Subsea architecture to be simplified to allow greater ease of intervention by ROVs or rigs, especially in the case of sustained casing pressure problems.

Intelligent well technology for subsea use needs to demonstrate it's reliability before it can be used extensively. 


\section{NOMENCLATURE}

\begin{tabular}{|c|c|}
\hline A & Area \\
\hline $\mathrm{C}$ & Constant \\
\hline $\mathrm{C}_{\mathrm{p}}$ & Specific heat at constant pressure \\
\hline $\mathrm{C}_{\mathrm{v}}$ & Specific heat at constant volume \\
\hline $\mathrm{D}, \mathrm{d}$ & Inner diameter of pipeline \\
\hline $\mathrm{e}_{\mathrm{v}}$ & Friction loss factor for pipe fittings \\
\hline $\mathrm{E}$ & Power \\
\hline $\mathrm{f}$ & Friction factor \\
\hline $\mathrm{g}$ & Gravitational acceleration \\
\hline $\mathrm{G}$ & Original gas in place \\
\hline $\mathrm{G}_{\mathrm{p}}$ & Gas produced \\
\hline $\mathrm{h}$ & Height of riser \\
\hline $\mathrm{H}$ & Enthalpy of gas \\
\hline $\mathrm{i}$ & Subscript denoting initial conditions \\
\hline $\mathrm{J}$ & Well productivity index \\
\hline $\operatorname{lm}_{1}$ & Total energy loss to friction \\
\hline $\operatorname{lm}_{2}$ & Total energy loss in fittings \\
\hline $\operatorname{lm}_{\mathrm{T}}$ & Total energy loss in the system \\
\hline $\mathrm{L}$ & Pipeline length \\
\hline $\mathrm{m}$ & Mass flow rate of gas \\
\hline M & Molecular weight of the gas \\
\hline $\mathrm{n}$ & Time step being simulated \\
\hline $\mathrm{n}_{\mathrm{p}}$ & Total moles of gas produced \\
\hline $\mathrm{P}$ & Absolute pressure of the gas \\
\hline$P_{b}, P_{s c}$ & Pressure at standard conditions \\
\hline$P_{\text {back }}$ & Backpressure \\
\hline
\end{tabular}




$\begin{array}{cc}\mathrm{P}_{1}, \mathrm{P}_{2}, \mathrm{P}_{3}, \mathrm{P}_{\mathrm{R}} & \text { Reservoir pressures } \\ \mathrm{P}_{\mathrm{wf}} & \text { Well flowing pressure } \\ \mathrm{Q}_{\mathrm{b}}, \mathrm{Q}_{\mathrm{sc}} & \text { Volumetric flow rate of gas } \\ \mathrm{R} & \text { Gas constant } \\ \mathrm{t} & \text { Time } \\ \mathrm{T} & \text { Temperature of the reservoir fluid } \\ \mathrm{T}_{\mathrm{bh}} & \text { Bottomhole temperature } \\ \mathrm{T}_{\mathrm{sc}} & \text { Temperature at standard conditions } \\ \mathrm{U} & \text { Overall heat transfer coefficient for the pipeline } \\ \mathrm{U}_{\mathrm{g}} & \text { Molar internal energy of gas } \\ \mathrm{V}, \mathrm{v} & \text { Velocity } \\ \mathrm{V}_{1}, \mathrm{~V}_{2} & \text { Gas volumes in reservoir } \\ \mathrm{W} & \text { Work done by the system } \\ \mathrm{Z}, \mathrm{Z} & \text { Real gas constant } \\ \alpha & \text { Ratio of smaller to larger cross-sectional area } \\ \Downarrow & \text { Ratio of gas specific heats } \\ \cdot & \text { Reservoir porosity } \\ \cdot & \text { Density }\end{array}$




\section{REFERENCES}

1. Bourgoyne, A.T., Jr., Scott, S.L. and Regg, J.: "Technology Allows Metering Multiphase Flow," Pumps \& Systems Magazine, (May 2002) 24-28.

2. Martin, A.M. and Scott, S.L.: "Modeling Reservor/Tubing/Pump Interaction Identifies Best Candidates for Multiphase Pumping," paper SPE 77500 presented at the 2002 Annual Technical Conference and Exhibition, San Antonio, 29 September-2 October.

3. Grant, D., Sones, G. and Speegel, S.: "Challenges in Designing the World's First 15,000 PSI Subsea Completion,” paper SPE 71682 presented at the 2001 Annual Technical Conference and Exhibition, New Orleans, 30 September-3 October.

4. Fjosne, E.: "Subsea Processing-Maximising Value in Areas With Existing Infrastructure,": paper OTC 14008 presented at the 2002 Offshore Technology Conference, Houston, May 6-9.

5. "Deepwater," www.bakerhughes.com/deepwater.

6. Golczynski, T.S. and Niesen, V.G.: "A Tale of Two Trees: Flow Assurance Challenges for Wet Tree and Dry Tree Systems in Ultradeepwater," paper 71545 presented at the 2001 Annual Technical Conference and Exhibition, New Orleans, 30 September-3 October.

7. “Kvaerner Oilfield Products,” KOP, www.kvaerner.com/kop

8. "The Fluid Engineering Center," www.bhrgroup.co.uk

9. “Brazil Deepwater Scenario”, www.petrobras.com

10. "A Wide Range of Products for Topsides and Subsea Applications," Framo Engineering, www.framoeng.no.

11. Shippen, M.E. and Scott, S.L.: "Multiphase Pumping as an Alternative to Conventional Separation, Pumping and Compression," paper PSIG 0210 presented at the 2002 PSIG Conference, Portland, Oregon, Oct 8-9.

12. Scott, S.L. and Martin, A.M.: "Multiphase-The Final Pumping Frontier," Pumps \& Systems (July 2001) 8-32. 
13. Scott, S.L.: "Multiphase Production Flows into Industry Mainstream," The American Oil \& Gas Reporter (June 2001) 68-73.

14. "Shell Exploration and Production-GOM Operations," SEPCO, www.shell.com

15. "Subsea Sand Monitoring System," Clampon, www.clampon.com

16. "BP-Deepwater Locations in Texas," www.bp.com

17. "Sencorr Subsea Sand/Erosion Sensor," www.corrocean.com/presstemp/653/

18. "Sand Handling Options," www.meppro.com

19. "Mentor Subsea," www.jraymcdermott.com/mentor.

20. Scott, S.L. and Yi J.: "Flow Testing Methods to Detect and Characterize Partial Blockages in Looped Subsea Flowlines," Proc. of the ASME Energy-Sources Technology Conference and Exhibition, Houston, Texas (Feb. 1-3, 1999); ASME J. of Energy Resources Tech., (September 1999) 121, 32-37.

21. Scott, S.L. and Satterwhite L.A.: "Evaluation of the Backpressure Technique for Blockage Detection in Gas Flowlines," ASME J. of Energy Resources Tech., (March 1998) 120, 27-31.

22. Liu, L.J. and Scott, S.L.: "A New Method to Locate Partial Blockages in Subsea Flowlines," paper SPE 63187 presented at the 2001 SPE Annual Technical Meeting \& Exhibition, New Orleans, 30 September-3 October.

23. Christie, A., Kishino, A. and Cromb, J.: "Subsea Solutions" Schlumberger, www.slb.com

24. "Subsea solutions," www.halliburton.com.

25. "Magnetic Flow Assurance," www.magwell.com

26. "Subsea Systems," ABB, www.abb.com

27. "Subsea Processing Systems," www.fmckongsbergsubsea.com.

28. "Services," www.caldive.com\services.html

29. Scott, S.L., Liu L. and Yi J.: "Modeling the Effects of a Deepwater Leak on Behavior of a Multiphase Production Flowline," SPE paper 52760 presented at the 1999 SPE/EPA Exploration and Production Environmental Conference, Austin, Texas (Feb. 28 - March 3, 1999). 
30. Wojtanowicz, A.K., Nishikawa, S. and Rong X.: "Diagnosis and Remediation of Sustained Casing Pressure in Wells," final report, United States Minerals Management Service (July 2001).

31. Rusch, D.W. and Ellis, B.C: "Use of Pressure Activated Sealants to Cure Sources of Casing Pressure," paper SPE 55996 presented at the 1999 Western Regional Meeting, Anchorage, Alaska, 26-28 May.

32. Bourgoyne, A.T., Jr., Scott S.L. and Regg J.: "Sustained Casing Pressure in Producing Wells," OTC paper 11029 presented at the Offshore Technology Conference (OTC), Houston, Texas (May 1999).

33. Stinessen, K.O.: "Norsk-Hydro Multiphase Subsea Test," presentation given at the Texas A\&M $4^{\text {th }}$ Annual Multiphase Pump User Roundtable (MPUR), Houston (May 9, 2002).

34. Pickard, B.: "Subsea Multiphase Pumps in the Ceiba Field - W. Africa," presentation given at the Texas A\&M $5^{\text {th }}$ Annual Multiphase Pump User Roundtable (MPUR), Houston (May 7-8, 2003).

35. Overland, A.M.: "Yme Marginal Field, 12 km Subsea Gas Lift Experience," paper SPE 71539 presented at the 2001 Annual Technical Conference and Exhibition, New Orleans, 30 September-3 October.

36. Havre, K. and Dalsmo, M.: “Active Feedback Control as the Solution to Severe Slugging," SPE paper 71540 presented at the 2001 Annual Technical Conference and Exhibition, New Orleans, Louisiana, 30 September-3 October.

37. Beggs, D.H.: Production Optimization, OGCI Publications, Houston (1999).

38. Muskat, M.: Physical Principles of Oil Production. McGraw-Hill, New York (1949).

39. Thrasher, T.S., Fetkovich E.J., and Scott S.L.: "Well Deliverability: A Case History," SPE Reservoir Engineering, (Nov. 1995) 293-300.

40. Bird, R.B., Stewart, W.E. and Lightfoot, E.N.: Transport Phenomena, John Wiley \& Sons Inc., New York City (1960).

41. “GasStore Manual,” www.haa.nl 
42. Jayawardena, S., Dykhno, L. and Hudson, J.: "Challenges in Pigging of Subsea Flowlines," paper SPE 77576 presented at the 2002 Annual Technical Conference and Exhibition, San Antonio, 29 September-2 October. 


\section{VITA}

Deepak Devegowda

Email address: deepak_deve@hotmail.com

3116, Richardson Building

Deptartment of Petroleum Engineering

Texas A\&M University

College Station, TX 77843

\section{Education}

Texas A\&M University: Master of Science in petroleum engineering

Graduation Date: Dec 2003

Indian Institute of Technology, Madras, India (Aug 1994-Aug.1998): Bachelor of Technology in electrical engineering

\section{Research}

Texas A\&M University, College Station, TX, U.S.A (May 2002-Aug 2003): Research associate, Multiphase Production Systems.

\section{Specialized Courses}

Reservoir fluids, reservoir models, reservoir simulation, well performance, fluid flow in petroleum reservoirs, well drilling, modern petroleum production, petroleum development strategy, fluid mechanics, transport phenomena, Advanced reservoir engineering, geostatistics, statistical analysis.

\section{Experience}

Halliburton Energy Services, India and Egypt (Aug 1998-Aug 2001): Responsible for open hole and cased hole well logging and log data interpretation and analysis. Also responsible for upkeep and maintenance of HSE objectives on location. 